\title{
The Time-Varying Effect of Monetary Policy on Asset Prices
}

\author{
Pascal Paul \\ Federal Reserve Bank of San Francisco \\ April 2019 \\ Working Paper 2017-09 \\ https://www.frbsf.org/economic-research/publications/working-papers/2017/09/
}

\section{Suggested citation:}

Paul, Pascal. 2019. “The Time-Varying Effect of Monetary Policy on Asset Prices,” Federal Reserve Bank of San Francisco Working Paper 2017-09. https://doi.org/10.24148/wp2017-09

The views in this paper are solely the responsibility of the authors and should not be interpreted as reflecting the views of the Federal Reserve Bank of San Francisco or the Board of Governors of the Federal Reserve System. 


\title{
The Time-Varying Effect of Monetary Policy on Asset Prices
}

\author{
Pascal Paul \\ Federal Reserve Bank of San Francisco*
}

April 2019

\begin{abstract}
This paper studies how monetary policy jointly affects asset prices and the real economy in the United States. I develop an estimator that uses high-frequency surprises as a proxy for the structural monetary policy shocks. This is achieved by integrating the surprises into a vector autoregressive model as an exogenous variable. I use current short-term rate surprises because these are least affected by an information effect. When allowing for time-varying model parameters, I find that, compared to the response of output, the reaction of stock and house prices to monetary policy shocks was particularly low before the 2007-09 financial crisis.
\end{abstract}

Keywords: Time-Varying Parameter VAR, Stock Prices, House Prices, External Instruments, Monetary Policy Surprises, Information Effect

JEL codes: E43, E44, E52, E58, G12

*Email: pascal.paul@sf.frb.org . First online version: November 2015.

I thank Paul Beaudry, Dario Caldara, Olivier Coibion, Gabriel Chodorow-Reich, Edward Herbst, Òscar Jordà, Sophocles Mavroeidis, Michele Piffer, Glenn Rudebusch, Jón Steinsson, Harald Uhlig, and three anonymous referees for detailed comments, Mark Gertler, Peter Karadi, Eric Swanson, and Michiel de Pooter for sharing their data, Anita Todd and Michael Tubbs for excellent research \& editorial assistance, and many seminar and conference participants for their insights at the 4th Time Series Econometrics Workshop, the 2017 EEA-ESEM Conference, the 2017 NBER-NSF Seminar on Bayesian Inference in Econometrics and Statistics, the 2017 Spring Macro Committee Meeting of the Federal Reserve, the 2016 IAAE Annual Conference, the 2016 Fall Midwest Macro Meetings, the 2015 OFCE \& Sciences Po Paris Empirical Monetary Economics Workshop, Federal Reserve Bank of San Francisco, Norges Bank, the 2018 Research Scrum Conference of the Federal Reserve, and University of Oxford. A previous version was circulated with the title "The Time Varying Transmission of Monetary Policy Surprises". Financial support by the German Academic Exchange Service, the German National Academic Foundation, and the David Walton Scholarship is gratefully acknowledged. All errors are my own. The views expressed herein are solely those of the author and do not necessarily reflect the views of the Federal Reserve Bank of San Francisco or the Federal Reserve System. 


\section{Introduction}

The goal of monetary policy is to stabilize fluctuations in output and inflation and keep these variables close to their desired targets. However, particularly during financial crises, output and inflation typically fall sharply and end up well below their targets for several years. To prevent such events, it may therefore be optimal to use monetary policy preemptively by leaning against developments that generally result in financial crises. Recent research finds that rapid increases in equity and house prices raise the likelihood and the severity of financial crises (e.g., Jordà, Schularick, and Taylor, 2015; Kiley, 2018; Paul, 2018). If central banks observe asset price booms, they could react to them by raising interest rates. But even if monetary policy is conducted in this way, it is unclear whether asset prices actually respond in times of frenzy. When there is momentum in the market and people are optimistic, do prices respond in the same way as they do in normal times? Do they respond more or less? And how does the reaction of asset prices compare and trade-off against the impact of monetary policy on output and inflation?

Up to this point, the literature has not provided the necessary tools to study the above questions. Within vector autogressive models (VAR) that capture the interdependence between asset prices and the real economy, accessible methods have identified monetary policy shocks based on, for example, timing or sign restrictions (e.g., Christiano, Eichenbaum, and Evans, 1999; Uhlig, 2005). These identification approaches have been extended to time-varying settings (e.g., Primiceri, 2005). However, when the interest lies in the response of asset prices to changes in monetary policy, such methods cannot address some key identification issues. First, since asset prices incorporate news about monetary policy quickly, their response is particularly sensitive to obtaining shocks that come as surprises to the economy. Second, more specific to an identification based on imposing timing restrictions, it is generally assumed that a monetary authority can either react contemporaneously to a financial variable or a financial variable can respond to a change in monetary policy within the same period - but not both. However, for stock and house prices, both directions are possible.

In this paper, I develop a new methodology to address the above identification problems, which allows to study the joint and time-varying effects of monetary policy on asset prices and the real economy. I follow Kuttner (2001) and Gürkaynak, Sack, and Swanson (2005) among others and obtain a series of monetary policy surprises. These are given by high-frequency price changes in federal funds futures around announcements of the Federal Open Market Committee (FOMC) and capture the unanticipated part within such announcements.

However, monetary policy surprises should not be taken as direct observations of monetary policy shocks. One concern is that the surprises may be confounded by a release of a central bank's private information (Romer and Romer, 2000, Melosi, 2017). For example, Nakamura and Steinsson (2018) show that private forecasters increase their expectations of output growth to unexpected increases in interest rates - the opposite of what standard models predict. I show empirically that 
these results do not hold for surprises with respect to current short-term rates as opposed to future short-term rates (forward guidance). I provide additional evidence to interpret these findings. Relative to private forecasts, the Federal Reserve possesses additional information in predicting macroeconomic developments farther out into the future. Surprises with respect to future shortterm rates release such information and are therefore contaminated by this "information effect". Hence, identified impulse responses based on such surprises would be biased since they would partly represent a response to the new information. I therefore use surprises with respect to current short-term rates in the empirical analysis instead. ${ }^{1,2}$

However, even with this restriction, monetary policy surprises and shocks are at best imperfectly correlated. First, even though price changes are measured in a small window around announcements, they may still reflect trading noise and news other than about monetary policy that is revealed at the same time. Hence, they likely contain measurement error. Second, the monthly series of surprises contains random zero observations, since there are calendar months during which an FOMC meeting does not take place. Third, within a month, a range of other monetary policy news is released that is not taken into account, for example through speeches of FOMC members.

I therefore use the monetary policy surprises as a proxy for the structural monetary policy shocks. That is achieved by integrating the surprises directly into a vector autoregressive model as an exogenous variable (VARX). ${ }^{3}$ I show analytically that this approach consistently identifies the true relative impulse responses - even when the surprises contain measurement error that is orthogonal to all other variables or random zero observations. ${ }^{4}$ Further, I show that one can extend a constant parameter VARX to allow for time-varying parameters in a simple way and use standard methods to estimate the model (as they are applied in Cogley and Sargent, 2001, for example).

Based on the time-varying parameter VARX, I obtain empirical evidence on the response of output, inflation, and stock and house prices to monetary policy shocks in the United States since the late 1980s. First, I find that stock and house prices always decrease following a monetary tightening. This result is in contrast to Galí and Gambetti (2015). They also study how monetary policy affects stock prices within a time-varying parameter VAR, but shocks are identified using timing restrictions. They find that stock prices increase after a monetary tightening during stock market booms and interpret these findings as evidence of the presence of rational bubbles. My results show that their findings are driven by the Cholesky identification of shocks that is subject to the mentioned concerns.

\footnotetext{
${ }^{1}$ For the same reason, I focus on regular FOMC meetings and do not include unscheduled FOMC meetings. Nevertheless, even with these constraints, an information release cannot be completely excluded, but rather the results show that the surprises that I use are much less likely to be confounded in this way.

${ }^{2}$ See Andrade and Ferroni (2016), Campbell et al. (2012, 2017), Cieslak and Schrimpf (2018), Lakdawala (2017), Jarocinski and Karadi (2018), and Miranda-Agrippino and Ricco (2017) for alternative approaches of identifying the importance or reducing the influence of information shocks.

${ }^{3}$ Bagliano and Favero (1999) have used a VARX in a similar way, but did not show that this approach consistently identifies the true (relative) impulse responses.

${ }^{4} \mathrm{~A}$ relative impulse response normalizes the initial response of one of the endogenous variables, but leaves the response of the rest of the variables unrestricted.
} 
Second, I find that stock and house prices show substantial time-variation to unanticipated changes in monetary policy. While the response of stock prices does not show a systematic pattern, the response of house prices strongly comoves with the level of house prices over most of the sample. They are less responsive when house prices are high, and more responsive when prices are low. Third, I find that, compared to output, the response of stock and house prices was particularly low before the Great Recession. Hence, attempts by the Federal Reserve to lean against the house price boom before the crisis may have been less effective.

Apart from the application in this paper, the exogenous variable approach can generally be applied when a proxy for the structural shock of interest is available. In this regard, the method is an alternative implementation of the external instrument or proxy SVAR approach, introduced by Stock and Watson (2012) and Mertens and Ravn (2013).5,6 Gertler and Karadi (2015) and Caldara and Herbst (2016) apply this method in the context of monetary policy identification. Both approaches consistently estimate the true relative impulse responses and I provide analytical derivations with respect to their equivalence. However, they use the proxy differently; once as an exogenous variable and the other time as an external instrument. In a comparison of these two methods, the exogenous variable approach allows for the simple extension with time-varying parameters since the VAR is estimated in a single step. In addition, I also compare the exogenous variable approach with the local projection instrumental variable approach (LP-IV), as proposed by Stock and Watson (2018) among others. ${ }^{7}$

The response of stock prices to monetary policy news (e.g, Bernanke and Kuttner, 2005, Rigobon and Sack, 2004) or macroeconomic news more generally (e.g., Law, Song, and Yaron, 2017) is well explored in the literature. However, the relation is typically analyzed by the immediate response within a narrow window around news releases. ${ }^{8}$ In contrast, this paper identifies the dynamic response of stock prices to monetary policy shocks. The reaction of house prices to monetary policy shocks is less explored, but interest in this question increased after the 2007-09 financial crisis. Kuttner (2013) provides an overview of the empirical findings.

Last, I focus on the response of asset prices to monetary policy shocks, that is, to unanticipated deviations from a perceived monetary policy reaction function. Aastveit, Furlanetto, and Loria (2017) consider the other side of the coin - whether U.S. monetary policy has historically reacted to asset prices and how this reaction has changed over time. However, both my paper and

\footnotetext{
${ }^{5}$ I have developed these results independently. Since then, I have been made aware that a similar derivation can be found in the unpublished notes by Montiel-Olea et al. (2012) which did not appear in their subsequent working paper (Montiel-Olea et al., 2015). The derivation in this paper is more detailed and allows for additional insights that are discussed in Section 2.4. Kilian and Luetkepohl (2017, chapter 15.2.) also debate the connection between the different approaches, but do not prove their equivalence.

${ }^{6}$ Caldara and Herbst (2016) and Drautzburg (2017) develop Bayesian versions of the proxy SVAR approach.

${ }^{7}$ In particular, I show analytically that the LP-IV and the VARX give the same relative impulse responses on impact if they include the same controls.

${ }^{8}$ See for example Swanson (2017), Lakdawala and Schaffer (2018), Leombroni et al. (2017), Brooks et al. (2019), and Lunsford (2018) for recent applications on the effects of monetary policy on financial markets.
} 
Aastveit et al. (2017) cannot speak to the question of whether monetary policy should incorporate asset prices into its reaction function and how agents would change their decisions because of that. Finding answers to these important questions is left to future research.

Road Map. The paper is organized as follows. The next section outlines the model that describes the data generating process and introduces the concept of relative impulse responses. The section proceeds to show that the exogenous variable approach consistently estimates the true relative impulse responses. Motivated by the findings, Section 3 extends the constant parameter VARX to allow for time-varying coefficients. Section 4 uses the model and obtains evidence on the timevarying impact of monetary policy on stock and housing markets. Section 5 concludes.

\section{General Methodology}

Let $y_{t}$ be an $n \times 1$ vector of observables, $H$ and $C_{m} \forall m \geq 0$ conformable coefficient matrices, and $\epsilon_{t}$ an $n \times 1$ vector of structural shocks. Assume that $y_{t}$ evolves according to a system of linear simultaneous equations, written in its general structural form,

$$
H y_{t}=C_{0}+C_{1} y_{t-1}+\ldots+C_{k} y_{t-k}+\epsilon_{t}
$$

with $\mathbb{E}\left[\epsilon_{t}\right]=0$ and the normalization $\mathbb{E}\left[\epsilon_{t} \epsilon_{t}^{\prime}\right]=I_{n}$ where $I_{n}$ is the identity matrix. Multiplying each side of the equation by $H^{-1}$ yields the reduced-form representation

$$
y_{t}=B_{0}+B_{1} y_{t-1}+\ldots+B_{k} y_{t-k}+u_{t},
$$

where $B_{m}=H^{-1} C_{m} \forall m \geq 0$. The reduced-form innovations $u_{t}$ are given by

$$
u_{t}=S \epsilon_{t}
$$

where the $n \times n$ matrix $S=H^{-1}$ collects the impulse vectors of the shocks. These capture the contemporaneous effect of the primitive shocks on the dependent variables. Assume that the interest lies in the identification of impulse responses to one of the structural shocks, denoted by $\epsilon_{1, t}$. Accordingly, equation (3) can be rewritten as

$$
u_{t}=s \epsilon_{1, t}+\underline{S} \epsilon_{2, t},
$$

where $s$ is the impulse vector associated with $\epsilon_{1, t}$ and the $(n-1) \times 1$ vector $\epsilon_{2, t}$ collects all other structural shocks. I distinguish between two types of impulse responses: absolute and relative impulse responses. Absolute impulse responses describe the change in $y_{t}$ to units of standard deviation of $\epsilon_{1, t}$. The response on impact to a one-standard-deviation shock is given by $s$, while subsequent responses are obtained by tracing the shock recursively through model (2).

Instead, relative impulse responses normalize the contemporaneous response of one of the endogenous variables. For example, one may consider a monetary policy shock that generates an 
initial fall in output of, say, one percent. However, the contemporaneous response of the other variables are left unrestricted and subsequent responses are again obtained by tracing the shock through system (2). In contrast to absolute impulse responses, relative ones do not require identification of the entire impulse vector $s$ but only of ratios of elements in $s$. To see why, consider a structural shock $\epsilon_{1, t}$ that leads to a one-unit increase of some variable $j$ in $y_{t}$. The contemporaneous relative impulse response of some other variable $i$ in $y_{t}$ with $i \neq j$ is then given by

$$
r_{i j}=\frac{s_{i}}{s_{j}}
$$

where $s_{i}$ and $s_{j}$ are the elements in $s$ related to variables $i$ and $j$.

The econometric problem in identifying absolute and relative impulse responses is that the structural shocks $\epsilon_{t}$ are not observed. In addition, the covariance matrix of the reduced-form innovations, $\mathbb{E}\left[u_{t} u_{t}^{\prime}\right]=S S^{\prime}$, does not provide enough identifying restrictions to obtain at least one of the columns in $S$ or ratios of elements within such a column. Until recently, the structural VAR literature has achieved identification from restrictions that are directly imposed upon the system of simultaneous equations (2) (e.g., Christiano et al., 1999; Uhlig, 2005).

Here, I follow the approach of the external instrument literature. The idea of this identification approach is to bring in information from external sources to identify the effects of structural shocks. In particular, assume that a proxy $z_{t}$ for the latent shock of interest $\epsilon_{1, t}$ exists and that $z_{t}$ satisfies the following conditions

$$
\begin{aligned}
& \mathbb{E}\left[z_{t} \epsilon_{1, t}\right]=\phi \\
& \mathbb{E}\left[z_{t} \epsilon_{2, t}\right]=0,
\end{aligned}
$$

with $\phi$ unknown but different from zero and $z_{t}$ assumed to have a zero mean for simplicity. ${ }^{9}$ Equation (6) implies that $z_{t}$ is correlated with the primitive shock of interest, while (7) states that it is uncorrelated with the remaining structural shocks. The key difference between the external instrument approach and the one that I propose in this paper lies in how the proxy $z_{t}$ is used. The external instrument approach proceeds in multiple steps. First, system (2) is estimated for a sample of observables. In a second step, the estimated reduced-form innovations $\hat{u}_{t}$ are regressed on $z_{t}$. These steps give consistent estimates of the true relative impulse responses (see Appendix A.1).

Instead of using the proxy in such external steps, I propose to integrate it directly into (2) as an exogenous variable, such that

$$
y_{t}=\widetilde{B}_{0}+\widetilde{B}_{1} y_{t-1}+\ldots+\widetilde{B}_{k} y_{t-k}+\widetilde{A} z_{t}+\widetilde{u}_{t},
$$

where tildes are used to distinguish variables and coefficients from the notation thus far. The

\footnotetext{
${ }^{9}$ Throughout the description of the methodology, I assume that $z_{t}$ is not serially correlated. If $z_{t}$ is autocorrelated, then it should first be projected on its own lags and the error from this projection be used in lieu of $z_{t}$. For the following application, I find that such a correction does not change the results.
} 
contemporaneous relative impulse response is now given by

$$
\widetilde{r}_{i j}=\frac{\widetilde{A}_{i}}{\widetilde{A}_{j}},
$$

where $\widetilde{A}_{i}$ and $\widetilde{A}_{j}$ with $i \neq j$ are two elements in $\widetilde{A}$. The subsequent impulse responses are again obtained by tracing an initial impulse through (8) via the lagged endogenous variables. Next, I show analytically that this approach also gives consistent estimates of the true relative impulse responses. In this regard, I distinguish between contemporaneous and subsequent impulse responses, since the necessary conditions to give consistent estimates for the two types of responses differ. The distinction is also useful for a comparison with the external instrument approach, as further discussed in Section 2.4. Throughout, I consider only the case of a single instrument $z_{t}$ that is used to obtain impulse responses to a single structural shock of interest. ${ }^{10}$

\subsection{Contemporaneous Impulse Responses}

Proposition 1. The exogenous variable approach gives consistent estimates of the true contemporaneous relative impulse responses. Proof. See Appendix A.3.1.

The intuition for this result is that any element $\hat{\widetilde{A}}_{i}$ in $\hat{\widetilde{A}}$ based on (8) converges to the product of a constant and the associated element $s_{i}$ in $s$. However, when taking ratios between any two elements $\hat{\widetilde{A}}_{i}$ and $\hat{\widetilde{A}}_{j}$ with $i \neq j$ in $\hat{\widetilde{A}}$, the constant cancels out, thereby giving a consistent estimate of the associated contemporaneous relative impulse response $r_{i j}=\frac{s_{i}}{s_{j}}$ as stated in (5). The proof to Proposition 1 is left to Appendix A.3.1.

\subsection{Subsequent Impulse Responses}

Proposition 2. If $z_{t}$ is uncorrelated with the remaining regressors in (8), then the exogenous variable approach gives consistent estimates of the true subsequent relative impulse responses.

Proof. See Appendix A.3.2.

Intuitively, if $z_{t}$ is uncorrelated with the rest of the explanatory variables in (8), then the estimated coefficients on the remaining regressors are unchanged whether $z_{t}$ is included in the VAR as in (8) or left out. Since these coefficients are used to trace an initial impulse through the system via the lagged endogenous variables, any subsequent impulse response will be equivalent to the true response. Note that one can always achieve the condition for Proposition 2 by projecting $z_{t}$ on all other regressors in (8) and using the error from this projection in lieu of $z_{t}$. The proof to Proposition 2 is left to Appendix A.3.2.11

\footnotetext{
${ }^{10} \mathrm{An}$ issue that arises with multiple instruments is the following. It is not clear which coefficients to use for the contemporaneous impulse response when they are integrated as multiple exogenous variables into a VAR. To resolve this issue, one could find a common factor across the instruments first and then integrate this factor as a single exogenous variable and proceed as described in the text.

${ }^{11}$ Appendix A.6 illustrates the relation of Proposition 2 with the Frisch-Waugh-Lovell-Theorem.
} 


\subsection{Robustness to Measurement Problems}

Depending on a specific application, various types of measurement problems may exist that invalidate the use of $z_{t}$ as direct observations of the structural shock of interest $\epsilon_{1, t}$. For example, Mertens and Ravn (2013) argue that $z_{t}$ likely contains measurement error and has observations that are censored at zero if it is derived from narrative sources for fiscal policy. Since the external instrument approach requires that $z_{t}$ is only imperfectly correlated with $\epsilon_{1, t}$, Mertens and Ravn (2013) show that this method is robust to various types of measurement problems. The following proposition and its proof illustrate that these results also hold for relative impulse responses derived with the exogenous variable approach.

Proposition 3. The exogenous variable approach gives consistent estimates of the true contemporaneous relative impulse responses, even if $z_{t}$ contains random observations that are censored at zero or an additive i.i.d. measurement error that is orthogonal to all other variables. If $z_{t}$ is additionally uncorrelated with the remaining regressors in (8), then the subsequent relative impulse responses are also consistently estimated. Proof. See Appendix A.3.3.

The proof to Proposition 3 is left to Appendix A.3.3. The presence of measurement error gives inconsistent least squares estimates of $\widehat{\widetilde{A}}$ in (8), such that $\widehat{\widetilde{A}}$ is biased towards zero. However, ratios of elements in $\hat{\widetilde{A}}$ still give consistent estimates of the related true contemporaneous relative impulse responses. Moreover, random zero observations reduce the sample for $z_{t}$. But if the original sample is large enough, then estimated ratios of elements in $\widetilde{A}$ remain unchanged. If the measurement error in $z_{t}$ is also uncorrelated with the remaining regressors in (8), then the presence of $z_{t}$ again does not change the estimated coefficients on the remaining regressors.

\subsection{Comparison with Alternative Identification Approaches}

\subsubsection{External Instrument Approach}

Propositions $1-3$ show that one can integrate the proxy $z_{t}$ directly into a VAR as an exogenous variable to identify the effects of structural shocks. In this regard, the exogenous variable approach is an alternative implementation of the external instrument approach; both consistently identify the true relative impulse responses. In fact, the contemporaneous relative impulse responses of the two approaches are always the same - even in small samples (see Appendix A.4). Any differences in such responses can only be due to an incorrect rescaling and not for example be due to measurement problems with respect to $z_{t}$.

However, relative impulse responses may differ subsequently. In large enough samples, such differences can only be due to the correlation of $z_{t}$ with the remaining regressors in a VAR - not because of other types of measurement problems of $z_{t}$ as considered in Section 2.3 (see Appendix A.4). A potential advantage of the external instrument approach is that it does not require that $z_{t}$ is available for the same sample as $y_{t}$, which may be beneficial if $z_{t}$ is available for a shorter sample than $y_{t}$ (as for example in Gertler and Karadi, 2015). 
The key difference between the two approaches is that the VARX is estimated in a single step. This feature allows for a simple extension to time-varying parameters to identify the time-varying effects of structural shocks. In comparison with an external instrument approach, a time-varying parameter VARX largely simplifies the analysis, since it does not require any external steps that would have to account for a time-varying contemporaneous relation between $z_{t}$ and the reducedform errors. $^{12}$

\subsubsection{Local Projection Instrumental Variable Approach}

Among others, Stock and Watson (2018) propose a so-called local projection instrumental variable approach (LP-IV) as an alternative to the external instrumental approach. In Appendix A.5, I illustrate the equivalence between this approach and the VARX. To this end, I again differentiate between the contemporaneous impulse responses and any subsequent ones.

I show that the VARX and the LP-IV give the same contemporaneous relative impulse responses if they include the same controls. Moreover, if the VARX captures the dynamics of $y_{t}$ well through the variables included in $y_{t}$ and their lags, then any subsequent response will also be the same in large samples. ${ }^{13}$

Moreover, as discussed in Appendix A.5, one can also integrate the instrument directly into a local projection as opposed to using it in a separate instrumental variable step. If the impulse responses are scaled appropriately, then this approach again gives consistent relative impulse responses under slightly stronger conditions for the instrument.

\section{The Time-Varying Parameter VARX}

The time-varying parameter VAR follows Cogley and Sargent (2001), but also includes an exogenous variable. Let $y_{t}$ be an $n \times 1$ vector of endogenous variables that evolves according to

$$
y_{t}=B_{0, t}+B_{1, t} y_{t-1}+\ldots+B_{k, t} y_{t-k}+A_{t} z_{t}+u_{t} \quad t=1, \ldots, T
$$

where $B_{0, t}$ is an $n \times 1$ vector of time-varying intercepts and $B_{j, t}$ for $j \in\{1, \ldots, k\}$ are $n \times n$ timevarying coefficient matrices with respect to the lagged endogenous variables. The innovations are given by the $n \times 1$ vector $u_{t}$. The model includes an exogenous variable $z_{t}-$ with $n \times 1$ vector of time-varying coefficients $A_{t}$ - which is again correlated with the structural shock of interest

\footnotetext{
${ }^{12}$ De Wind (2014) considers the external instrument approach with respect to a time-varying parameter VAR. But his method does not allow for time-varying contemporaneous impulse responses, which is undesirable in a context where time-varying simultaneous relations are important, as in this paper.

${ }^{13}$ See also Plagborg-Moeller and Wolf (2018) on the estimation of impulse responses with local projections and VARs. Regarding the use of external instruments, the proposed method by Plagborg-Moeller and Wolf (2018) to order an instrument first in a VAR and use a recursive identification coincides with the VARX in my paper if the instrument is uncorrelated with the controls in a VAR, including lags of the instrument itself (see also Noh, 2018).
} 
$\epsilon_{1, t}$, but not with any of the other structural shocks. An additional assumption compared with the constant parameter case is that $z_{t}$ is linked to the structural shock $\epsilon_{1, t}$ via

$$
z_{t}=\phi \epsilon_{1, t}+\eta_{t}
$$

where $\eta_{t} \sim N\left(0, \sigma_{\eta}^{2}\right)$ and $\eta_{t}$ is orthogonal to all other variables. ${ }^{14}$ This assumption implies that the identified time-variation in $A_{t}$ is not due to time-variation in the relation between $z_{t}$ and $\epsilon_{1, t}$, which is useful to compute impulse responses over time as discussed below and in Section 4.3.2. Next, I define $B_{t}$ to be a vector that stacks all coefficients on the right-hand side of (9) - coefficients to the constant terms, to the lags of the endogenous variables, and to the exogenous variable. $B_{t}$ is assumed to follow a driftless random walk,

$$
B_{t}=B_{t-1}+v_{t}
$$

The model's innovations are assumed to be jointly normally distributed with mean zero and the variance-covariance matrix to be block diagonal, which takes the form

$$
V=\operatorname{Var}\left(\left[\begin{array}{l}
u_{t} \\
v_{t}
\end{array}\right]\right)=\left[\begin{array}{cc}
\Omega & 0 \\
0 & Q
\end{array}\right],
$$

where $\Omega$ and $Q$ are positive definite matrices and termed "hyperparameters". Denote by $B^{\tau}=$ $\left[B_{1}^{\prime}, \ldots, B_{\tau}^{\prime}\right]^{\prime}$ the history of coefficients $B_{t}$. I use Bayesian methods and Gibbs sampling to evaluate the posterior distributions of $B^{T}$ and the hyperparameters $V$. The steps of the sampler are summarized in Appendix A.9.

Given the estimated model and a structural shock $\epsilon_{1, t}$ that leads to a one-unit increase in some variable $j$ in $y_{t}$ at time $t$, the contemporaneous relative impulse response of some other variable $i$ in $y_{t}$ at time $t$ is given by

$$
r_{t, i j}=\frac{\bar{A}_{t, i}}{\bar{A}_{t, j}}
$$

where $\bar{A}_{t, i}$ and $\bar{A}_{t, j}$ are the posterior means of the coefficients for variables $i$ and $j$, respectively, that are associated with $z_{t}$ at time $t$. The posterior means of the remaining coefficients in $B_{t}$ are then used to derive any subsequent impulse responses. To obtain relative impulse responses over time, one has to normalize the initial response of one of the endogenous variables for a particular period. For example, one can consider a monetary policy shock that lowers output in period $k$ by, let's say, one percent. This shock implies a particular variation in $z_{t}$ that can then be used to calculate the impulse responses for the remaining periods to ensure a consistent comparison over time. ${ }^{15}$ I discuss this normalization in more detail for the application in Section 4.3.2.

\footnotetext{
${ }^{14}$ The squared correlation between $z_{t}$ and $\epsilon_{1, t}$ is then given by $\frac{\phi^{2}}{\phi^{2}+\sigma_{\eta}^{2}}$ which is directly related to the signal-to-noise ratio $\frac{\phi}{\sigma_{\eta}}$ (see also Caldara and Herbst, 2016).

${ }^{15}$ Note that by equation (10), the relation between $z_{t}$ and $\epsilon_{1, t}$ is constant over time. By fixing the implied variation in $z_{t}$, one therefore considers same-size $\epsilon_{1, t}$ shocks over time.
} 


\section{Time-Varying Response of Stock and House Prices}

I use the described framework to obtain evidence on the time-varying impulse responses of stock and house prices to monetary policy shocks. I estimate a monthly model for the U.S. economy. Define the vector of endogenous variables to be

$$
y_{t} \equiv\left[i_{t}, \Delta q_{t}, \Delta d_{t}, \Delta h p_{t}, \Delta p_{t}, \Delta \widetilde{y}_{t}\right]^{\prime},
$$

where $i_{t}$ denotes the federal funds rate, $q_{t}$ the (log) real stock price index (S\&P 500), $d_{t}$ the associated $(\log )$ real dividends, $h p_{t}$ the $(\log )$ real S\&P/Case-Shiller national home price index, $p_{t}$ the $(\log )$ consumer price index (CPI), and $\widetilde{y}_{t}(\log )$ real industrial production (IP). Hence, I have added all variables in first-differences (of their log-levels) apart from the federal funds rate. ${ }^{16,17}$

\subsection{Monetary Policy Surprises}

To address the identification problems mentioned in the introduction, I use monetary policy surprises based on federal funds futures. For reasons explained shortly, I consider surprises extracted from 30-day federal funds futures that are settled at the end of the month $t$ during which a policy announcement is made (also denoted MP1 by Gürkaynak et al., 2005). ${ }^{18}$ These surprises therefore reflect unanticipated movements in current short-term interest rates. Let $f_{t}^{k}$ be the settlement price for the current month's federal funds futures following an FOMC meeting $k$ which takes place in month $t$. Denote by $f_{t,-1}^{k}$ the settlement price before the FOMC meeting $k$ in month $t$. Then, a surprise $\mathrm{S}_{t}^{k}$ around FOMC meeting $k$ is given by

$$
\mathrm{S}_{t}^{k}=f_{t}^{k}-f_{t,-1}^{k}
$$

which is measured in a 30-minute window around a policy announcement. ${ }^{19}$ This gives a sufficiently tight window to minimize any potential bias due to other information released around the policy announcement that might also trigger financial market or monetary authority reactions. The series of surprises $S_{t}^{k}$ are on a meeting-by-meeting basis and are converted into a time series of surprises $S_{t}$ with the same frequency as the variables that enter the VAR. If a meeting occurs in some period $t$, the associated surprise is assigned to that period. If multiple FOMC meetings occur within a period $t$, then the surprises with respect to these meetings are summed up (as in Romer and Romer, 2004). ${ }^{20}$ However, as explained in the introduction, the resulting series of surprises $S_{t}$ should not be taken as direct observations of the primitive monetary policy shock, but the two are

\footnotetext{
${ }^{16}$ See Appendix A.13 for the time series in log-levels and in first-differences.

${ }^{17}$ The time series of stock prices is the end of the month price of the S\&P 500. The time series of the associated dividends is the one provided on Robert Shiller's webpage for monthly U.S. data.

${ }^{18}$ When considering federal funds futures with respect to the current month, one has to adjust the surprise series for the remaining days within a month, since 30-day federal funds futures are bets on the average federal funds rate within a month. In this regard, the surprise series are adjusted as suggested by Kuttner (2001), multiplying $S_{t}^{k}$ by $\frac{T}{T-m}$ where $T$ is the total number of days in month $t$ and $m$ the number of days that have elapsed until meeting $k$.

${ }^{19}$ The surprise series are based on calculations in Gürkaynak et al. (2005). I thank Peter Karadi, Mark Gertler, Eric Swanson, and Michiel de Pooter for sharing their data in this regard.

${ }^{20}$ Such an aggregation is not needed for the series of surprises used for the main analysis in this paper. That is because this series excludes intermeeting surprises and at most one scheduled FOMC meeting takes place per month.
} 
rather imperfectly correlated. $S_{t}$ therefore enters the following models as an exogenous variable $z_{t}$, as in (8) and (9).

\subsubsection{The Federal Reserve's Private Information}

A potential concern regarding the series of monetary policy surprises is that the Federal Reserve (Fed) may have a different information set than the private sector prior to FOMC meetings and releases its private information when changing interest rates. A positive monetary policy surprise may reflect the fact that the Fed's forecasts about the behavior of the economy in the near future is more positive than the private sector's forecasts. The monetary policy surprises could therefore be affected by this information release and could bias the impulse responses.

The following set of regressions tests for this "information effect". Similar to Campbell et al. (2012) and Nakamura and Steinsson (2018), I regress revisions of the private sector forecasts for real GDP growth on the series of surprises $\mathrm{S}_{t}^{k}$,

$$
\Delta \text { Forecast }_{t+1, t}=\alpha+\beta \mathrm{S}_{t}^{k}+\xi_{t}
$$

where the dependent variable is given by changes in the Blue Chip Economic Indicators forecasts from month $t$ to $t+1$ and meeting $k$ takes place between these two forecasts. Nakamura and Steinsson (2018) find that $\beta$ is of the "wrong" sign; it is positive and statistically significant, such that private forecasters increase their expectations of output growth in the near future after positive monetary policy surprises - evidence of the information effect. However, Nakamura and Steinsson (2018) consider a combination of monetary surprises with respect to current and future short-term rates. Instead, I restrict the series of surprises to the current month's short-term rates only (MP1). Based on this series, Table 1 shows the results for the change in the forecast of average real GDP growth over the next year. I also differentiate by whether unscheduled FOMC meetings are taken into account. Such meetings typically occur in turbulent times and may be more prone to a release of a central bank's private information.

The estimated $\hat{\beta}$ are statistically significant and of the wrong sign, when unscheduled meetings are included. ${ }^{21}$ In contrast, if surprises with respect to unscheduled meetings are excluded, then the coefficients are not statistically different from zero and much smaller in magnitude. In Tables 3 and 4 in Appendix A.10, I also show the results for forecast revisions of inflation and unemployment and additionally differentiate by various forecast horizons. Again, when unscheduled meetings are included, the coefficients tend to be of the wrong sign and statistically significant. In contrast, for scheduled FOMC meetings only, the coefficients are mostly of the correct sign and largely statistically insignificant. Hence, including unscheduled meeting surprises leads to revisions in the private sector forecasts that strongly indicate a release of private information. ${ }^{22}$

\footnotetext{
${ }^{21}$ For the shorter sample 1995 M1-2007 M12, the results are almost entirely driven by the September 2001 meeting. In contrast, excluding this meeting for the longer sample 1988 M11-2017 M9 leaves the results largely unchanged.

${ }^{22}$ However, even with respect to scheduled FOMC meetings, the estimated coefficients are not negative as standard theory would predict. There are two possible explanations. First, it may be the case that an information release still
} 


$\begin{array}{ccc}\text { Scheduled FOMC Meetings } & 0.202 & 0.131 \\ & (0.282) & (0.361) \\ \text { Observations } & 186 & 83 \\ & & \\ \text { All FOMC Meetings } & 0.685^{* * *} & 0.967^{* *} \\ \text { Observations } & (0.180) & (0.308) \\ & 202 & 87\end{array}$

Table 1: Change in Expected Output Growth over the Next Year. Regression results for (13). The dependent variable is the change from one month to the next in the Blue Chip forecast for average output growth over the next year (average of current quarter to four quarters ahead). The explanatory variable is the series of monetary surprises in the current month's federal funds rate (MP1). FOMC meetings that occur in the first week of the month are excluded, because it cannot be ensured that they took place after the Blue Chip forecasts are submitted. If multiple FOMC meetings occur between two surveys, then the surprises with respect to these meetings are summed up. Notation: Standard errors are in parentheses, ${ }^{* * *}$ $p<0.01,{ }^{* *} p<0.05,{ }^{*} p<0.1$.

Next, I estimate regression (13) for series of monetary policy surprises with respect to short-term rates at various horizons. Table 2 shows the estimation results. The information effect becomes visible for future contracts that capture unanticipated changes in short-term interest rates several months after a scheduled policy meeting, from around five months onwards after a meeting. Similar results can be obtained when separating movements in futures into target- and path-factors according to Gürkaynak et al. (2005). Applying their decomposition for scheduled FOMC meetings, it is the path-factor that shows an information release. The results for the target-factor are very close to the ones for MP1-series that I use. Since the target-factor is orthogonal to any future policy change, the results cannot simply be explained by a change in the timing of policy. ${ }^{23}$

The reason for these results may be that the Fed's forecasts contain additional information relative to the private sector's forecasts for macroeconomic developments farther out in the future. Surprises with respect to short-term rates several months after a policy announcement reveal such information. In contrast, surprises with respect to short-term rates in the very near future are less contaminated in this way since there is potentially less disagreement about the current state of the economy.

exists with respect to such surprises, but is not as dominant. Second, it may be the case that forecasters change their views after salient information releases quickly, but are otherwise slow to adapt their expectations to aggregate shocks (Coibion and Gorodnichenko, 2012). In support of the second explanation, I found evidence that forecast changes for GDP over the next year to MP1-surprises around scheduled meetings turn negative after several months. However, the coefficients remain statistically insignificant.

${ }^{23}$ Table 5 in Appendix A.10 shows the analogous results for forecast revisions of inflation and unemployment. When unscheduled FOMC meetings are included, surprises with respect to short-term rates in the very near future already indicate an information release (see Table 6 in Appendix A.10). 


\begin{tabular}{cccccc}
\hline MP1 & FF2 & FF3 & FF4 & FF5 & FF6 \\
\hline \hline $\begin{array}{c}0.168 \\
(0.297)\end{array}$ & $\begin{array}{c}0.296 \\
(0.348)\end{array}$ & $\begin{array}{c}0.448 \\
(0.400)\end{array}$ & $\begin{array}{c}0.543 \\
(0.365)\end{array}$ & $\begin{array}{c}0.453 \\
(0.363)\end{array}$ & $\begin{array}{c}0.591^{*} \\
(0.338)\end{array}$ \\
\hline \multicolumn{7}{c}{ ED2 } & ED3 & ED4 & NS & GSS-Target & GSS-Path \\
\hline \hline & & & & & \\
$0.583^{* *}$ & $0.634^{* *}$ & $0.465^{* *}$ & $0.029^{* *}$ & 0.193 & $0.223^{* *}$ \\
$(0.286)$ & $(0.252)$ & $(0.228)$ & $(0.014)$ & $(0.305)$ & $(0.101)$ \\
\hline
\end{tabular}

Table 2: Change in Expected Output Growth over the Next Year. Regression results for (13). The dependent variable is the change from one month to the next in the Blue Chip forecast for average output growth over the next year (average of current quarter to four quarters ahead). The explanatory variables are series of surprises with respect to different future contracts around scheduled FOMC meetings. MP1 are the surprises used in the main analysis. "FFX" denotes federal funds futures at horizon of " $X$ " months. "EDX" denotes euro-dollar interest rate futures at horizon of " $X$ " quarters. "NS" denotes the policy news shock by Nakamura and Steinsson (2018): the first principal component across MP1, FF4, ED2, ED3, and ED4 (not standardized). "GSS-Target" and "GSS-Path" refer to the target factor and the path factor by Gürkaynak et al. (2005). FOMC meetings that occur in the first week of the month are excluded, because it cannot be ensured that they took place after the Blue Chip forecasts are submitted. Sample: 1990 M2-2017 M9. Observations: 179. Notation: Standard errors are in parentheses, ${ }^{* *} p<0.01,{ }^{* *} p<0.05,{ }^{*} p<0.1$.

In Appendix A.11 and A.12, I provide evidence in favor of such an interpretation. Differences between the Fed's and the private sector's forecasts predict surprises farther out in the future (see Tables 7, 8, and 9). In turn, surprises with respect to future short-term rates help to predict the Fed's forecast, controlling for the private sector's forecast (see Tables 10 and 11). Last, following the empirical strategy in Romer and Romer (2000), I show that one would attach a higher weight to the Fed's forecasts compared to private forecasts, when both are available, with respect to future macroeconomic developments as opposed to more current ones (see Tables 12, 14, and 13).

While an information effect cannot be entirely excluded for surprises with respect to current shortterm rates around scheduled meetings, the results show that such surprises are less likely to be biased in this way. I therefore use the MP1-series around scheduled meetings in the following analysis. The series is shown in Figure (1). It is available from the start of the futures market in 1988 M11 until 2017 M9 - restricting the estimation to this sample period. ${ }^{24}$

\footnotetext{
${ }^{24}$ From 1994 M1 onward, the Fed released a statement immediately after each meeting. Before 1994 M1, changes to the target rate had to be inferred by the size and type of open market operations. Hence, it might have taken market participants some time to absorb the relevant information and the 30-minute window to extract the surprises might be too restrictive. The results in the next sections are robust to starting the sample in $1994 \mathrm{M} 1$ or using daily surprises pre-1994 (as, e.g., Kuttner, 2001).
} 


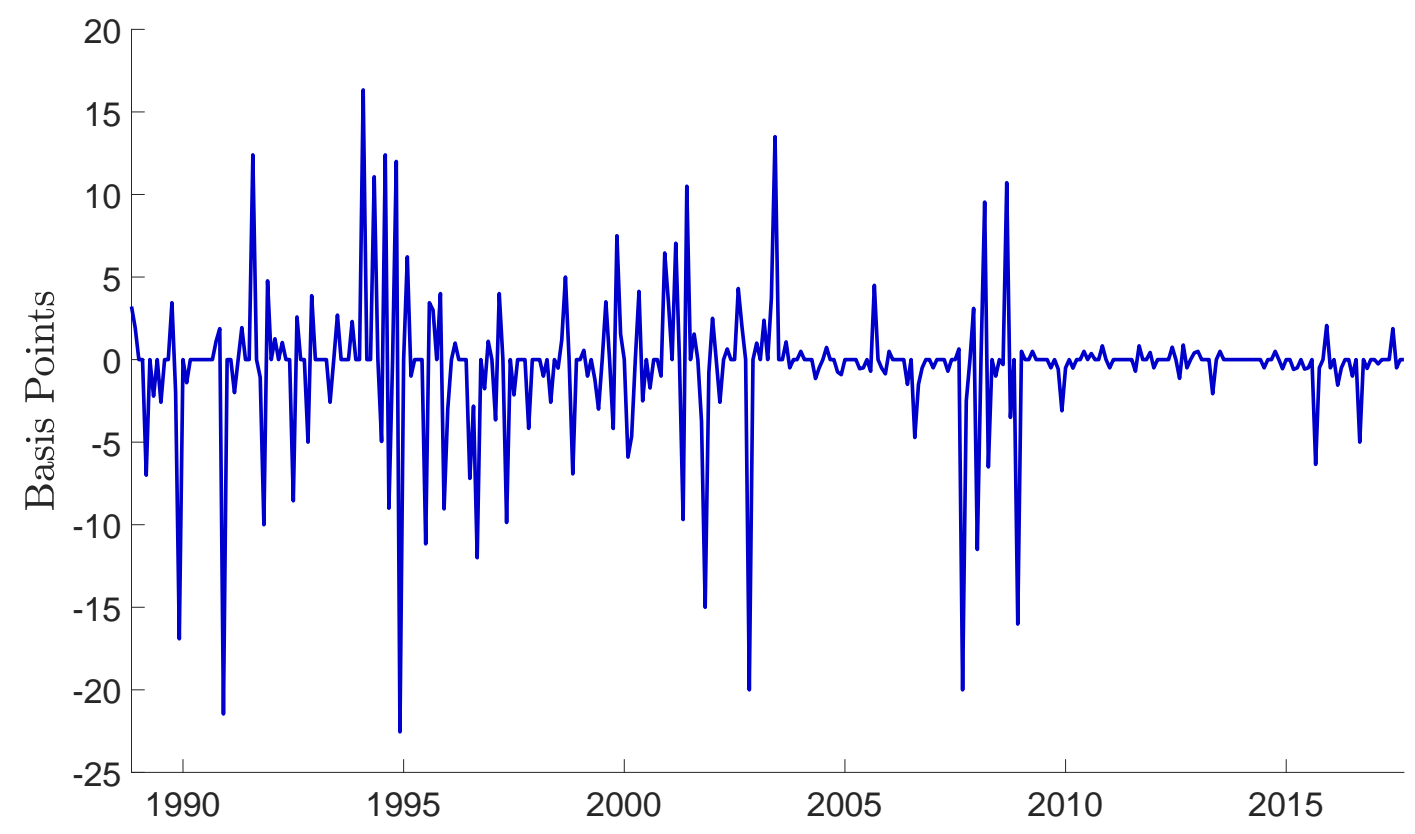

Figure 1: Monetary Policy Surprises.

\subsection{Constant Parameter VAR}

Next, I gather some intuition using a constant parameter VARX in (8). Figure (2) shows impulse responses to a contractionary monetary policy shock. ${ }^{25}$ The size of the shock is normalized to match the initial increase in the federal funds rate to a one-standard-deviation monetary policy shock as obtained with the external instrument approach (shown below). ${ }^{26,27}$ Based on the critique by Lunsford and Jentsch (2016), confidence bands are computed via a residual-based moving block bootstrap, resulting in relatively wide confidence intervals. ${ }^{28}$ In comparison, Figure (8) in Appendix A.14 shows the impulse responses using a recursive wild bootstrap as in Mertens and Ravn (2013) and Gertler and Karadi (2015).

The federal funds rate and the real interest rate (indicated by the dashed line in the same plot) both increase in the short run. The model shows standard responses of macroeconomic variables since IP and the CPI both decrease. However, the response of the CPI shows a price puzzle initially and the 68 percent confidence interval includes the zero-response. Stock prices, their associated dividends, and house prices all decrease persistently following a monetary tightening and the zero-responses lie outside the one-standard-deviation confidence intervals for the first few

\footnotetext{
${ }^{25}$ I choose a lag length of $k=4$ based on Akaike's IC. The responses for $k=3$ (the lag length of the TVP-VAR) are much the same. In addition, I also find that VARs with 12 lags - both in log-levels and in first-differences of log-levels - give very similar results.

${ }^{26}$ The series of surprises is projected on the lags of $y_{t}$ and the residual from this projection is used as the exogenous variable $z_{t}$ instead, which ensures that the condition in Proposition 2 is satisfied. The orthogonalization is repeated for each bootstrap repetition after the distorted $y_{t}$ are obtained. I find that the impulse responses are nearly equivalent when using the original $z_{t}$ instead.

${ }^{27}$ For each bootstrap repetition, the size of the shock is renormalized in the same way. The proxy $z_{t}$ is corrected for autocorrelation as discussed in footnote 9. The same is the case for any of the following estimations. All results are nearly equivalent when using the uncorrected $z_{t}$ instead.

${ }^{28}$ See also Montiel-Olea et al. (2015) and Mertens and Ravn (2018) in this regard.
} 
months. The stock price response is also stronger than the implied fundamental price response based on discounted dividends and constant risk premia, indicated by the dashed line in the same plot (see Appendix A.8 for a derivation). The difference can be accounted for by an increase in risk premia. The results are therefore in line with the findings in Bernanke and Kuttner (2005), who show that stock returns decrease after a monetary tightening and risk premia account for a large part of this response.


Figure 2: Exogenous Variable Approach. Cumulative impulse responses to a contractionary monetary policy shock, normalized to give the same initial increase in the federal funds rate as obtained with external instrument approach to a one-standard-deviation monetary policy shock, median response along with 68 and 95 percent confidence intervals. The dashed line in the plot of the federal funds rate shows the real interest rate. The dashed line in the plot of stock prices shows the fundamental price response (see Appendix A.8 for the derivation). Residual-based moving block bootstrap as in Lunsford and Jentsch (2016) is used to obtain confidence bands (block size: 20). Sample: 1988 M11-2017 M9.

In comparison, Figure (9) in Appendix A.14 shows the impulse responses based on a Cholesky identification. The results are counterintuitive, since the CPI increases persistently to a monetary tightening, and IP and stock prices rise mildly after several periods. Clearly, a recursive identification is undesirable within the context of this paper.

I conduct several robustness checks. First, the previous sample includes the effective lower bound (ELB) episode from late 2008 to the end of 2015. Over this period, the surprises with respect to 
the current month's federal funds rate are essentially zero (see Figure 1). Hence, this episode provides little information for the estimation of the contemporaneous impulse responses. However, it is also not an obstacle for the estimation approach since the contemporaneous relative impulse responses are identified from the remaining non-zero observations of the instrument. ${ }^{29}$ Leaving in the ELB episode has the advantage that the surprises after the ELB episode are taken into account. To check whether the results are sensitive to the inclusion of the ELB episode, I estimate the VAR for a sample that ends in 2007 M12. Figure (10) in Appendix A.14 shows the impulse responses. Compared with Figure (2), house prices respond more strongly and the zero-response lies outside the two-standard-deviation confidence intervals for several months after the shock. While the CPI still shows a price puzzle initially, in the long run it responds more negatively. The other impulse responses are much the same. ${ }^{30}$

Second, Gertler and Karadi (2015) and Caldara and Herbst (2016) show that financial markets provide an important channel through which monetary policy works. Following these papers, I include the excess bond premium by Gilchrist and Zakrajsek (2012). The results are shown in Figure (11) in Appendix A.14. The excess bond premium rises to a monetary tightening and the responses of the remaining variables are much the same compared with the ones in Figure (2).

Third, I further check whether the price puzzle disappears if the monetary surprises are purged of the Federal Reserve's expectations about the behavior of the economy in the near future. I project the surprises on the Greenbook forecasts and use the residual from this projection instead of the original $z_{t} .{ }^{31}$ However, even with this new series of surprises, I find that the price puzzle persists. The FOMC may therefore respond to more information than the Greenbook forecasts capture. Ramey (2016) obtains similar results. However, she finds that the price puzzle vanishes if a zero restriction on the contemporaneous response of slow-moving macroeconomic variables is imposed. I therefore assume that the CPI does not respond on impact. This additional constraint indeed resolves the price puzzle (see Figure (12) in Appendix A.14).

Next, I use the proxy $z_{t}$ as an external instrument (see Appendix A.1 for a description). Figure (13) in Appendix A.14 shows the impulse responses. ${ }^{32}$ As shown in Appendix A.1 and A.4, this identification approach also gives consistent relative impulse responses and they coincide with the ones based on the VARX in large samples given Propositions 1-3. The obtained impulse re-

\footnotetext{
${ }^{29}$ See for example equation (25) in Appendix A.3.1 and the discussion about measurement problems in Appendix A.3.3.

${ }^{30}$ For this sample, the quantitative effects of a monetary policy shock are comparable to the ones in the literature. A 100 basis point increase in the federal funds rate leads to a decline of industrial production of about 2 percent. Ramey (2016) obtains similar results using an external instrument approach as in Gertler and Karadi (2015).

${ }^{31}$ The surprises are orthogonalized against the Greenbook forecasts for real GDP (current quarter, one quarter ahead, two quarters ahead), for the GDP deflator (current quarter, one quarter ahead, two quarters ahead), and the unemployment rate (current quarter), resembling the information set used in Romer and Romer (2004). Given the availability of the Greenbook forecasts, the sample is restricted to end in 2013 M12.

${ }^{32}$ The external steps of the external instrument approach can also be expressed as a 2SLS estimation (e.g., Gertler and Karadi, 2015). Given the application here, the F-statistic from the first-stage regression is 16.78, which should also be tested when applying the VARX framework.
} 
sponses in Figures (2) and (13) are therefore nearly equivalent - both contemporaneously as well as subsequently. In the next section, I explore how the responses of stock and house prices vary over time.

\subsection{Time-Varying Parameter VAR}

\subsubsection{Priors}

Based on the description in Section 3, I consider a VAR with time-varying parameters collected in $B_{t}$ and use Bayesian methods to evaluate the posterior distribution of $B^{T}$ and the hyperparameters

$$
V=\operatorname{Var}\left(\left[\begin{array}{l}
u_{t} \\
v_{t}
\end{array}\right]\right)=\left[\begin{array}{cc}
\Omega & 0 \\
0 & Q
\end{array}\right] .
$$

Following Primiceri (2005), the prior distributions are calibrated based on a training sample of around 12 years (1978 M11-1990 M12). Unfortunately, for a large part of the training sample, the series of monetary policy surprises is not available since the futures market only started trading in 1988 M11. I therefore set the surprises equal to zero for periods with no available data. While this is certainly a limitation to calibrating the priors, the robustness checks in Section 4.4 show that this constraint does not affect the findings of the paper. Based on the OLS estimates of a constant parameter VAR for the training sample, mean and variance of $B_{0}$ and scale matrix and degrees of freedom for the inverse-Wishart prior of $\Omega$ and $Q$ are set to

$$
\begin{aligned}
& B_{0} \sim N\left(\widehat{B}_{O L S}, 4 \cdot V\left(\widehat{B}_{O L S}\right)\right) \\
& \Omega \sim I W\left(I_{n}, n+1\right) \\
& Q \sim I W\left(\kappa_{Q}^{2} \cdot \tau \cdot V\left(\widehat{B}_{O L S}\right), \tau\right) .
\end{aligned}
$$

$\widehat{B}_{\text {OLS }}$ collects the OLS point estimates for the training sample, $V\left(\widehat{B}_{O L S}\right)$ their variance, and $\tau=143$ is the size of the training sample. The parameter $\kappa_{Q}$ pins down the prior belief about the amount of time variation in $B_{t}$. For the main analysis, I set $\kappa_{Q}$ to 0.015 . The robustness checks in Section 4.4 report the results for different values of $\kappa_{Q}$. The simulation of the model is based on 5,000 iterations of the Gibbs sampler and the first 2,000 are discarded for convergence. The lag length is reduced to $k=3$ to lower the dimension of both $B_{t}$ and $Q$ to ensure convergence. I check parameter convergence via trace plots and autocorrelation functions of the draws. The results show that the estimation algorithm produces posterior draws efficiently.

\subsubsection{Results}

Figure (3) shows the time-varying impulse responses for the sample 1991 M1-2017 M9. Before discussing the results, it is worth explaining in more detail how the impulse responses are calculated. I start by normalizing the response of the federal funds rate on impact to 20 basis points at the beginning of the sample (1991 M1), giving a particular value $\bar{z}$ of the instrument to achieve this 
response. ${ }^{33}$ I then use the same variation $\bar{z}$ to obtain contemporaneous impulse responses for any other variable in $1991 \mathrm{M} 1$ or any subsequent period. ${ }^{34}$ This procedure ensures that one considers the reaction to the same-size shocks $\epsilon_{1, t}$ over time, since the relation between $\epsilon_{1, t}$ and $z_{t}$ is assumed to be constant (see equation 10).

As an alternative, one could also normalize the impact response of the federal funds rate for each period. However, such a normalization would consider monetary policy shocks of different sizes for the following reason. Note that a contractionary monetary policy shock can occur without an increase of the federal funds rate (or even a decrease). For example, if the private sector expected the federal funds rate to drop by 50 basis points, but in fact it remains unchanged, then this is recorded as a 50 basis points positive surprise. The response of the federal funds rate to the samesize monetary policy shocks can then change over time, as shown in Figure (3), since the private sector's expectations about future movements in the federal funds rate fluctuate.

While the response of the federal funds rate fluctuates over time, it typically increases to a monetary tightening as shown in Figure (3). The recent ELB episode is reflected in the fact that the response is close to zero since late 2008. However, it is still possible to capture responses to hypothetical monetary policy shocks over this period. Nonetheless, due to the lack of substantial additional variation of the monetary policy surprises (see Figure 1), the posterior distribution of the relevant parameters is not sharpened over this period.

Continuing with the responses in Figure (3), IP always decreases to a monetary tightening and the same is the case for the CPI over most of the sample. House and stock prices always fall and their responses are significantly different from zero at the one- and two-standard deviation confidence intervals over the whole sample. ${ }^{35}$ The behavior of stock prices is in contrast to the findings in Galí and Gambetti (2015). They find that stock prices increase to a monetary tightening during stock market booms.

\footnotetext{
${ }^{33}$ The variation in $z_{t}$ is given by $\bar{z}=0.2 / \bar{A}_{1991 M 1,1}$, where $\bar{A}_{1991 M 1,1}$ is the estimated posterior mean for the federal funds rate at time $1991 M 1$.

${ }^{34}$ The contemporaneous impulse response of variable $i$ at time $t$ is therefore given by $\bar{A}_{t, i} \cdot \bar{z}$, where $\bar{A}_{t, i}$ is the estimated posterior mean for variable $i$ at time $t$. The contemporaneous relative impulse response of any two variables $i$ and $j$ at time $t$ can then be obtained from the ratio of their two responses $\frac{\bar{A}_{t, i} \cdot \bar{z}}{\bar{A}_{t, j} \cdot \bar{z}}=\frac{\bar{A}_{t, i}}{\bar{A}_{t, j}}=r_{t, i j}$ (see equation (12)).

${ }^{35}$ Figure (14) in Appendix A.15 shows that stock prices always respond more strongly than fundamentals imply. Again, an increase in risk premia can explain this difference. Quantitatively, the time-varying response of stock prices is largely due to the time-varying response of risk premia; both show a very similar pattern over the whole sample.
} 

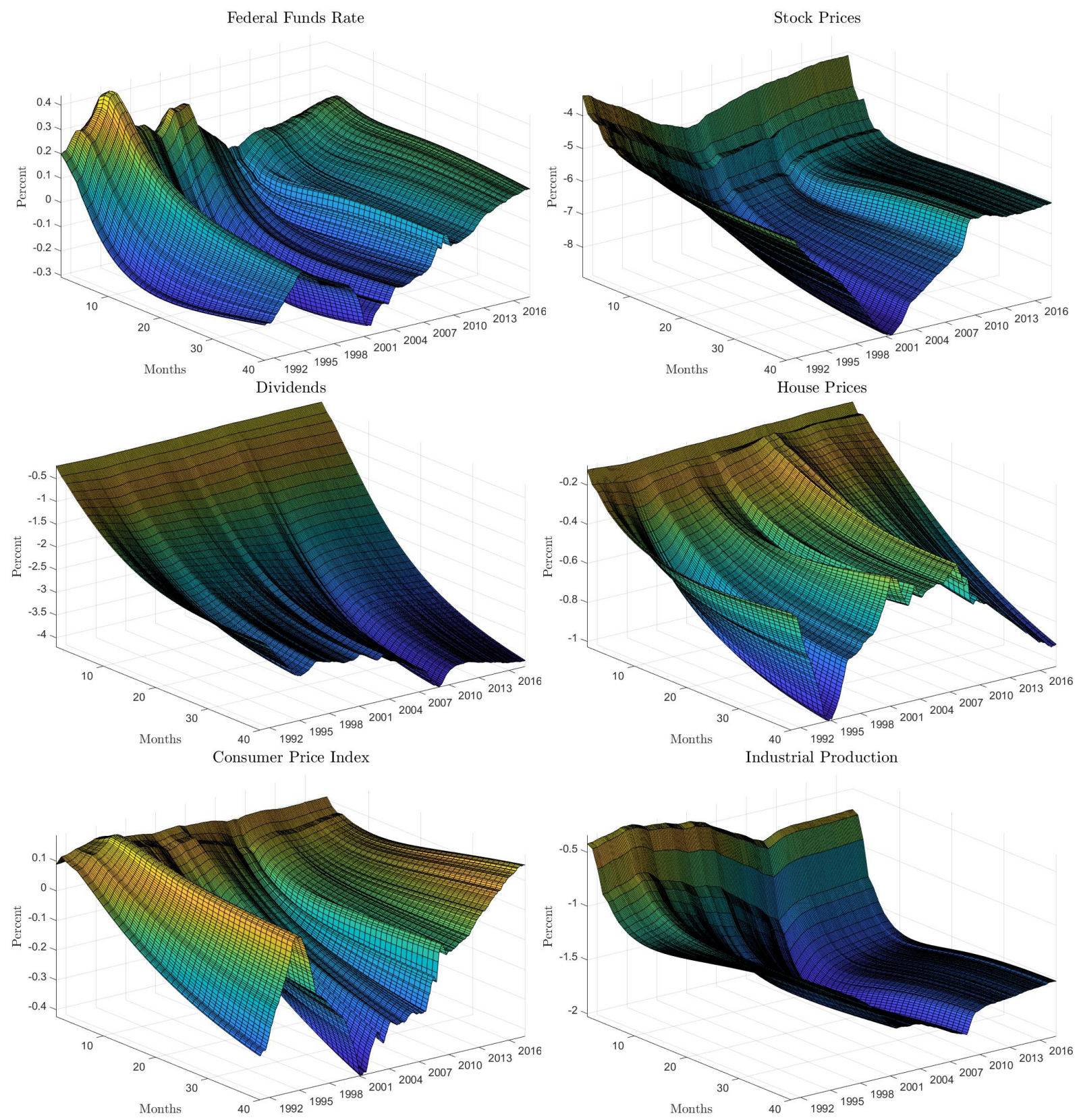

Figure 3: Time-Varying Impulse Responses. Cumulative impulse responses to a monetary tightening. Vertical axis: Percentage change. Front axis left: Months (Horizon IRF). Front axis right: Years.

For a selected period, Figure (16) in Appendix A.15.1 shows the impulse responses with posterior credibility intervals. Based on a Cholesky identification as in their paper, Figure (15) in Appendix A.15 shows the time-varying impulse responses. Again, the results are counterintuitive, since IP, the CPI, and stock and house prices all increase after a monetary tightening.

Figure (4) illustrates the results in a different format, showing the response of stock and house prices after one and three years (left axis). Additionally, the stock market and the house price index are displayed in log-levels (right axis). The upper graph shows that stock prices are not very responsive during the 1990s stock market growth period. However, around this time, their 
response is changing in the opposite direction as the underlying index. During the stock market crash in the early 2000s, stock prices are strongly responsive; but this pattern changes again afterwards, interrupted by a slight uptick in the response during the Great Recession. Over most of the sample, the response of house prices follows a clear pattern with respect to the house price index: house prices are less responsive to monetary policy shocks when house prices are high, and more responsive when prices are low. For selected time periods of strong and weak asset price responses, Figures (17) and (18) in Appendix A.15.1 shows that these differences in the response of house and stock prices are mostly significantly different from zero, but only at a smaller confidence level than typically used. ${ }^{36}$


Figure 4: Time-Varying Impulse Responses for Different Horizons. Left axis: Percentage change in stock and house prices after one year (dashed-dotted) and three years (dotted). Right axis: Stock market or house price index in log-levels (solid). Gray bars denote NBER recessions.

Next, similar to the sacrifice ratio (e.g., Ball, 1994), which is defined as the percentage loss of output per percentage change in a broad price index, I define sacrifice ratios for stock and house prices, substituting the broad price index response with the response of either house or stock prices. Figure (5) shows the sacrifice ratios for different horizons (left axis) and again compares them with the associated price index in log-levels.

The upper graph illustrates that the sacrifice ratio for stock prices was particularly high around the Great Recession. At this time, the response of output, measured by IP, increased, while the response of stock prices did not change much. After the crisis, the sacrifice ratio remained at a relatively elevated level. Overall, there is no consistent relation between the sacrifice ratio for stock

\footnotetext{
${ }^{36}$ In particular, for most differences, around two-thirds of the responses lie either above or below zero (equivalent to the mass of a one-standard deviation interval under normality).
} 
prices and the stock market index.

In contrast, the sacrifice ratio for house prices and the house price index nearly perfectly comove. Moreover, the time variation in the sacrifice ratio for house prices is substantial. While a one percentage point decrease in house prices in the mid-1990s is associated with a similar percentage change in output, this number increases 4-8 times around the peak of the housing boom prior to the Great Recession. Around this time, the response of output was historically high, while the opposite was the case for house prices. After the Great Recession, the sacrifice ratio declined again while house prices recovered. In comparison, the constant parameter VARX in Section 4.2 gives a constant sacrifice ratio for house prices of about 1.5 after 3 years and therefore masks the sizable time-varying trade-off. Comparing the periods 1995 M1 and 2007 M12, Figure (19) in Appendix A.15.1 shows that these differences in the response of the sacrifice ratios for house and stock prices are significantly different from zero, but generally at a lower confidence level than typically used. ${ }^{37}$
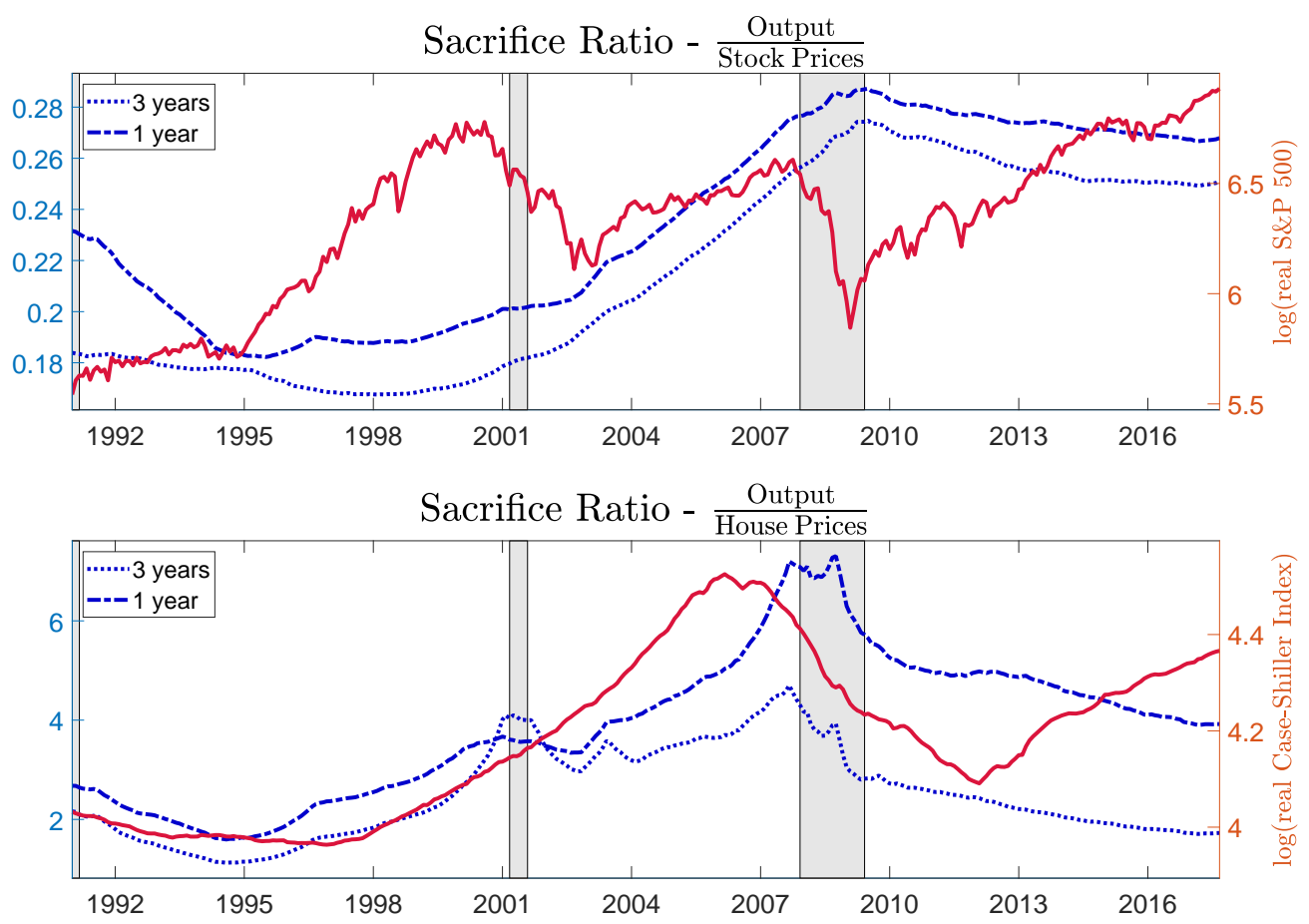

Figure 5: Sacrifice Ratios. Left axis: Percentage change output per one-percent change in stock and house prices after one year (dashed-dotted) and three years (dotted). Right axis: Stock market or house price index in log-levels (solid). Gray bars denote NBER recessions.

Overall, these findings suggest that it would have been difficult for the Federal Reserve to lean against the house price boom before the Great Recession. A monetary tightening with the goal to elicit a response in house prices would have come at the exact time when house prices were least

\footnotetext{
${ }^{37}$ To compare responses of sacrifice ratios over time, I condition on negative responses of IP and asset prices to monetary tightenings. That is because a positive response in either IP or asset prices leads to a negative sacrifice ratio. This response cannot only be negative, but also very large in absolute terms if the response of either stock or house prices is small in absolute terms. The considered time-variation of sacrifice ratios is still statistically significant without this conditioning.
} 
responsive. Instead, such attempts would have come with the risk of deviating from the Federal Reserve's output target, since IP was quite responsive around this time.

\subsection{Sensitivity Analysis}

This section checks the robustness of the results obtained with the time-varying parameter VARX. Figures are shown in Appendix A.16.

Priors. Regarding the training sample, I find that the results are unaffected for training samples that start earlier or end later. In this regard, I consider the training samples 1975 M11-1990 M12 and 1978 M11-1994 M12. Moreover, I check the robustness of the results for different calibrations of $\kappa_{Q}$, since Primiceri (2005) finds that the results may be sensitive to this parameter. Figures (20), (21), and (22) in Appendix A.16 show the results for $\kappa_{Q}=0.01$. While the results are qualitatively unchanged, setting $\kappa_{Q}$ to a lower value decreases the time variation in the coefficients $B_{t}$, which is reflected in less time variation in some of the impulse responses. However, the time variation of house prices remains substantial. Setting $\kappa_{Q}$ to a higher value has the opposite effect, increasing time variation. For $\kappa_{Q}=0.02$, the shape of the impulse responses and parameter convergence remain much the same.

Effective Lower Bound. A potential caveat is that the sample for the TVP-VARX includes the effective lower bound episode from late 2008 to late 2015. During this period, the surprises with respect to the current month's federal funds rate were much smaller in absolute size (see Figure 1). Hence, there was little information in the data to identify contemporaneous impulse responses over this period. To address this issue, I estimate a TVP-VARX on a sample that ends in 2007 M12, thereby simply excluding the ELB-episode. The results are shown in Figures (23), (24), and (25) in Appendix A.16. The findings are also robust to this variation as the relative responses of output-to-asset prices rise in the run-up to the crisis. ${ }^{38}$

Timing of Policy Actions. As pointed out by Bernanke and Kuttner (2005), surprises with respect to the current month's federal funds futures may only reflect unanticipated changes in the timing of policy actions. I therefore follow Gürkaynak et al. (2005) and construct a target and a path factor from a rotation of the first two principal components across a set of future surprises around scheduled FOMC meetings. ${ }^{39}$ The target factor moves the MP1-series, but is orthogonal to any surprises with respect to futures that expire after the current month. Based on this new series,

\footnotetext{
${ }^{38}$ To increase the sample size of the estimation, I consider a slightly shorter training sample from 1978 M11-1989 M12. In Figure (25), I exclude the responses after three years since house prices increase to a monetary tightening around this time (see Figure (23)). The associated sacrifice ratios therefore flip signs. Moreover, the previously mentioned statistical significance of the time-variation in asset prices and sacrifice ratios also remains for this shorter sample.

${ }^{39}$ The set includes the current month's federal funds futures (MP1), the three month ahead federal funds futures (FF4), and the six month, nine month, and year ahead futures on three month Eurodollar deposits (ED2, ED3, ED4). Based on regression (13), I confirm that the target-factor is not strongly confounded by an information release. For example, with respect to scheduled FOMC meetings, $\beta$ in (13) is not statistically different from zero (dependent variable: change in private output forecast over the next year; sample: 1988 M11-2017 M9, see Table 2). If unscheduled meetings are included, $\beta$ is positive and statistically different from zero at the 99 percent confidence level. The time-varying impulse responses that I report are for $\kappa_{Q}=0.01$.
} 
the results remain largely unchanged and are shown in Figures (26), (27), and (28) in Appendix A.16.

Unscheduled Meetings. As argued above, the inclusion of monetary policy surprises around unscheduled meetings may distort the impulse responses, since the Federal Reserve is likely to release private information around such meetings by changing interest rates. I check whether that is indeed the case by considering a time-varying parameter VAR and using a series of surprises from the current month's federal funds futures around scheduled and unscheduled meetings. The results show that dividends and house prices initially increase after a monetary tightening and the response of the consumer price index is positive throughout the sample - justifying the initial restriction.

Excess Bond Premium. As for the constant parameter VAR, I check whether the results are robust to including the excess bond premium by Gilchrist and Zakrajsek (2012). To lower the dimensionality of the model and ensure convergence, I exclude the dividend series. In unreported work, I find that the results are much the same, also when ending the sample in 2007 M12.

\section{Conclusion}

Swings in asset prices can have large effects on economies. During boom periods, rising asset prices can boost an economy that is already running hot. When asset prices reverse, they can amplify a downturn in economic activity. Recent research finds that such movements are important for financial stability: quickly rising stock and house prices are strong early-warning indicators of financial crises and their severity (Jordà et al., 2015; Kiley, 2018; Paul, 2018). To avoid the generally large costs of financial crises, it may therefore be optimal to use monetary policy to lean against asset price booms.

A monetary tightening typically decreases economic activity and asset prices. However, based on U.S. data over the past 30 years, I find that these effects are far from constant over time. Stock and house prices show substantial time-variation in their response to monetary policy shocks. The response of house prices strongly comoves with the level of house prices: they are less responsive to monetary policy shocks when house prices are high, and more responsive when prices are low. In addition, I find time-variation in the relative impact of monetary policy on asset prices and economic activity. The response of stock and house prices - relative to the response of output - was particularly low in the run-up to the Great Recession. Hence, attempts by the Federal Reserve to lean against the house price boom at the time may have been less effective.

These findings are based on the identified responses to unanticipated deviations of monetary policy from a perceived reaction function. Thus, my analysis cannot speak to the question of whether monetary policy should incorporate asset prices into its reaction function and how agents would change their decisions because of that. Finding answers to these important questions is left to 
future research.

In addition, there are a few other avenues for future research with respect to the methodology developed in the paper. First, it would be interesting to see a thorough analysis of the weak instrument problem for the VARX and the TVP-VARX. Second, a fixed-design wild bootstrap as applied by Goncalves and Kilian (2004) may produce valid confidence bands since the impulse responses with a VARX can be obtained from the estimated coefficients on the controls and the instrument. It would be great to see a formal proof whether such a bootstrap indeed produces valid confidence bands given the recent critique by Lunsford and Jentsch (2016) with respect to the recursive wild bootstrap. And last, I think that it be fruitful to extend the TVP-VARX in this paper to allow for time-varying variances along the lines of Primiceri (2005). 


\section{References}

Aastveit, K., F. Furlanetto, and F. Loria (2017). Has the fed responded to house and stock prices? a time-varying analysis. Norges Bank Working Paper 01/2017.

Andrade, P. and F. Ferroni (2016). Delphic and odyssean monetary policy shocks: Evidence from the euro-area. Unpublished Manuscript.

Bagliano, F. C. and C. A. Favero (1999). Information from financial markets and VAR measures of monetary policy. European Economic Review 43(4-6), 825-837.

Ball, L. (1994). What Determines the Sacrifice Ratio? NBER Chapters, 155-193.

Barakchian, S. M. and C. Crowe (2013). Monetary policy matters: Evidence from new shocks data. Journal of Monetary Economics 60(8), 950-966.

Bernanke, B. S. and K. N. Kuttner (2005). What Explains the Stock Market's Reaction to Federal Reserve Policy? Journal of Finance 60(3), 1221-1257.

Brooks, J., M. Katz, and H. Lustig (2019). Post-fomc announcement drift in u.s. bond markets. Stanford University Graduate School of Business Research Paper No. 18-2.

Caldara, D. and E. Herbst (2016). Monetary Policy, Real Activity, and Credit Spreads : Evidence from Bayesian Proxy SVARs. Board of Governors of the Federal Reserve System (U.S.), Finance and Economics Discussion Series (2016-049).

Campbell, J. R., C. L. Evans, J. D. Fisher, and A. Justiniano (2012). Macroeconomic Effects of Federal Reserve Forward Guidance. Brookings Papers on Economic Activity 44(1 (Spring), 1-80.

Campbell, J. R., J. D. M. Fisher, A. Justiniano, and L. Melosi (2017). Forward guidance and macroeconomic outcomes since the financial crisis. NBER Macroeconomics Annual 31(1), 283-357.

Christiano, L. J., M. Eichenbaum, and C. L. Evans (1999). Monetary policy shocks: What have we learned and to what end? Handbook of macroeconomics 1, 65-148.

Cieslak, A. and A. Schrimpf (2018). Non-monetary news in central bank communication. NBER Working Paper No. w25032.

Cochrane, J. (2001). Asset pricing. Princeton University Press.

Cogley, T. and T. J. Sargent (2001). Evolving Post-World War II U.S. Inflation Dynamics. NBER Macroeconomics Annual 16(1), 331-388.

Coibion, O. and Y. Gorodnichenko (2012). What can survey forecasts tell us about informational rigidities? Journal of Political Economy 120(1), 116-159.

De Wind, J. (2014). Time variation in the dynamic effects of unanticipated changes in tax policy. CPB Discussion Paper (271). 
Drautzburg, T. (2017). A narrative approach to a fiscal dsge model. Unpublished Manuscript.

Engle, R., D. Hendry, and J.-F. Richard (1983). Exogeneity. Econometrica 51(2), 277-304.

Florens, J., M. Mouchart, and J. Rolin (1990). Elements of Bayesian Statistics. Marcel Dekker, New York.

Galí, J. and L. Gambetti (2015). The Effects of Monetary Policy on Stock Market Bubbles: Some Evidence. American Economic Journal: Macroeconomics 7(1), 233-57.

Gertler, M. and P. Karadi (2015). Monetary Policy Surprises, Credit Costs, and Economic Activity. American Economic Journal: Macroeconomics 7(1), 44-76.

Gilchrist, S. and E. Zakrajsek (2012). Credit spreads and business cycle fluctuations. American Economic Review 102(4), 1692-1720.

Goncalves, S. and L. Kilian (2004). Bootstrapping autoregressions with conditional heteroskedasticity of unknown form. Journal of Econometrics 123(1), 89-120.

Gürkaynak, R. S., B. Sack, and E. Swanson (2005). Do Actions Speak Louder Than Words? The Response of Asset Prices to Monetary Policy Actions and Statements. International Journal of Central Banking 1(1), 55-93.

Hansen, L. P. and R. J. Hodrick (1980). Forward exchange rates as optimal predictors of future spot rates: An econometric analysis. Journal of Political Economy, 829-53.

Jarocinski, M. and P. Karadi (2018). Deconstructing monetary policy surprises: the role of information shocks. ECB Working Paper (2133).

Jordà, O., M. Schularick, and A. Taylor (2015). Leveraged bubbles. Journal of Monetary Economics 76(S), S1-S20.

Kiley, M. (2018). What macroeconomic conditions lead financial crises. Finance and Economics Discussion Series, Board of Governors of the Federal Reserve System (038).

Kilian, L. and H. Luetkepohl (2017). Structural vector autoregressive analysis. Themes in Modern Econometrics, Cambridge University Press.

Kuttner, K. N. (2001). Monetary policy surprises and interest rates: Evidence from the Fed funds futures market. Journal of Monetary Economics 47(3), 523-544.

Kuttner, K. N. (2013). Low interest rates and housing bubbles: Still no smoking gun. The Role of Central Banks in Financial Stability, 159-185.

Lakdawala, A. (2017). Decomposing the Effects of Monetary Policy Using an External Instruments SVAR. Michigan State University, Unpublished Manuscript.

Lakdawala, A. and M. Schaffer (2018). Federal reserve private information and the stock market. Unpublished Manuscript, Michigan State University. 
Law, T.-H., D. Song, and A. Yaron (2017). Fearing the fed: How wall street reads main street. Unpublished manuscript, Boston College.

Leombroni, M., A. Vedolin, G. Venter, and P. Whelan (2017). Central bank communication and the yield curve. Unpublished Manuscript.

Lunsford, K. (2015). Identifying Structural VARs with a Proxy Variable and a Test for a Weak Proxy. Federal Reserve Bank of Cleveland, Working Paper (1528).

Lunsford, K. (2018). Understanding the aspects of federal reserve forward guidance. Federal Reserve Bank of Cleveland, Working Paper no. 18-15.

Lunsford, K. and C. Jentsch (2016). Proxy SVARs: Asymptotic Theory, Bootstrap Inference, and the Effects of Income Tax Changes in the United States. Federal Reserve Bank of Cleveland, Working Paper (1619).

Melosi, L. (2017). Signaling effects of monetary policy. The Review of Economic Studies 84(2), 853884.

Mertens, K. and M. Ravn (2018). The dynamic effects of personal and corporate income tax changes in the united states: Reply to jentsch and lunsford. Dallas Fed Working Paper 1805.

Mertens, K. and M. O. Ravn (2013). The Dynamic Effects of Personal and Corporate Income Tax Changes in the United States. American Economic Review 103(4), 1212-1247.

Miranda-Agrippino, S. and G. Ricco (2017). The transmission of monetary policy shocks. Bank of England Staff Working Paper 657.

Miranda-Agrippino, S. and G. Ricco (2018). Identification with external instruments in structural vars under partial invertibility. Unpublished Manuscript.

Montiel-Olea, J., J. Stock, and M. Watson (2012). Inference in structural vars with external instruments https: / / scholar.harvard.edu/files/stock/files/inferencestructuralvarspresentationslides.pdf. Unpublished Slides.

Montiel-Olea, J., J. Stock, and M. Watson (2015). Uniform inference in svars identified with external instruments. Unpublished Manuscript, Columbia University.

Nakamura, E. and J. Steinsson (2018). High frequency identification of monetary non-neutrality: The information effect. Quarterly Journal of Economics 133(3), 1283-1330.

Newey, W. K. and K. D. West (1987). A simple, positive-definite, heteroskedasticity and autocorrelation consistent covariance matrix. Econometrica 55, 703708.

Noh, E. (2018). Impulse-response analysis with proxy variables. Unpublished Manuscript.

Paul, P. (2018). Historical patterns of inequality and productivity around financial crises. Federal Reserve Bank of San Francisco Working Paper 2017-23. 
Plagborg-Moeller, M. and C. Wolf (2018). Local projections and vars estimate the same impulse responses. Unpublished Manuscript, Princeton University.

Primiceri, G. E. (2005). Time Varying Structural Vector Autoregressions and Monetary Policy. Review of Economic Studies 72(3), 821-852.

Ramey, V. A. (2016). Macroeconomic Shocks and Their Propagation. Handbook of Macroeconomics, Volume 2, 71-162.

Rigobon, R. and B. Sack (2004). The impact of monetary policy on asset prices. Journal of Monetary Economics 51(8), 1553-1575.

Romer, C. D. and D. H. Romer (2000). Federal reserve information and the behavior of interest rates. American Economic Review 90(3), 429-457.

Romer, C. D. and D. H. Romer (2004). A New Measure of Monetary Shocks: Derivation and Implications. American Economic Review 94(4), 1055-1084.

Stock, J. H. and M. W. Watson (2012). Disentangling the Channels of the 2007-09 Recession. Brookings Papers on Economic Activity 44(1 (Spring), 81-156.

Stock, J. H. and M. W. Watson (2018). Identification and estimation of dynamic causal effects in macroeconomics. Economic Journal, forthcoming.

Swanson, E. T. (2017). Measuring the Effects of Federal Reserve Forward Guidance and Asset Purchases on Financial Markets. NBER Working Papers (23311).

Uhlig, H. (2005). What are the effects of monetary policy on output? Results from an agnostic identification procedure. Journal of Monetary Economics 52(2), 381-419. 


\section{A ONLINE APPENDIX}

\section{A.1 The External Instrument Approach}

Given a finite sample for $y_{t}$, the external instrument approach first estimates

$$
y_{t}=B_{0}+B_{1} y_{t-1}+\ldots+B_{k} y_{t-k}+u_{t} \quad t=1, \ldots, T .
$$

Collecting the regressors in $x_{t}=\left[1, y_{t-1}^{\prime}, \ldots, y_{t-k}^{\prime}\right]^{\prime}$, the coefficients in $B=\left[B_{0}, \ldots, B_{k}\right]^{\prime}$, and defining the matrices

$$
\underset{[T \times n]}{Y}=\left[\begin{array}{c}
y_{1}^{\prime} \\
\vdots \\
y_{T}^{\prime}
\end{array}\right], \underset{[T \times n k+1]}{X}=\left[\begin{array}{c}
x_{1}^{\prime} \\
\vdots \\
x_{T}^{\prime}
\end{array}\right], \underset{[T \times n]}{\hat{U}}=\left[\begin{array}{c}
\hat{u}_{1}^{\prime} \\
\vdots \\
\hat{u}_{T}^{\prime}
\end{array}\right],
$$

least squares yields

$$
\hat{B}=\left(X^{\prime} X\right)^{-1} X^{\prime} Y, \quad \hat{U}=Y-X \hat{B} .
$$

If $T$ is large, then $\hat{B} \stackrel{p}{\rightarrow} B$. The relation between the reduced-form innovations and the structural shocks is again described by (3) and (4), with the interest in impulse responses to the structural shock $\epsilon_{1, t}$. However, the impulse vector $s$ cannot simply be obtained from a regression of the estimated residuals $\hat{u}_{t}$ on $\epsilon_{1, t}$, because $\epsilon_{1, t}$ is not observed. ${ }^{40}$ Instead, one can regress $\hat{u}_{t}$ on $z_{t}$

$$
\hat{u}_{t}=A^{\prime} z_{t}+\xi_{t} \quad t=1, \ldots, T
$$

and the coefficients are again estimated using least squares

$$
\hat{A}=\left(Z^{\prime} Z\right)^{-1} Z^{\prime} \hat{U} \text {, where } Z=\left[z_{1}, \ldots, z_{T}\right]^{\prime} .
$$

When $T$ is large, convergence of $\hat{A}$ is given by

$$
\hat{A} \stackrel{p}{\rightarrow} \operatorname{var}\left(z_{t}\right)^{-1} \phi s^{\prime},
$$

taking into account conditions (4), (6), and (7). Next, constructing a ratio of any two elements in $\hat{A}$ gives a consistent estimate of the ratio of the corresponding elements in $s$ since the unknown $\phi$, as well as $\operatorname{var}\left(z_{t}\right)^{-1}$, cancel out. Let $\hat{A}_{i}$ and $\hat{A}_{j}$ denote the elements in $\hat{A}$ related to variables $i$ and $j$ with $i \neq j$. Then, the ratio $\frac{\hat{A}_{i}}{\hat{A}_{j}}$ gives a consistent estimate of $\frac{s_{i}}{s_{j}}$. While the ratio $\frac{s_{i}}{s_{j}}$ can be obtained in this way, $s_{i}$ and $s_{j}$ remain unknown. However, since ratios are available, the external instrument approach gives consistent estimates of the true contemporaneous relative impulse responses $r_{i j}$ in (5) and any subsequent response, given that $\hat{B} \stackrel{p}{\rightarrow} B .{ }^{41}$

\footnotetext{
${ }^{40}$ The econometric problem therefore differs from the standard instrumental variable case, even though conditions (6) and (7) resemble the usual relevance and exogeneity conditions. The problem is not that $\epsilon_{1, t}$ and $\epsilon_{2, t}$ are correlated and that $z_{t}$ serves as an instrument for $\epsilon_{1, t}$, but that $\epsilon_{1, t}$ is not observed and $z_{t}$ serves as a proxy for it, given that it is uncorrelated with any of the other primitive shocks.

${ }^{41}$ Besides relative impulse responses, it is also possible to derive impulse responses to units of standard deviations of the structural shock of interest - also referred to as absolute impulse responses in Section 2. For example, Lunsford
} 


\section{A.2 The Exogenous Variable Approach ${ }^{42}$}

Given a finite sample for $y_{t}$ from $t-k$ to $T$, the exogenous variable approach estimates

$$
y_{t}=\widetilde{B}_{0}+\widetilde{B}_{1} y_{t-1}+\ldots+\widetilde{B}_{k} y_{t-k}+\widetilde{A} z_{t}+\widetilde{u}_{t} \quad t=1, \ldots, T
$$

Collecting the regressors in $\widetilde{x}_{t}=\left[1, y_{t-1}^{\prime}, \ldots, y_{t-k^{\prime}}^{\prime} z_{t}\right]^{\prime}$, the coefficients by $\widetilde{B}=\left[\widetilde{B}_{0}, \widetilde{B}_{1}, \ldots, \widetilde{B}, \widetilde{A}\right]^{\prime}$, and defining the matrices

$$
\underset{[T \times n k+2]}{\widetilde{X}}=\left[\begin{array}{c}
\widetilde{x}_{1}^{\prime} \\
\vdots \\
\widetilde{x}_{T}^{\prime}
\end{array}\right], \underset{[T \times n]}{\hat{\tilde{U}}}=\left[\begin{array}{c}
\hat{\widetilde{u}}_{1}^{\prime} \\
\vdots \\
\hat{\widetilde{u}}_{T}^{\prime}
\end{array}\right],
$$

least squares gives

$$
\hat{\widetilde{B}}=\left(\tilde{X}^{\prime} \widetilde{X}\right)^{-1} \widetilde{X}^{\prime} Y, \hat{\widetilde{U}}=Y-\widetilde{X} \hat{\widetilde{B}}
$$

Assume again that

$$
\begin{aligned}
& \mathbb{E}\left[z_{t} \epsilon_{1, t}\right]=\phi \\
& \mathbb{E}\left[z_{t} \epsilon_{2, t}\right]=0,
\end{aligned}
$$

such that $z_{t}$ is correlated with the structural shock of interest $\epsilon_{1, t}$, but not with any of the other structural shocks. Then, one can use ratios of elements in the estimated $\hat{\widetilde{A}}$ to obtain contemporaneous relative impulse responses. The remaining coefficients in $\hat{\widetilde{B}}$ can again be used to trace an initial shock through system (18). ${ }^{43}$

The following sections prove that the exogenous variable approach gives consistent estimates of the true relative impulse responses. In this regard, I distinguish between contemporaneous and subsequent impulse responses.

(2015) shows that the vector $s$ can be obtained in the following simple way. Note that $\mathbb{E}\left[\hat{u}_{t} z_{t}\right]=s \phi$ and

$$
\begin{aligned}
\mathbb{E}\left[z_{t} \hat{u}_{t}^{\prime}\right] \mathbb{E}\left[\hat{u}_{t} \hat{u}_{t}^{\prime}\right]^{-1} \mathbb{E}\left[\hat{u}_{t} z_{t}\right] & =\phi s^{\prime}\left(s \sum S^{\prime}\right)^{-1} s \phi \\
& =\phi e_{1}^{\prime} \sum e_{1} \phi \\
& =\phi^{2} \sigma_{\epsilon_{1}}^{-2}
\end{aligned}
$$

where $\mathbb{E}\left[\epsilon_{t} \epsilon_{t}^{\prime}\right]=\sum$ and $\mathbb{E}\left[\epsilon_{1, t}^{2}\right]=\sigma_{\epsilon_{1}}^{2}$. The first line simplifies to the second line since $S^{-1} S=e_{1}=[1,0, \ldots, 0]^{\prime}$. Given a normalization for $\sigma_{\epsilon_{1}}$, one can use (17) to derive an estimate for $\phi$ (up to a sign convention) which in turn allows one to obtain an estimate for $s$ using $\mathbb{E}\left[\hat{u}_{t} z_{t}\right] \phi^{-1}=s$. Note that this normalization is irrelevant for point estimates if the interest lies in impulse responses to units of standard deviation of the structural shock, since any change in the normalization of $\sigma_{\epsilon_{1}}$ leads to an adjustment in $\phi$ that leaves their product unchanged.

${ }^{42}$ Related concepts of exogeneity as introduced by Engle et al. (1983) are discussed in Appendix A.7.

${ }^{43}$ This definition of an impulse response considers a one-time change in $z_{t}$. In the data, $z_{t}$ should therefore not be autocorrelated. I find that the impulse responses in Section 4.2 are much the same when orthogonalizing $z_{t}$ against its own lags and replacing $z_{t}$ with the error from this projection. 


\section{A.3 Proofs}

\section{A.3.1 Contemporaneous Impulse Response}

Based on the exogenous variable approach, the estimated coefficients $\hat{\widetilde{B}}=\left(\widetilde{X}^{\prime} \widetilde{X}\right)^{-1} \widetilde{X}^{\prime} Y$ in (19) can be expressed as

$$
\hat{\widetilde{B}}=\left(\begin{array}{cc}
X^{\prime} X & X^{\prime} Z \\
Z^{\prime} X & Z^{\prime} Z
\end{array}\right)^{-1}\left(\begin{array}{c}
X^{\prime} Y \\
Z^{\prime} Y
\end{array}\right)
$$

using the partition

$$
\widetilde{X}=[X Z],
$$

where $X$ and $Z$ are defined in (14) and (16). The last row in (22) is associated with the exogenous variable $Z$ and is given by

$$
\hat{\widetilde{A}}^{\prime}=m \cdot\left[Z^{\prime}\left(I-X\left(X^{\prime} X\right)^{-1} X^{\prime}\right) Y\right]
$$

where $m=\left(Z^{\prime} Z-Z^{\prime} X\left(X^{\prime} X\right)^{-1} X^{\prime} Z\right)^{-1} \cdot{ }^{44}$ Since $\hat{B}=\left(X^{\prime} X\right)^{-1} X^{\prime} Y$ and $\hat{U}=Y-X \hat{B}$ (see equations in (15)), equation (23) can be rewritten as

$$
\hat{\widetilde{A}}^{\prime}=m \cdot\left[Z^{\prime} \hat{U}\right]
$$

The ratio of any two elements $\hat{\widetilde{A}}_{i}$ and $\hat{\widetilde{A}}_{j}$ with $i \neq j$ in $\tilde{\widetilde{A}}$ is then given by

$$
\frac{\widetilde{\widetilde{A}}_{i}}{\widehat{\widetilde{A}}_{j}}=\frac{m \cdot\left[Z^{\prime} \hat{U}_{[i]}\right]}{m \cdot\left[Z^{\prime} \hat{U}_{[j]}\right]}=\frac{Z^{\prime} \hat{U}_{[i]}}{Z^{\prime} \hat{U}_{[j]}},
$$

where $\hat{U}_{[i]}$ and $\hat{U}_{[j]}$ denote the associated columns $i$ and $j$ in $\hat{U}$. The ratio (25) converges to

$$
\frac{\tilde{\widetilde{A}}_{i}}{\hat{\widetilde{A}}_{j}} \stackrel{p}{\rightarrow} \frac{\phi s_{i}}{\phi s_{j}}=\frac{s_{i}}{s_{j}},
$$

taking into account conditions (4), (6), and (7). Hence, the ratio of any two elements $\hat{\widetilde{A}}_{i}$ and $\hat{\widetilde{A}}_{j}$ converges to the true contemporaneous relative impulse response $r_{i j}$ defined in (5). Q.E.D.

$$
\begin{aligned}
& { }^{44} \text { Given the partition } \widetilde{X}=[X \quad] \text {, the first part of } \hat{\widetilde{B}} \text { can be expressed as } \\
& \left(\begin{array}{cc}
X^{\prime} X & X^{\prime} Z \\
Z^{\prime} X & Z^{\prime} Z
\end{array}\right)^{-1}=\left[\begin{array}{cc}
\left(X^{\prime} X-X^{\prime} Z\left(Z^{\prime} Z\right)^{-1} Z^{\prime} X\right)^{-1} & -\left(X^{\prime} X-X^{\prime} Z\left(Z^{\prime} Z\right)^{-1} Z^{\prime} X\right)^{-1} X^{\prime} Z\left(Z^{\prime} Z\right)^{-1} \\
-\left(Z^{\prime} Z-Z^{\prime} X\left(X^{\prime} X\right)^{-1} X^{\prime} Z\right)^{-1} Z^{\prime} X\left(X^{\prime} X\right)^{-1} & \left(Z^{\prime} Z-Z^{\prime} X\left(X^{\prime} X\right)^{-1} X^{\prime} Z\right)^{-1}
\end{array}\right],
\end{aligned}
$$

such that the last row in $\hat{\widetilde{B}}$ which is associated with the exogenous variable $Z$ can be written as

$$
\hat{\tilde{A}}^{\prime}=-\left(Z^{\prime} Z-Z^{\prime} X\left(X^{\prime} X\right)^{-1} X^{\prime} Z\right)^{-1} Z^{\prime} X\left(X^{\prime} X\right)^{-1} X^{\prime} Y+\left(Z^{\prime} Z-Z^{\prime} X\left(X^{\prime} X\right)^{-1} X^{\prime} Z\right)^{-1} Z^{\prime} Y,
$$

which simplifies to (23). 


\section{A.3.2 Subsequent Impulse Responses}

Based on the exogenous variable approach, the estimated coefficients $\hat{\widetilde{B}}=\left(\widetilde{X}^{\prime} \widetilde{X}\right)^{-1} \widetilde{X}^{\prime} Y$ in (19) can be expressed as

$$
\hat{\widetilde{B}}=\left(\begin{array}{cc}
X^{\prime} X & X^{\prime} Z \\
Z^{\prime} X & Z^{\prime} Z
\end{array}\right)^{-1}\left(\begin{array}{c}
X^{\prime} Y \\
Z^{\prime} Y
\end{array}\right)
$$

using the partition

$$
\widetilde{X}=[X Z],
$$

where $X$ and $Z$ are defined in (14) and (16). If $z_{t}$ is uncorrelated with all other regressors $x_{t}=$ $\left[1, y_{t-1}^{\prime}, \ldots, y_{t-k}^{\prime}\right]^{\prime}$ in (18), then (27) converges to

$$
\left(\begin{array}{cc}
\left(X^{\prime} X\right)^{-1} & 0 \\
0 & \left(Z^{\prime} Z\right)^{-1}
\end{array}\right)\left(\begin{array}{c}
X^{\prime} Y \\
Z^{\prime} Y
\end{array}\right)
$$

since $\left(X^{\prime} X\right)^{-1} X^{\prime} Z$ and $\left(Z^{\prime} Z\right)^{-1} Z^{\prime} X$ in (24, footnote 44$)$ converge to zero when $T$ becomes large.

Since $Y=X \hat{B}+\hat{U},(28)$ can be written as

$$
\left(\begin{array}{c}
\left(X^{\prime} X\right)^{-1} X^{\prime} Y \\
\left(Z^{\prime} Z\right)^{-1} Z^{\prime} \hat{U}
\end{array}\right)
$$

Note that

$$
\left(X^{\prime} X\right)^{-1} X^{\prime} Y=\hat{B}
$$

which converges to $B$ when $T$ is large. Hence, if $z_{t}$ and $x_{t}$ are uncorrelated and $T$ is large, then the estimated coefficients on the lagged endogenous variables in (18) converge to the true coefficients $B$. Under these conditions, the exogenous variable approach gives the true subsequent relative impulse responses. Q.E.D.

\section{A.3.3 Robustness to Measurement Problems}

Assume again that conditions (6) and (7) hold. However, instead of $z_{t}$, one observes

$$
\widetilde{z}_{t}=z_{t}+\eta_{t}
$$

where $\eta_{t}$ is an additive i.i.d measurement error that is orthogonal to any other variable and has a zero mean.

Contemporaneous Impulse Responses. To show that the contemporaneous relative impulse responses remain unchanged in the presence of measurement error in $z_{t}$, I continue from equation 
(25) in Section A.3.1. The ratio of any two elements $\widehat{\widetilde{A}}_{i}$ and $\widehat{\widetilde{A}}_{j}$ with $i \neq j$ in $\hat{\widetilde{A}}$ is now given by

$$
\frac{\widetilde{\widetilde{A}}_{i}}{\hat{\widetilde{A}}_{j}}=\frac{\widetilde{Z}^{\prime} \hat{U}_{[i]}}{\widetilde{Z}^{\prime} \hat{U}_{[j]}}
$$

where $\widetilde{Z}=\left[\widetilde{z}_{1}, \ldots, \widetilde{z}_{T}\right]^{\prime}$ is now observed instead of $Z$. However, since $\eta_{t}$ is uncorrelated with $y_{t}$, (30) converges to

$$
\frac{Z^{\prime} \hat{U}_{[i]}}{Z^{\prime} \hat{U}_{[j]}},
$$

which was shown to converge to $r_{i j}$ in Section A.3.1. If $\widetilde{z}_{t}$ additionally has observations that are randomly censored at zero, then the length of $\widetilde{Z}$ and the number of observations both in the numerator and the denominator of (30) and (31) are reduced, leaving the ratio unchanged if the sample size is large. Q.E.D.

Subsequent Impulse Responses. To show that the subsequent relative impulse responses remain unchanged in the presence of measurement error in $z_{t}$, I continue from equation (27) in Section A.3.2. The partitioning of $\hat{\widetilde{B}}$ is now given by

$$
\left(\begin{array}{cc}
X^{\prime} X & X^{\prime} \widetilde{Z} \\
\widetilde{Z}^{\prime} X & \widetilde{Z}^{\prime} \widetilde{Z}
\end{array}\right)^{-1}\left(\begin{array}{c}
X^{\prime} Y \\
\widetilde{Z}^{\prime} Y
\end{array}\right)
$$

If $z_{t}$ is additionally uncorrelated with all other regressors $x_{t}=\left[1, y_{t-1}^{\prime}, \ldots, y_{t-k}^{\prime}\right]^{\prime}$, then convergence of $\hat{\widetilde{B}}$ is given by

$$
\hat{\widetilde{B}} \stackrel{p}{\rightarrow}\left(\begin{array}{cc}
\left(X^{\prime} X\right)^{-1} & 0 \\
0 & \left(\widetilde{Z}^{\prime} \widetilde{Z}\right)^{-1}
\end{array}\right)\left(\begin{array}{c}
X^{\prime} Y \\
\widetilde{Z}^{\prime} Y
\end{array}\right)
$$

since $\left(X^{\prime} X\right)^{-1} X^{\prime} \widetilde{Z}$ and $\left(\widetilde{Z}^{\prime} \widetilde{Z}\right)^{-1} \widetilde{Z}^{\prime} X$ (in a modified version of (24), footnote 44 ) converge to zero when $T$ becomes large. Since $Y=X \hat{B}+\hat{U}$, (32) can be written as

$$
\left(\begin{array}{c}
\left(X^{\prime} X\right)^{-1} X^{\prime} Y \\
\left(\widetilde{Z}^{\prime} \widetilde{Z}\right)^{-1} \widetilde{Z}^{\prime} \hat{U}
\end{array}\right)
$$

Note again that

$$
\left(X^{\prime} X\right)^{-1} X^{\prime} Y=\hat{B}
$$

which converges to $B$ when $T$ is large. Thus, not only the contemporaneous relative impulse responses, but also any subsequent response remains unchanged. These results continue to hold if randomly censored zero-observations are present. Such observations reduce the sample, but leave the estimators unchanged if the overall sample size is large. Q.E.D. 
However, note that the least squares estimator of $\widehat{\widetilde{A}}$ is inconsistent, with a bias towards zero. This bias manifests itself in the term $\left(\widetilde{Z}^{\prime} \widetilde{Z}\right)^{-1}$ in (33). This term, however, cancels out when taking a ratio of any two elements in $\widehat{\widetilde{A}}$, as in (30). The contemporaneous relative impulse response is therefore not affected by the measurement error.

\section{A.4 Comparison with External Instrument Approach}

Contemporaneous Impulse Responses. Following the derivations of the external instrument approach in Section A.1, equation (16) states that the estimation of $A$ yields

$$
\hat{A}=\left(Z^{\prime} Z\right)^{-1} Z^{\prime} \hat{U}
$$

Based on the exogenous variable approach, the equivalent coefficient vector $\widetilde{A}$ is estimated to be

$$
\hat{\widetilde{A}}=m \cdot Z^{\prime} \hat{U}
$$

where $m=\left(Z^{\prime} Z-Z^{\prime} X\left(X^{\prime} X\right)^{-1} X^{\prime} Z\right)^{-1}$. The ratios of any two elements in (34) or (35) gives

$$
\frac{\hat{A}_{i}}{\hat{A}_{j}}=\frac{\hat{\widetilde{A}}_{i}}{\hat{\widetilde{A}}_{j}}=\frac{Z^{\prime} \hat{U}_{[i]}}{Z^{\prime} \hat{U}_{[j]}} .
$$

Hence, even in small samples, both approaches give equivalent contemporaneous impulse responses. In large enough samples, (36) converges to the ratio of the true contemporaneous impulse responses, that is

$$
\frac{\hat{A}_{i}}{\hat{A}_{j}}=\frac{\hat{\widetilde{A}}_{i}}{\hat{\widetilde{A}}_{j}} \stackrel{p}{\rightarrow} \frac{\phi s_{i}}{\phi s_{j}}=\frac{s_{i}}{s_{j}} .
$$

Subsequent Impulse Responses. Following again the description of the external instrument approach in Section A.1, the estimation of $B$ yields

$$
\hat{B}=\left(X^{\prime} X\right)^{-1} X^{\prime} Y
$$

If $T$ is large, $\hat{B} \rightarrow B$. Following the description of the exogenous variable approach in Sections A.2 and A.3.2 (see equation (29)), the coefficients $\widetilde{B}$ converge to

$$
\left(\begin{array}{c}
\left(X^{\prime} X\right)^{-1} X^{\prime} Y \\
\left(Z^{\prime} Z\right)^{-1} Z^{\prime} \hat{U}
\end{array}\right)=\left(\begin{array}{c}
\hat{B} \\
\hat{A}
\end{array}\right),
$$

if $z_{t}$ and $x_{t}$ are uncorrelated. If $T$ is large, $\hat{B}$ in (37) again converges to $B$. Any subsequent relative impulse responses of the two approaches will therefore be equivalent. 


\section{A.5 Comparison with Local Projection Instrumental Variable Approach}

This section compares estimates of impulse responses obtained from a VARX with the local projection instrumental variable approach (LP-IV) as described in Stock and Watson (2018). I show that the estimated contemporaneous relative impulse responses based on a L-IV are equivalent to the contemporaneous relative impulse responses obtained with a VARX if the two include the same controls. Moreover, if the VARX captures the dynamics of $y_{t}$ well with the variables included in $y_{t}$ and their lagged values, then any estimated subsequent relative impulse responses additionally coincide with the ones obtained from a LP-IV in large samples.

Assume that one is interested in the dynamic effects of a $(n-1) \times 1$ vector of observables $y_{2, t+h}$ at horizon $t+h$ to $\epsilon_{1, t}$. Following the notation thus far, one estimates

$$
y_{2, t+h}=A^{h} y_{1, t}+u_{2, t+h} \text { for } \mathrm{t}=1, \ldots, \mathrm{T} \text { and } \mathrm{h} \geq 0
$$

using $z_{t}$ as an instrument for $y_{1, t}$. For convenience and without loss of generality, I omit constant terms and controls for the moment. The instrument $z_{t}$ is assumed to satisfy the conditions

1. $E\left(\epsilon_{1, t} z_{t}\right)=\phi \neq 0$ (relevance)

2. $E\left(\epsilon_{2, t} z_{t}\right)=0$ (contemporaneous exogeneity)

3. $E\left(\epsilon_{t+j} z_{t}\right)=0$ for $j \neq 0$ (lead/lag exogeneity)

The predicted values from the first stage regression are given by

$$
\hat{Y}_{1}=Z \cdot\left(Z^{\prime} Z\right)^{-1} Z^{\prime} Y_{1}
$$

where $Z=\left[z_{1}, \ldots, z_{T}\right]^{\prime}$ and $Y_{1}=\left[y_{1,1}, \ldots, y_{1, T}\right]^{\prime}$. For the contemporaneous response $h=0$, the associated vector $A^{0}$ is estimated to be

$$
\hat{A}^{0^{\prime}}=\left(\hat{Y}_{1}^{\prime} \hat{Y}_{1}\right)^{-1}\left(\hat{Y}_{1}^{\prime} Y_{2}\right)
$$

where $Y_{2}=\left[y_{2,1}^{\prime}, \ldots, y_{2, T}^{\prime}\right]^{\prime}$. The ratio of any two elements $\hat{A}_{i}^{0}$ and $\hat{A}_{j}^{0}$ in $\hat{A}^{0}$ with $i \neq j$ is given by

$$
\frac{\hat{A}_{i}^{0}}{\hat{A}_{j}^{0}}=\frac{\left(\hat{Y}_{1}^{\prime} \hat{Y}_{1}\right)^{-1}\left(\hat{Y}_{1}^{\prime} Y_{2,[i]}\right)}{\left(\hat{Y}_{1}^{\prime} \hat{Y}_{1}\right)^{-1}\left(\hat{Y}_{1}^{\prime} Y_{2,[j]}\right)}=\frac{\hat{Y}_{1}^{\prime} Y_{2,[i]}}{\hat{Y}_{1}^{\prime} Y_{2,[j]}},
$$

where $Y_{2,[i]}$ and $Y_{2,[j]}$ denote the associated columns $i$ and $j$ in $Y_{2}$. In addition, using $\hat{Y}_{1}^{\prime}=\left(Y_{1}^{\prime} Z\right)$. $\left(Z^{\prime} Z\right)^{-1} Z^{\prime}$ yields

$$
\frac{\hat{A}_{i}^{0}}{\hat{A_{j}^{0}}}=\frac{\left(Y_{1}^{\prime} Z\right) \cdot\left(Z^{\prime} Z\right)^{-1} Z^{\prime} Y_{2,[i]}}{\left(Y_{1}^{\prime} Z\right) \cdot\left(Z^{\prime} Z\right)^{-1} Z^{\prime} Y_{2,[j]}}=\frac{Z^{\prime} Y_{2,[i]}}{Z^{\prime} Y_{2,[j]}} .
$$

If one includes the same controls in (38) as in the VARX in (18) - that is, a constant and $k$ lags of $y_{t}-$ then 


$$
\hat{A}^{0^{\prime}}=\left(\hat{Y}_{1}^{\perp \prime} \hat{Y}_{1}^{\perp}\right)^{-1}\left(\hat{Y}_{1}^{\perp \prime} \hat{U}_{2}\right)
$$

where $\hat{U}_{2}=Y_{2}-X \hat{B_{2}}$ for $X$ as defined in (14) and $\hat{B}_{2}=\left(X^{\prime} X\right)^{-1} X^{\prime} Y_{2}$. Moreover, $\hat{Y}_{1}^{\perp}=Z$. $\left(Z^{\prime} Z\right)^{-1} Z^{\prime} \hat{U}_{1}$, where $\hat{U}_{1}$ is the residual from a projection of $Y_{1}$ on a constant and the $k$ lags of $y_{t}$. The ratio of any two elements $\hat{A}_{i}^{0}$ and $\hat{A}_{j}^{0}$ in (39) is then given by

$$
\frac{\hat{A}_{i}^{0}}{\hat{A}_{j}^{0}}=\frac{Z^{\prime} \hat{U}_{2,[i]}}{Z^{\prime} \hat{U}_{2,[j]}} \stackrel{p}{\rightarrow} \frac{\phi s_{i}}{\phi s_{j}}=\frac{s_{i}}{s_{j}},
$$

where $\hat{U}_{2,[i]}$ and $\hat{U}_{2,[j]}$ are the associated elements in $\hat{U}_{2}$. The ratio (40) is equivalent to the associated ratio in (25) obtained with the VARX. The only difference is that one can additionally trace out the effects of $Y_{1}$ to $\epsilon_{1, t}$ with the VARX.

Moreover, if $z_{t}$ is uncorrelated with the lags in the VARX, then any element $\hat{A}_{i}^{0}$ in (39) simplifies to

$$
\hat{A}_{i}^{0}=\left(Z^{\prime} \hat{U}_{1}\right)^{-1}\left(Z^{\prime} \hat{U}_{2,[i]}\right) \stackrel{p}{\rightarrow} \frac{\phi s_{i}}{\phi s_{1}}=\frac{s_{i}}{s_{1}}=\theta_{i 1}
$$

where $\theta_{i 1}$ gives the contemporaneous response of variable $i$, given a unit normalization for the response of $y_{1, t}$ to $\epsilon_{1, t}$ (as assumed in Stock and Watson, 2018).

Next, whether any subsequent relative impulse responses coincide between the VARX and the LP-IV depends on whether the variables that are included in the VARX and their lags capture the dynamics of $y_{t}$ well. If that is the case, then the two methods will also give the same impulse responses in large samples. For $h \geq 1$,

$$
\begin{aligned}
& \hat{A}^{1}=B_{1}^{1} \cdot \hat{A}^{0} \\
& \hat{A}^{2}=B_{1} \cdot \hat{A}^{0}+B_{2} \cdot \hat{A}^{0} \\
& \hat{A}^{3}=B_{1}\left(B_{1} \cdot \hat{A}^{0}+B_{2} \cdot \hat{A}^{0}\right)+B_{2}\left(B_{1} \cdot \hat{A}^{0}\right)+B_{3} \cdot \hat{A}^{0}
\end{aligned}
$$

where the $B$-matrices are the ones estimated with the VARX in (18).

In fact, identification can also be obtained by integrating the instrument directly into a local projection, such that

$$
y_{h, t}=A^{h} z_{t}+\text { controls }+u_{h, t} \text { for } h=0,1,2, \ldots,
$$

which coincides with the VARX in (8) for $h=0$ if the same controls are included. Hence, as shown with propositions 1-3, this approach identifies the true contemporaneous relative impulse responses. This is different from many previous papers that have treated the instrument as direct observations of the shock of interest. Instead, here it is used as an instrument and impulse responses therefore have to scaled appropriately. However, as highlighted by Stock and Wat- 
son (2018), the conditions for the instrument to be valid are stronger than for the VARX (see above). Stock and Watson (2018) further discuss the trade-offs between local projection-based approaches and VARs, in particular with respect to the assumption of invertibility (see also MirandaAgrippino and Ricco, 2018).

\section{A.6 Frisch-Waugh-Lovell Theorem}

Proposition 2 is related to the Frisch-Waugh-Lovell Theorem.

The Frisch-Waugh-Lovell Theorem states that the least-squares-estimate of $\beta_{2}$ in

$$
Y=X_{1} \beta_{1}+X_{2} \beta_{2}+u
$$

where $X_{1}$ is a $T \times k_{1}$ matrix and $X_{2}$ is a $T \times k_{2}$ matrix, is equivalent to the least-squares-estimate of $\beta_{2}$ in

$$
M \cdot Y=M \cdot X_{2} \beta_{2}+M \cdot u
$$

where $M=\left(I-X_{1}\left(X_{1}^{\prime} X_{1}\right)^{-1} X_{1}^{\prime}\right)$.

To illustrate the relation to Proposition 2, note first that equation (42) can be written as

$$
\widetilde{u}=\bar{u} \beta_{2}+\underline{u}
$$

where $\tilde{u}$ and $\bar{u}$ are the residuals from the regressions

$$
\begin{aligned}
Y & =X_{1} \widetilde{\beta}+\widetilde{u} \\
X_{2} & =X_{1} \bar{\beta}+\bar{u},
\end{aligned}
$$

and $\underline{u}=M \cdot u$. Next, assume that $X_{1}$ collects all the lagged values of $Y$ and $X_{2}$ denotes the exogenous variable $Z$. If $X_{1}$ and $X_{2}$ are uncorrelated (the condition of Proposition 2), then $X_{2}$ is equal to $\bar{u}$ in equation (44) since $\bar{\beta}=0$. Hence, regression (43) simplifies to

$$
\widetilde{u}=X_{2} \beta_{2}+\underline{u}
$$

where $\widetilde{u}$ is obtained from

$$
Y=X_{1} \widetilde{\beta}+\widetilde{u}
$$

Based on this reformulation, the Frisch-Waugh-Lovell Theorem states that the estimate of $\beta_{2}$ in (45) is equivalent to the estimate of $\beta_{2}$ in

$$
Y=X_{1} \beta_{1}+X_{2} \beta_{2}+u
$$

In fact, this equivalence can be seen by comparing the estimated coefficients $\hat{A}$ based on the external instrument approach (see equation (16) in Appendix A.1) with $\widehat{\widetilde{A}}$ based on the exogenous 
variable approach (see equation (37) in Appendix A.4). Proposition 2 additionally notes that the estimate of $\beta_{1}$ in (46) is also unaffected whether $X_{2}$ is included or not.

\section{A.7 Exogeneity}

When can $z_{t}$ be treated as an exogenous variable? Engle et al. (1983) introduced two useful concepts, called weak and strong exogeneity, which address this question.

Weak exogeneity. Under weak exogeneity, analyzing the conditional model for $y_{t}$ given its lags and $z_{t}$ as in (8) is without loss of information for the evaluation of the parameters of interest collected by $\psi=\left(\widetilde{B}_{0}, \ldots, \widetilde{B}_{k}, \widetilde{A}\right) .{ }^{45}$ Hence, nothing more can be learned about $\psi$ from modeling $y_{t}$ and $z_{t}$ jointly. If $z_{t}$ is weakly exogenous, it can be considered as determined outside of the model for $y_{t}$ and understood as the statistical formalization of taking $z_{t}$ as given. Weak exogeneity requires that no natural or imposed cross-restrictions or dependencies between the parameters of the conditional model of $y_{t}$ (given $z_{t}$ and lags of $y_{t}$ ) and the ones of a marginal model for $z_{t}$ (given lags of $y_{t}$ ) exist and the two can vary freely.

Strong Exogeneity. The conditional model in (8) together with the impulse response analysis may be missing a potential feedback loop. This is the case if the marginal model of $z_{t}$ depends on lagged values of $y_{t}$, i.e. $y_{t}$ is Granger-causing $z_{t}$. For example, $z_{t}$ could depend on $y_{t-1}$

$$
z_{t}=\beta y_{t-1}+\xi_{t} \quad t=1, \ldots, T
$$

where $\beta$ is a $1 \times n$ vector and $\xi_{t}$ is the innovation to this equation. In this case, an impulse response of $y_{t}$ to a change in $z_{t}$ affects next period's $z_{t+1}$ via equation (47), which in turn has an impact on $y_{t+1}$ via (8) and so on. However, this feedback loop is not active if $y_{t}$ is not Granger-causing $z_{t}$, which is testable for a specific application of the model. Engle et al. (1983) term $z_{t}$ "strongly exogenous" if two conditions are satisfied. First, $z_{t}$ is weakly exogenous. Second, $y_{t}$ does not Granger-cause $z_{t}$.

With respect to the application in this paper, $z_{t}$, the series of monetary policy surprises, is both weakly and strongly exogenous. The latter is achieved by construction, since the monetary policy surprises are regressed on the lagged values of $y_{t}$ and the residual from this regression is used instead in order to satisfy the condition in Proposition 2.

\section{A.8 Derivation Fundamental Stock Price Response}

This section derives the impulse response of the fundamental component of stock prices to a monetary policy shock. The derivation largely follows Cochrane (2001, page 396). Start with an iden-

\footnotetext{
${ }^{45}$ The original formulation of weak exogeneity by Engle et al. (1983) did not consider a Bayesian approach as in Section 3. Concepts of exogeneity from a Bayesian point of view, for which the interest lies in the posterior distribution of the parameters of interest, are discussed in Florens, Mouchart, and Rolin (1990).
} 
tity and rearrange

$$
\begin{aligned}
1 & =\tilde{R}_{t+1}^{-1} \tilde{R}_{t+1}= \\
& =\tilde{R}_{t+1}^{-1}\left(\frac{P_{t+1}^{F}+D_{t+1}}{P_{t}^{F}}\right) \\
P_{t}^{F} & =\tilde{R}_{t+1}^{-1}\left(1+\frac{P_{t+1}^{F}}{D_{t+1}}\right) D_{t+1}
\end{aligned}
$$

Take logs, indicated by small letters,

$$
p_{t}^{F}=-\tilde{r}_{t+1}+d_{t+1}+\ln \left(1+e^{p_{t+1}^{F}-d_{t+1}}\right)
$$

Take a Taylor expansion of $\ln \left(1+e^{p_{t+1}^{F}-d_{t+1}}\right)$ around $p^{F}-d$

$$
p_{t}^{F}=-\tilde{r}_{t+1}+d_{t+1}+\ln \left(1+\frac{P^{F}}{D}\right)+\frac{\frac{P^{F}}{D}}{1+\frac{P^{F}}{D}}\left(p_{t+1}^{F}-d_{t+1}-\left(p^{F}-d\right)\right)
$$

In steady state, the price is

$$
P^{F}=D\left(\Lambda+\Lambda^{2}+\Lambda^{3}+\ldots\right)
$$

where $\Lambda=\frac{\Gamma}{R}, \Gamma$ is the gross real growth rate of dividends, and $R$ is the gross real interest rate. Then, the price-to-dividend ratio is given by

$$
\frac{P^{F}}{D}=\frac{\Lambda}{1-\Lambda}
$$

and equation (48) can be written as

$$
p_{t}^{F}=-\tilde{r}_{t+1}+d_{t+1}+\text { const. }+\Lambda\left(p_{t+1}^{F}-d_{t+1}\right)
$$

Assume that the return $\tilde{r}_{t+1}$ is equal to the real interest rate $r_{t}$ plus the risk-premium $r p_{t+1}$. Taking this into account and solving the above equation forward gives

$$
p_{t}^{F}=\text { const. }+\sum_{j=0}^{\infty} \Lambda^{j}\left[(1-\Lambda) d_{t+j+1}-r_{t+j}-r p_{t+j+1}\right]
$$

The impulse response of the fundamental component to a monetary policy shock $\epsilon_{t}^{P}$ is then

$$
\frac{\partial p_{t+k}^{F}}{\partial \epsilon_{t}^{P}}=\sum_{j=0}^{\infty} \Lambda^{j}\left[(1-\Lambda) \frac{\partial d_{t+k+j+1}}{\partial \epsilon_{t}^{P}}-\frac{\partial r_{t+k+j}}{\partial \epsilon_{t}^{P}}-\frac{\partial r p_{t+k+j+1}}{\partial \epsilon_{t}^{P}}\right] \quad \text { for } k=0,1,2, \ldots
$$

and the response of the fundamental price in the impulse response figures is obtained using this equation and holding the response of risk premia constant. $\Lambda$ is set to $\frac{1}{1+\frac{0.04}{12}}$ consistent with monthly data. 250 periods are used to approximate the sum and I find that the results of the time-varying parameter VARs are robust to approximating the sum for longer periods. 


\section{A.9 Estimation Algorithm}

The unknown objects of the model are the history of the coefficients $B^{T}$ and the variance-covariance matrix $V$. I use Gibbs sampling to evaluate the posterior distribution of these unknown objects. The steps of the sampler are:

1. Initialize $V$

2. Sample $B^{T}$ from $p\left(B^{T} \mid y^{T}, z^{T}, V\right)$

3. Sample $V$ by sampling $\Omega$ and $Q$ from $p\left(\Omega, Q \mid y^{T}, z^{T}, B^{T}\right)$

4. Repeat step 2.

where $p(\cdot \mid \cdot)$ denotes a conditional density and $y^{T}=\left[y_{1}, \ldots, y_{T}\right]^{\prime}$ the history of $y_{t}$ for $t=1, \ldots, T$, respectively $z^{T}$ denotes the history of $z_{t}$. I check parameter convergence via trace plots and autocorrelation functions of the draws. The results show that the estimation algorithm produces posterior draws efficiently. 


\section{A.10 The Federal Reserve's Private Information - Private Forecast Revisions}

\begin{tabular}{crrcc}
\hline & Real GDP & Unemploy. & GDP Defl. & \\
\hline \hline & & & & Observations \\
Current Quarter & 0.834 & 0.072 & 0.217 & 186 \\
Next Quarter & 0.290 & -0.064 & 0.108 & 186 \\
2 Quarters ahead & -0.132 & 0.092 & -0.141 & 186 \\
3 Quarters ahead & -0.078 & 0.074 & $-0.270^{* *}$ & 186 \\
4 Quarters ahead & 0.095 & -0.082 & 0.071 & 186 \\
5 Quarters ahead & -0.137 & 0.411 & $-0.415^{* * *}$ & 137 \\
6 Quarters ahead & -0.181 & -0.122 & 0.196 & 88 \\
7 Quarters ahead & -0.076 & -0.510 & -0.311 & 46 \\
& & & & \\
Over next year & 0.202 & 0.015 & -0.003 & 186 \\
\hline
\end{tabular}

Table 3: Revision of private forecasts around scheduled FOMC meetings. Regression results for (13). Each coefficient comes from a separate regression. The dependent variable is the month-to-month change in the Blue Chip forecast for the current and the following quarters. "Over next year" is the average forecast from the current quarter to four quarters ahead. The explanatory variable is the series of monetary surprises in the current month's federal funds rate (MP1). FOMC meetings that occur in the first week of the month are excluded, because it cannot be ensured that they took place after the Blue Chip forecasts are submitted. Sample: 1988 M11-2017 M9. Notation: ${ }^{* *} p<0.01,{ }^{* *} p<0.05,{ }^{*} p<0.1$.

\begin{tabular}{ccccc}
\hline & Real GDP & Unemploy. & GDP Defl. & \\
\hline \hline & & & & Observations \\
Current Quarter & $1.469^{* * *}$ & $-0.165^{* *}$ & 0.225 & 202 \\
Next Quarter & $1.459^{* * *}$ & $-0.272^{* * *}$ & 0.107 & 202 \\
2 Quarters ahead & $0.418^{* *}$ & $-0.312^{* * *}$ & 0.043 & 202 \\
3 Quarters ahead & 0.087 & $-0.364^{* * *}$ & -0.004 & 202 \\
4 Quarters ahead & -0.006 & $-0.379^{* * *}$ & $0.123^{*}$ & 202 \\
5 Quarters ahead & $-0.208^{* *}$ & -0.225 & -0.100 & 147 \\
6 Quarters ahead & -0.119 & $-0.220^{*}$ & 0.080 & 93 \\
7 Quarters ahead & -0.047 & -0.330 & -0.073 & 44 \\
& & & & \\
Over next year & $0.685^{* * *}$ & $-0.300^{* * *}$ & 0.099 & 202 \\
\hline
\end{tabular}

Table 4: Revision of private forecasts around all FOMC meetings. Regression results for (13). Each coefficient comes from a separate regression. The dependent variable is the month-to-month change in the Blue Chip forecast for the current and the following quarters. "Over next year" is the average forecast from the current quarter to four quarters ahead. The explanatory variable is the series of monetary surprises in the current month's federal funds rate (MP1). FOMC meetings that occur in the first week of the month are excluded, because it cannot be ensured that they took place after the Blue Chip forecasts are submitted. If multiple FOMC meetings occur between two surveys, then the surprises with respect to these meetings are summed up. Sample: 1988 M11-2017 M9. Notation: ${ }^{* * *} p<0.01,{ }^{* *} p<0.05,{ }^{*} p<0.1$. 


\begin{tabular}{ccccc}
\hline & Real GDP & Unemploy. & GDP Defl. \\
\hline \hline & & & & Observations \\
MP1 & 0.168 & 0.043 & 0.027 & 179 \\
FF2 & 0.296 & 0.001 & 0.088 & 179 \\
FF3 & 0.448 & -0.018 & 0.031 & 179 \\
FF4 & 0.543 & -0.115 & 0.064 & 179 \\
FF5 & 0.453 & -0.141 & 0.160 & 179 \\
FF6 & $0.591^{*}$ & -0.205 & 0.108 & 179 \\
ED2 & $0.583^{* *}$ & -0.215 & 0.109 & 179 \\
ED3 & $0.634^{* *}$ & -0.208 & 0.088 & 179 \\
ED4 & $0.465^{* *}$ & -0.164 & 0.061 & 179 \\
& & & & \\
NS & $0.029^{* *}$ & -0.009 & 0.004 & 179 \\
\hline
\end{tabular}

Table 5: Revision of private forecasts for the next year around scheduled FOMC meetings. Regression results for (13). Each coefficient comes from a separate regression. The dependent variable is the month-to-month change in the Blue Chip forecast for the next year (average of current quarter to four quarters ahead). The explanatory variables are series of surprises with respect to different future contracts. MP1 are the surprises used in the main analysis. "FFX" denotes federal funds futures at horizon of " $X$ " months. "EDX" denotes euro-dollar interest rate futures at horizon of " $X$ " quarters. "NS" denotes the policy news shock by Nakamura and Steinsson (2018): the first principal component across MP1, FF4, ED2, ED3, and ED4 (not standardized). FOMC meetings that occur in the first week of the month are excluded, because it cannot be ensured that they took place after the Blue Chip forecasts are submitted. Sample: 1990 M2-2017 M9. Notation: ${ }^{* * *} p<0.01,{ }^{* *} p<0.05,{ }^{*} p<0.1$. 


\begin{tabular}{ccccc}
\hline & Real GDP & Unemploy. & GDP Defl. \\
\hline \hline & & & & Observations \\
MP1 & $0.696^{* * *}$ & $-0.309^{* *}$ & 0.078 & 192 \\
FF2 & $0.486^{* *}$ & $-0.244^{*}$ & 0.064 & 192 \\
FF3 & $0.662^{* *}$ & $-0.292^{* *}$ & 0.058 & 192 \\
FF4 & $0.519^{*}$ & $-0.260^{*}$ & 0.068 & 192 \\
FF5 & $0.505^{*}$ & $-0.240^{*}$ & 0.113 & 192 \\
FF6 & $0.589^{* *}$ & $-0.316^{* *}$ & 0.129 & 192 \\
ED2 & $0.509^{* *}$ & $-0.301^{* *}$ & 0.140 & 192 \\
ED3 & 0.070 & -0.084 & 0.056 & 192 \\
ED4 & -0.140 & 0.000 & 0.030 & 192 \\
& & & & \\
NS & 0.025 & $-0.015^{*}$ & 0.006 & 192 \\
\hline
\end{tabular}

Table 6: Revision of private forecasts around all FOMC meetings. Regression results for (13). Each coefficient comes from a separate regression. The dependent variable is the month-to-month change in the Blue Chip forecast for the next year (average of current quarter to four quarters ahead). The explanatory variables are series of surprises with respect to different future contracts. MP1 are the surprises used in the main analysis. "FFX" denotes federal funds futures at horizon of " $X$ " months. "EDX" denotes euro-dollar interest rate futures at horizon of " $X$ " quarters. "NS" denotes the policy news shock by Nakamura and Steinsson (2018): the first principal component across MP1, FF4, ED2, ED3, and ED4 (not standardized). FOMC meetings that occur in the first week of the month are excluded, because it cannot be ensured that they took place after the Blue Chip forecasts are submitted. If multiple FOMC meetings occur between two surveys, then the surprises with respect to these meetings are summed up. Sample: 1990 M2-2017 M9. Notation: ${ }^{* * *} p<0.01,{ }^{* *} p<0.05,{ }^{*} p<0.1$.

\section{A.11 The Federal Reserve's Private Information - Differences in Forecasts}

The following set of regressions tests whether an empirical proxy for the Federal Reserve's private information prior to a meeting can predict the monetary policy surprises (see also Barakchian and Crowe, 2013). I regress the surprises for scheduled FOMC meetings on the difference between the Fed's forecasts (Greenbook, GB, or Tealbook) and the private sector's forecasts (Blue Chip, BC),

$$
\mathrm{S}_{t}^{k}=\alpha+\beta\left(\text { Forecast }_{t, q}^{G B}-\text { Forecast }_{t, q}^{B C}\right)+u_{t}
$$

where $q$ denotes the forecast horizon. Nakamura and Steinsson (2018) show that $\beta$ is positive and statistically significant for real GDP growth at various forecast horizons based on their policy news series. Hence, their results indicate that the Federal Reserve tends to raise interest rates when its own expectation of output growth is more positive than the private forecast and this change in interest rates comes as a surprise to the market. Next, I estimate regression (49) for the series of surprises used in this paper (MP1) and consider differences in forecasts for average real GDP growth over the next year. The results are shown in Table 7 for different samples. The Greenbook is only prepared for scheduled meetings and both samples are restricted in this regard. In addition, the first sample is limited to 2013 M12, the latest available Greenbook forecasts. 


\begin{tabular}{ccc}
\hline \hline & & \\
Scheduled FOMC Meetings & 0.013 & 0.016 \\
& $(0.009)$ & $(0.010)$ \\
Observations & 159 & 83 \\
\hline
\end{tabular}

Table 7: Forecast Differences for Expected Output Growth over the Next Year. Regression results for (49). The dependent variable is the series of monetary surprises in the current month's federal funds rate $S_{t}^{k}$ for scheduled FOMC meeting $k$ (MP1). The explanatory variable is the difference between the Greenbook and the Blue Chip forecast for output growth over the next year (current quarter to four quarters ahead). FOMC meetings that occur in the first week of the month are excluded, because it cannot be ensured that they took place after the Blue Chip forecasts are submitted. Notation: Standard errors are in parentheses, ${ }^{* * *} p<0.01,{ }^{* *} p<0.05,{ }^{*} p<0.1$.

While the estimate of $\beta$ is positive, it is not statistically different from zero at conventional confidence levels. In Table 8, I also show the results for forecast differences of inflation and unemployment and additionally differentiate by various forecast horizons. For some specific forecast horizons, $\beta$ is statistically significant at conventional levels; however, for unemployment and inflation, these coefficients are actually of the "wrong" sign, such that a central bank would raise rates if its unemployment forecast is higher than the private sector's forecast or lower rates to a relatively higher inflation forecast. In Table 9, I show that the information effect based on regression (49) becomes visible for surprises with respect to short-term rates several months after policy announcements and for the policy news shock considered by Nakamura and Steinsson (2018). However, the results for inflation are of the "reverse" sign according to the information effect.

\begin{tabular}{clllc}
\hline & Real GDP & Unemploy. & GDP Defl. & \\
\hline \hline & & & & Observations \\
Current Quarter & 0.006 & 0.061 & 0.002 & 159 \\
Next Quarter & 0.003 & 0.038 & $-0.021^{* *}$ & 159 \\
2 Quarters ahead & 0.001 & $0.043^{*}$ & -0.020 & 159 \\
3 Quarters ahead & 0.007 & $0.035^{* *}$ & -0.018 & 159 \\
4 Quarters ahead & $0.015^{* *}$ & 0.024 & $-0.021^{*}$ & 159 \\
5 Quarters ahead & $0.012^{*}$ & $0.031^{* *}$ & $-0.040^{* * *}$ & 115 \\
6 Quarters ahead & $0.016^{* *}$ & 0.019 & $-0.027^{* *}$ & 73 \\
7 Quarters ahead & 0.013 & 0.010 & -0.007 & 38 \\
& & & & \\
Over next year & 0.013 & $0.047^{*}$ & $-0.029^{*}$ & 159 \\
\hline
\end{tabular}

Table 8: Differences in forecasts for various horizons. Regression results for (49). Each coefficient comes from a separate regression. The dependent variable is the series of monetary surprises in the current month's federal funds rate (MP1). The explanatory variable is the difference between the Greenbook and the Blue Chip forecast for various horizons. "Over next year" is the average forecast from the current quarter to four quarters ahead. FOMC meetings that occur in the first week of the month are excluded, because it cannot be ensured that they took place after the Blue Chip forecasts are submitted. Sample: 1988 M11-2013 M12. Notation: ${ }^{* * *} p<0.01,{ }^{* *} p<0.05,{ }^{*} p<0.1$. 


\begin{tabular}{clclc}
\hline & Real GDP & Unemploy. & GDP Defl. \\
\hline \hline & & & & Observations \\
MP1 & 0.012 & $0.054^{* *}$ & -0.025 & 152 \\
FF2 & 0.012 & $0.035^{*}$ & -0.022 & 152 \\
FF3 & $0.018^{* * *}$ & 0.006 & -0.014 & 152 \\
FF4 & $0.016^{* *}$ & 0.006 & $-0.023^{*}$ & 152 \\
FF5 & $0.018^{* *}$ & -0.016 & -0.009 & 152 \\
FF6 & $0.020^{* * *}$ & -0.012 & -0.012 & 152 \\
ED2 & $0.025^{* * *}$ & -0.024 & -0.023 & 152 \\
ED3 & $0.036^{* * *}$ & -0.036 & $-0.032^{*}$ & 152 \\
ED4 & $0.034^{* * *}$ & -0.032 & $-0.038^{*}$ & 152 \\
& & & & \\
NS & $0.530^{* * *}$ & -0.169 & $-0.606^{*}$ & 152 \\
\hline
\end{tabular}

Table 9: Differences in forecasts over the next year. Regression results for (49). Each coefficient comes from a separate regression. The dependent variable is one of the following series of monetary policy surprises. $M P 1$ are the surprises used in the main analysis. "FFX" denotes federal funds futures at horizon of " $X$ " months. "EDX" denotes euro-dollar interest rate futures at horizon of " $X$ " quarters. "NS" denotes the policy news shock by Nakamura and Steinsson (2018): the first principal component across MP1, FF4, ED2, ED3, and ED4 (not standardized). The explanatory variable is the difference between the Greenbook and the Blue Chip forecast for output growth, the GDP deflator, and the unemployment rate over the next year (average of current quarter to four quarters ahead). FOMC meetings that occur in the first week of the month are excluded, because it cannot be ensured that they took place after the Blue Chip forecasts are submitted. Sample: 1990 M2-2013 M12. Notation: ${ }^{* *} p<0.01,{ }^{* *} p<0.05,{ }^{*} p<0.1$. 
Next, I consider the slightly modified regression

$$
\text { Forecast }_{t, q}^{G B}=\alpha+\beta \mathrm{S}_{t}^{k}+\gamma \text { Forecast }_{t, q}^{B C}+u_{t}
$$

where $q$ again denotes the forecast horizon. If the forecast is, for example, with respect to output growth, a positive $\beta$ states that a positive surprise predicts a higher output growth forecast by the Fed, conditional on the private sector's forecast. I estimate again regression (50) for the series of surprises used in this paper (MP1) and for surprises with respect to short-term rates at various horizons. Tables 10 and 11 show the results. The conclusions are similar to above. A positive surprise only predicts a higher output growth or lower unemployment rate forecast of the Fed for future contracts with respect to short-term rates several months after policy announcements. Again, the results for inflation are different. These results raise the question whether the Fed is actually better than the private sector in predicting macroeconomic developments farther ahead in the future. The next section provides evidence in support of this hypothesis.

\begin{tabular}{crllc}
\hline & Real GDP & Unemploy. & GDP Defl. & \\
\hline \hline & & & & Observations \\
Current Quarter & 0.422 & 0.207 & 0.362 & 159 \\
Next Quarter & -0.392 & 0.288 & $-1.331^{* *}$ & 159 \\
2 Quarters ahead & -0.699 & $0.549^{*}$ & -0.640 & 159 \\
3 Quarters ahead & -0.098 & $0.734^{* *}$ & -0.602 & 159 \\
4 Quarters ahead & 1.274 & 0.638 & $-0.894^{*}$ & 159 \\
5 Quarters ahead & 1.089 & $1.491^{* *}$ & $-2.482^{* * *}$ & 115 \\
6 Quarters ahead & 1.692 & 1.620 & $-2.289^{* *}$ & 74 \\
7 Quarters ahead & 1.732 & 1.432 & -0.212 & 39 \\
& & & & \\
Over next year & 0.085 & $0.487^{*}$ & $-0.638^{*}$ & 159 \\
\hline
\end{tabular}

Table 10: Predicting Fed forecast for various horizons. Regression results for (50). Each coefficient comes from a separate regression. The dependent variable is the Fed's forecast for various horizons. The explanatory variables are the series of monetary surprises in the current month's federal funds rate (MP1) and the Blue Chip forecast for various horizons. "Over next year" is the average forecast from the current quarter to four quarters ahead. FOMC meetings that occur in the first week of the month are excluded, because it cannot be ensured that they took place after the Blue Chip forecasts are submitted. Sample: 1988 M11-2013 M12. Notation: ${ }^{* * *} p<0.01,{ }^{* *} p<0.05,{ }^{*} p<0.1$. 


\begin{tabular}{clllc}
\hline & Real GDP & Unemploy. & GDP Defl. \\
\hline \hline & & & & Observations \\
MP1 & 0.037 & $0.598^{* *}$ & -0.590 & 152 \\
FF2 & 0.177 & $0.529^{*}$ & -0.706 & 152 \\
FF3 & $1.505^{*}$ & 0.114 & -0.636 & 152 \\
FF4 & 0.744 & 0.105 & $-0.852^{*}$ & 152 \\
FF5 & 1.273 & -0.279 & -0.351 & 152 \\
FF6 & 1.199 & -0.181 & -0.405 & 152 \\
ED2 & 1.053 & -0.276 & -0.586 & 152 \\
ED3 & $1.519^{* *}$ & -0.328 & $-0.660^{*}$ & 152 \\
ED4 & $1.213^{* *}$ & -0.241 & $-0.650^{*}$ & 152 \\
& & & & \\
NS & $0.061^{*}$ & -0.005 & $-0.040^{*}$ & 152 \\
\hline
\end{tabular}

Table 11: Predicting Fed forecast over the next year. Regression results for (50). Each coefficient comes from a separate regression. The dependent variable is the Fed's forecast over the next year (average of current quarter to four quarters ahead). The explanatory variables are one of the following series of monetary policy surprises and the Blue Chip forecast over the next year. MP1 are the surprises used in the main analysis. "FFX" denotes federal funds futures at horizon of " $X$ " months. "EDX" denotes euro-dollar interest rate futures at horizon of " $X$ " quarters. "NS" denotes the policy news shock by Nakamura and Steinsson (2018): the first principal component across MP1, FF4, ED2, ED3, and ED4 (not standardized). FOMC meetings that occur in the first week of the month are excluded, because it cannot be ensured that they took place after the Blue Chip forecasts are submitted. Sample: 1990 M2-2013 M12. Notation: ${ }^{* * *} p<0.01,{ }^{* *} p<0.05$, * $p<0.1$.

\section{A.12 Forecast Horse Race - The Fed vs. the Private Sector}

Following Romer and Romer (2000), I estimate the following type of regressions

$$
y_{q}^{\text {realized }}=\alpha+\beta_{1} \text { Forecast }_{t, q}^{G B}+\beta_{2} \text { Forecast }_{t, q}^{B C}+u_{t},
$$

where the dependent variable is the realized growth rate of GDP, the GDP Deflator, or the level of the unemployment rate. The regressors are the forecasts of these variables by the Fed and the private sector at time $t$. For example, if $\beta_{1}=1$ and $\beta_{2}=0$, then the best strategy would be to trust the Fed forecast and ignore the private sector forecast.

For the following regressions, I take the Blue Chip forecast that is submitted in the month after the Greenbook is prepared. The private sector therefore has a strong timing advantage. However, the Fed's forecast is not known to the private sector in the month after it is prepared. The results of regression (51) for the three macro indicators are shown in Tables 12, 14, and 13. Across these regressions, with respect to the near future, the two forecasts each provide information. However, farther out, one would attach a higher weight to the Fed forecast, even though the Fed has a timing disadvantage. The exception is inflation very far out, potentially explaining the findings in Appendix A.11.

Overall, the Fed's forecast contains additional information relative to the private forecasts for 
macroeconomic developments that will occur a few months in the future. These results can explain why the surprises with respect to short-term rates several months after policy announcements lead the private sector to revision its forecasts. They indicate that the Fed has different information about the macroeconomy in the future and the interest rate change releases this information. In contrast, surprises with respect to current short-term rates do not have such an effect.

\begin{tabular}{cccc}
\hline GDP & Greenbook $\left(\beta_{1}\right)$ & Blue Chip $\left(\beta_{2}\right)$ & \\
\hline \hline & & & Observations \\
Current Quarter & $0.574^{*}$ & 0.463 & 273 \\
Next Quarter & -0.131 & $1.107^{* * *}$ & 273 \\
2 Quarters ahead & 0.371 & 0.264 & 273 \\
3 Quarters ahead & 0.260 & -0.045 & 273 \\
4 Quarters ahead & $0.831^{* * *}$ & -0.641 & 272 \\
5 Quarters ahead & $0.853^{* * *}$ & $-0.952^{*}$ & 228 \\
6 Quarters ahead & $0.635^{* * *}$ & -0.692 & 153 \\
7 Quarters ahead & $0.364^{* * *}$ & -0.274 & 90 \\
\hline
\end{tabular}

Table 12: Forecast Horse Race for GDP. Regression results for (51). Each coefficient comes from a separate regression. The dependent variable is the realized (annualized) growth rate of GDP from one quarter to the next (seasonally-adjusted). The explanatory variables are the Fed's forecast and the Blue Chip forecast for various horizons. Sample: 1980 M2-2013 M12. Notation: ${ }^{* * *} p<0.01,{ }^{* *} p<0.05,{ }^{*} p<0.1$. Hansen and Hodrick (1980) standard errors are used with lag length $3(h+1)$ for h quarter ahead forecast as in Romer and Romer (2000). Based on this procedure, variances can be negative, in which case Newey and West (1987) standard errors are used instead.

\begin{tabular}{cllc}
\hline Unemployment Rate & Greenbook $\left(\beta_{1}\right)$ & Blue Chip $\left(\beta_{2}\right)$ & \\
\hline \hline & & & Observations \\
Current Quarter & 0.049 & $0.969^{* * *}$ & 271 \\
Next Quarter & 0.346 & $0.661^{* *}$ & 273 \\
2 Quarters ahead & 0.271 & $0.731^{*}$ & 273 \\
3 Quarters ahead & 0.449 & 0.534 & 273 \\
4 Quarters ahead & 0.699 & 0.252 & 272 \\
5 Quarters ahead & $0.974^{* *}$ & -0.048 & 228 \\
6 Quarters ahead & $0.997^{* * *}$ & -0.103 & 153 \\
7 Quarters ahead & $1.126^{* * *}$ & -0.275 & 92 \\
\hline
\end{tabular}

Table 13: Forecast Horse Race for Unemployment Rate. Regression results for (51). Each coefficient comes from a separate regression. The dependent variable is the realized unemployment rate (seasonallyadjusted). The explanatory variables are the Fed's forecast and the Blue Chip forecast for various horizons. Sample: 1980 M2-2013 M12. Notation: *** $p<0.01,{ }^{* *} p<0.05,{ }^{*} p<0.1$. Hansen and Hodrick (1980) standard errors are used with lag length $3(h+1)$ for $h$ quarter ahead forecast as in Romer and Romer (2000). Based on this procedure, variances can be negative, in which case Newey and West (1987) standard errors are used instead. 


\begin{tabular}{cclc}
\hline GDP Deflator & Greenbook $\left(\beta_{1}\right)$ & Blue Chip $\left(\beta_{2}\right)$ & \\
\hline \hline & & & Observations \\
Current Quarter & $0.199^{* *}$ & $0.730^{* * *}$ & 272 \\
Next Quarter & 0.348 & $0.530^{* *}$ & 273 \\
2 Quarters ahead & $0.726^{*}$ & 0.084 & 273 \\
3 Quarters ahead & $0.731^{*}$ & 0.005 & 273 \\
4 Quarters ahead & 0.394 & 0.241 & 272 \\
5 Quarters ahead & 0.099 & $0.376^{* *}$ & 228 \\
6 Quarters ahead & -0.245 & $0.618^{* * *}$ & 153 \\
7 Quarters ahead & -0.136 & 0.454 & 92 \\
\hline
\end{tabular}

Table 14: Forecast Horse Race for GDP Deflator. Regression results for (51). Each coefficient comes from a separate regression. The dependent variable is the realized (annualized) growth rate of GDP Deflator from one quarter to the next (seasonally-adjusted). The explanatory variables are the Fed's forecast and the Blue Chip forecast for various horizons. Sample: 1980 M2-2013 M12. Notation: ${ }^{* * *} p<0.01,{ }^{* *} p<0.05,{ }^{*}$ $p<0.1$. Hansen and Hodrick (1980) standard errors are used with lag length $3(h+1)$ for $h$ quarter ahead forecast as in Romer and Romer (2000). Based on this procedure, variances can be negative, in which case Newey and West (1987) standard errors are used instead. 


\section{A.13 Data}
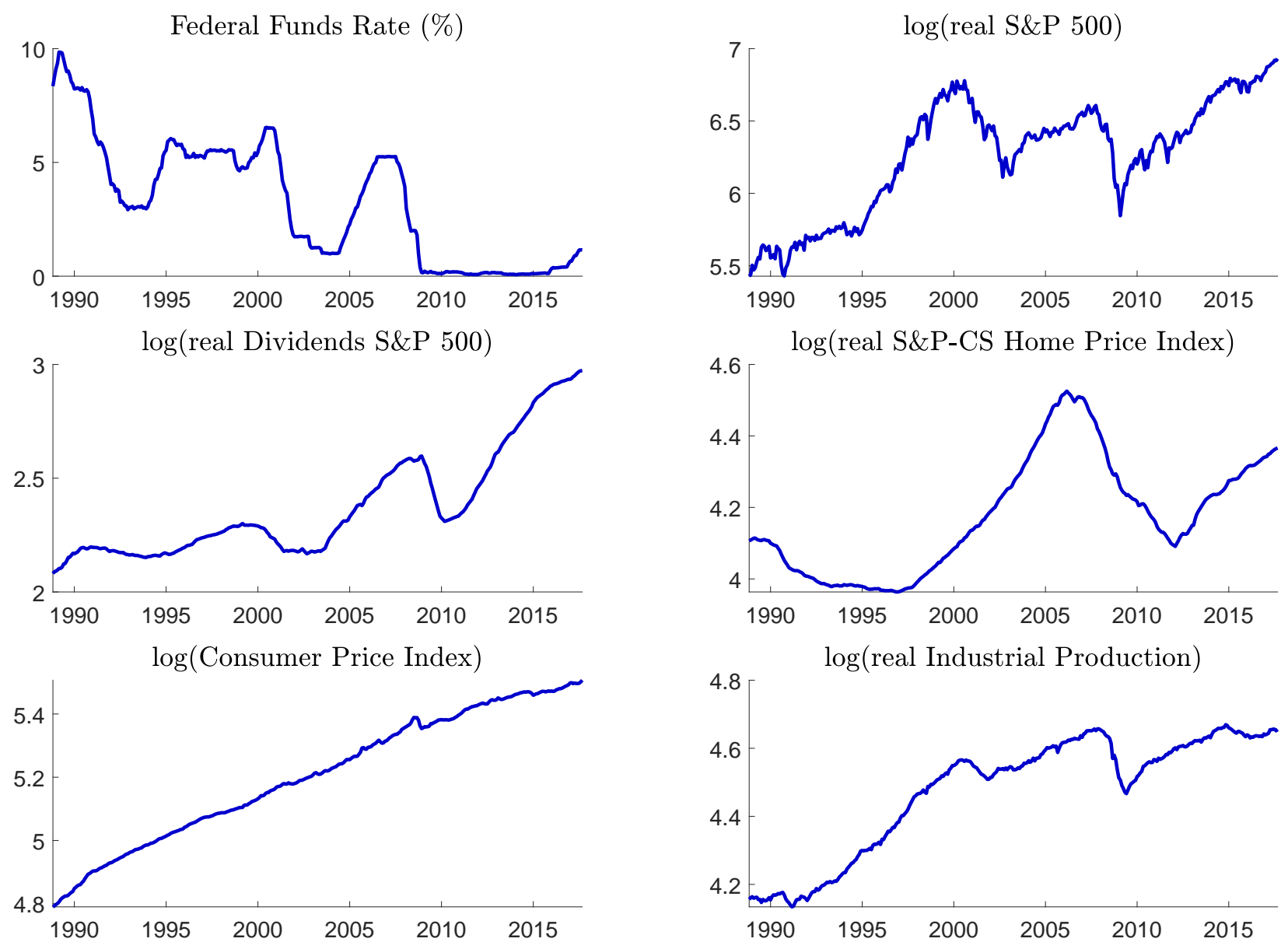

Figure 6: Data. Data series in (log)-levels. 



Figure 7: Data. Data series in first-differences (apart from the federal funds rate). 


\section{A.14 Constant Parameter VAR}
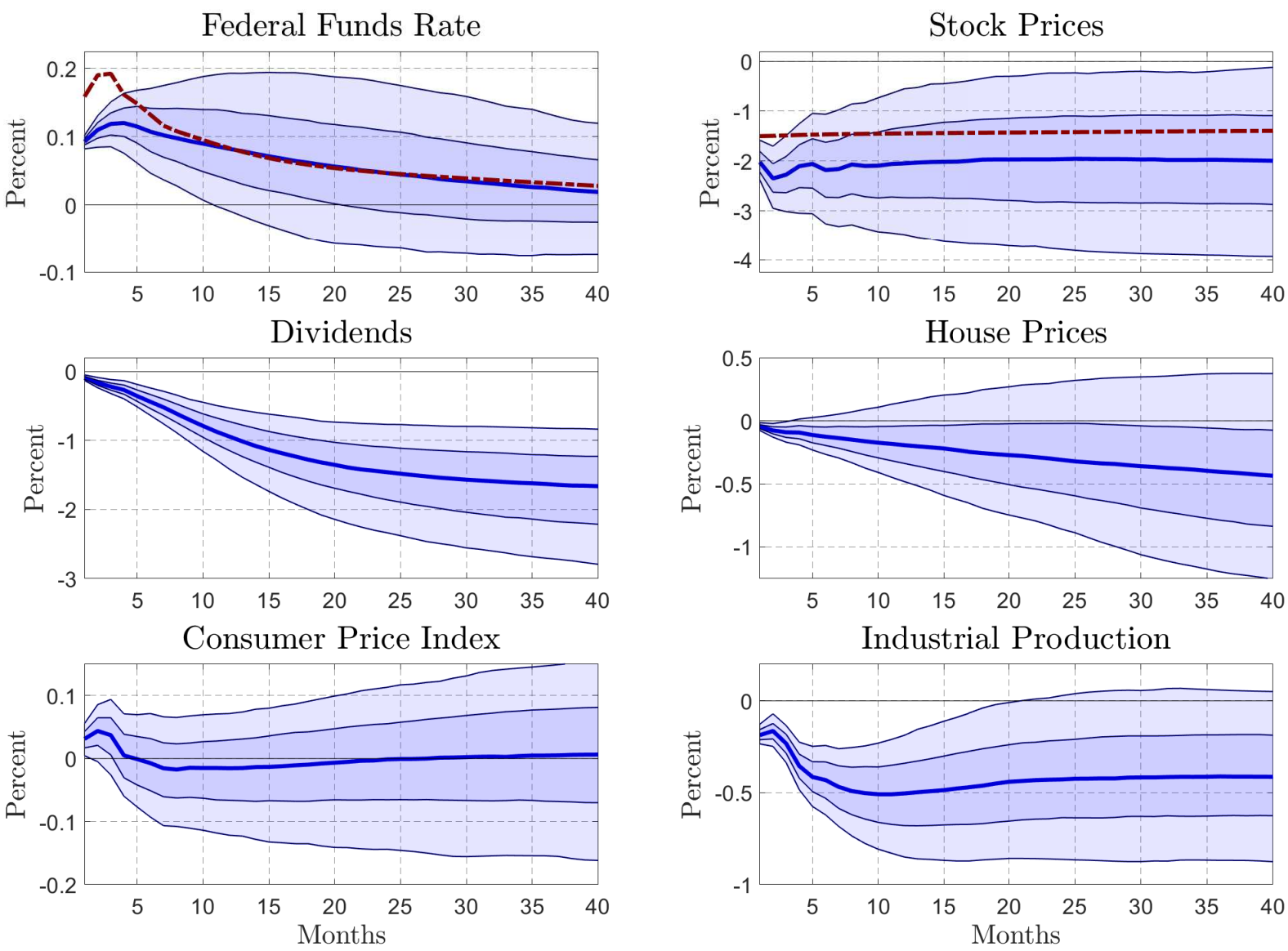

Figure 8: Impulse Responses - Exogenous Variable Approach - Recursive Wild Bootstrap as in Mertens and Ravn (2013). Cumulative impulse responses to a contractionary monetary policy shock, normalized to give the same initial increase in the federal funds rate as obtained with external instrument approach to a one-standard-deviation monetary policy shock, median response along with 68 and 95 percent confidence intervals. The dashed line in the plot of the federal funds rate shows the real interest rate. The dashed line in the plot of stock prices shows the fundamental price response based on discounted dividends and constant risk premia (see Appendix A.8 for the derivation). Sample: 1988 M11-2017 M9. 

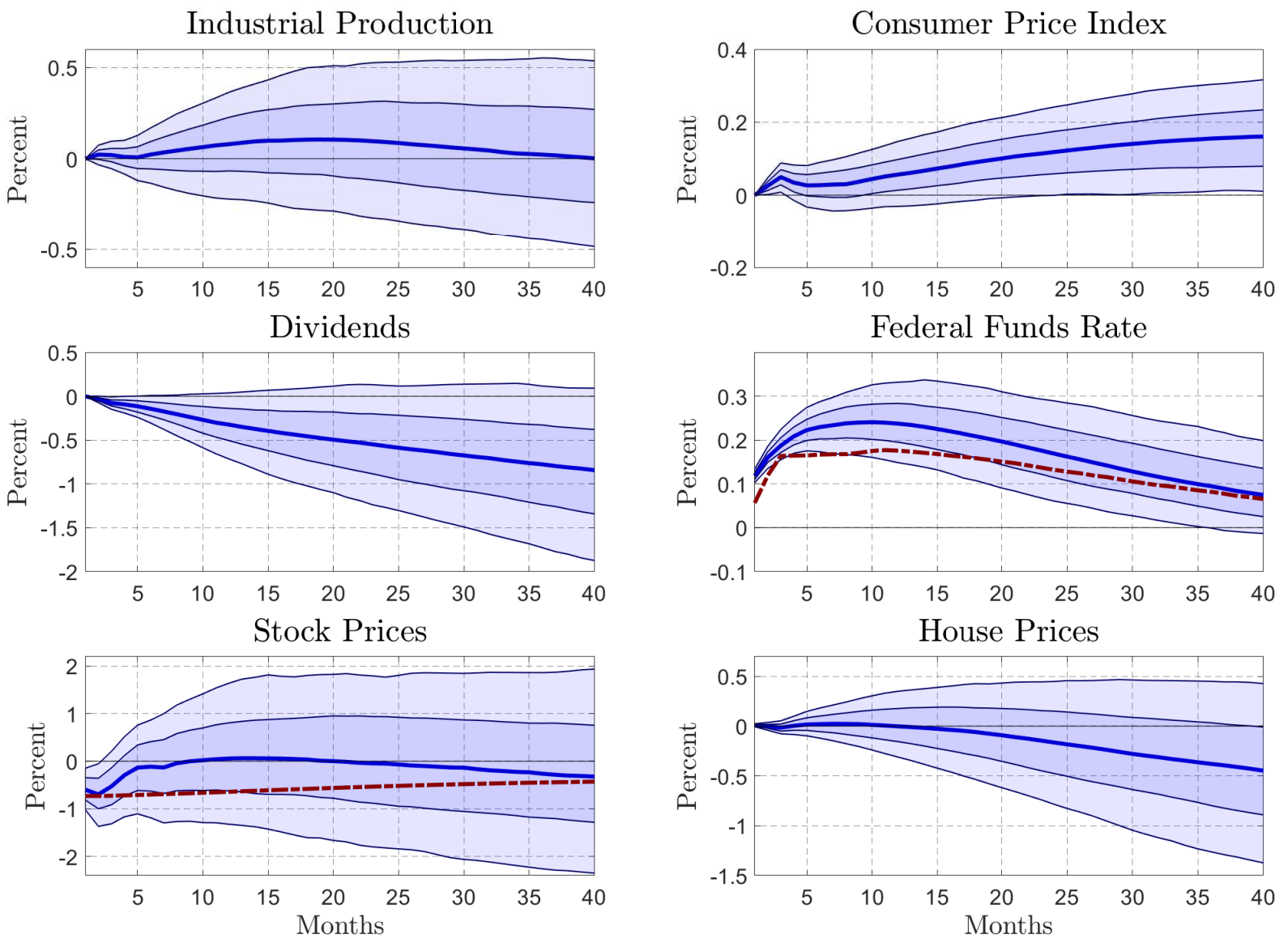

Figure 9: Impulse Responses - Cholesky Decomposition. Cumulative impulse responses to a onestandard-deviation contractionary monetary policy shock, median response along with 68 and 95 percent confidence intervals. The dashed line in the plot of the federal funds rate shows the real interest rate. The dashed line in the plot of stock prices shows the fundamental price response based on discounted dividends and constant risk premia (see Appendix A.8 for the derivation). The Cholesky identification imposes the following order: Industrial Production, Consumer Price Index, Dividends, Federal Funds Rate, Stock Prices, and House Prices. Sample: 1988 M11-2017 M9. 

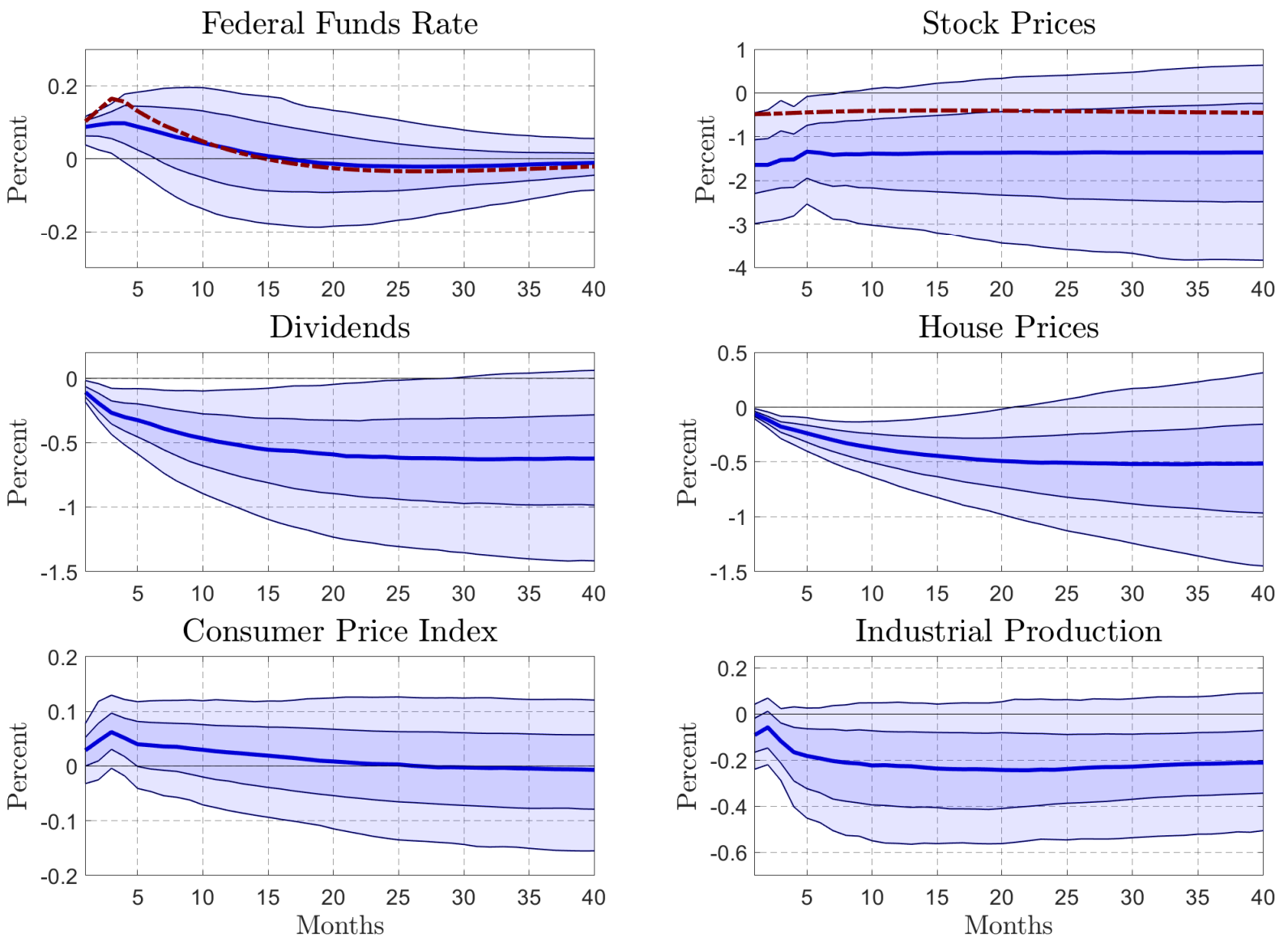

Figure 10: Impulse Responses - Exogenous Variable Approach - Excluding ELB-Episode. Cumulative impulse responses to a contractionary monetary policy shock, normalized to give the same initial increase in the federal funds rate as obtained with external instrument approach to a one-standard-deviation monetary policy shock, median response along with 68 and 95 percent confidence intervals. The dashed line in the plot of the federal funds rate shows the real interest rate. The dashed line in the plot of stock prices shows the fundamental price response based on discounted dividends and constant risk premia (see Appendix A.8 for the derivation). Residual-based moving block bootstrap as in Lunsford and Jentsch (2016) is used to obtain confidence bands (block size: 20). Sample: 1988 M11-2007 M12. 

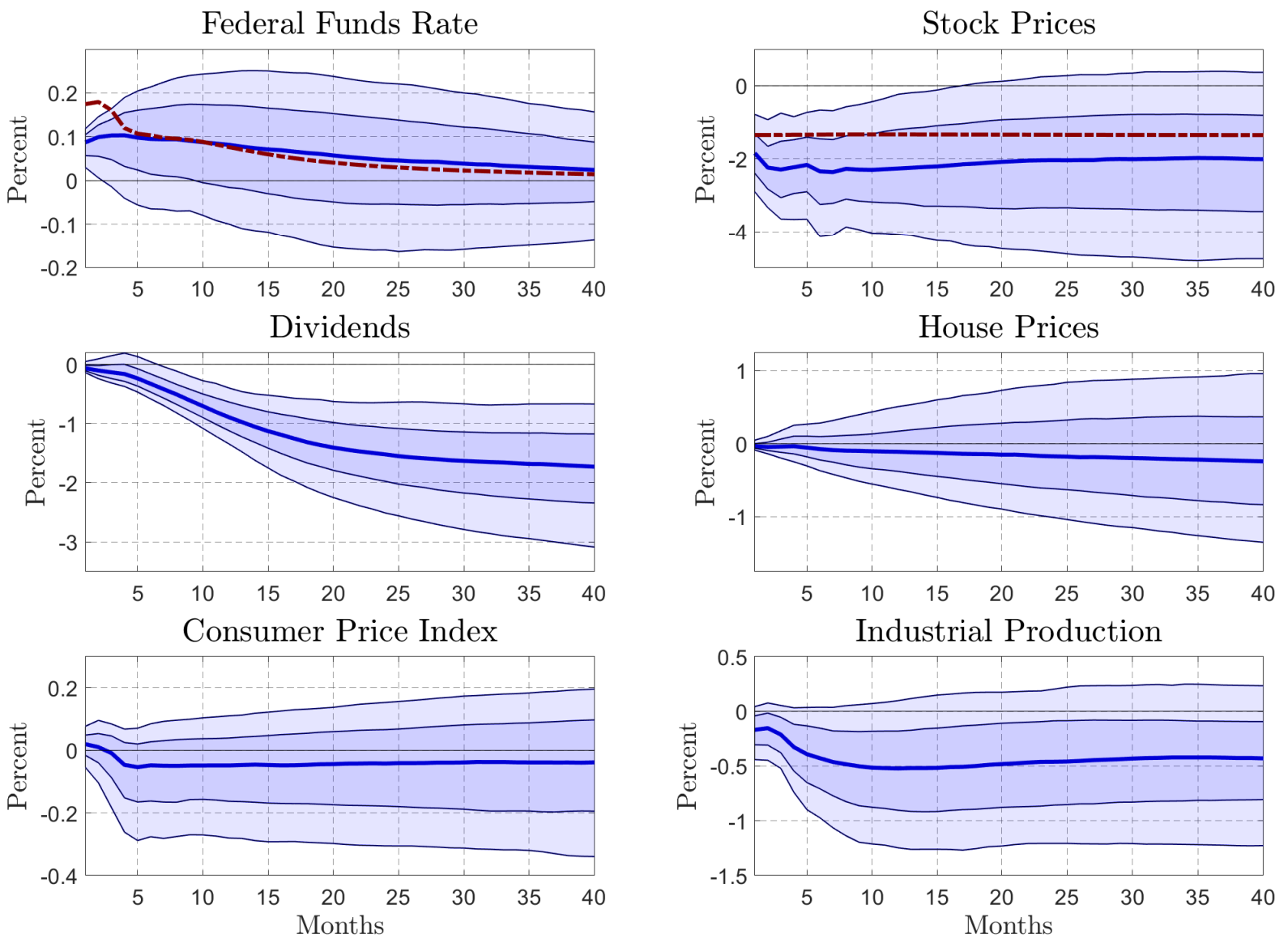

Excess Bond Premium



Figure 11: Impulse Responses - Exogenous Variable Approach - Excess Bond Premium. Cumulative impulse responses to a contractionary monetary policy shock, normalized to give the same initial increase in the federal funds rate as obtained with external instrument approach to a one-standard-deviation monetary policy shock as well as for each bootstrap repetition, median response along with 68 and 95 percent confidence intervals. The dashed line in the plot of the federal funds rate shows the real interest rate. The dashed line in the plot of stock prices shows the fundamental price response based on discounted dividends and constant risk premia (see Appendix A.8 for the derivation). Residual-based moving block bootstrap as in Lunsford and Jentsch (2016) is used to obtain confidence bands (block size: 20). Sample: 1988 M11-2016 M8. 



Figure 12: Impulse Responses - Exogenous Variable Approach - Short-run restriction. Cumulative impulse responses to a contractionary monetary policy shock, normalized to give the same initial increase in the federal funds rate as obtained with external instrument approach to a one-standard-deviation monetary policy shock as well as for each bootstrap repetition, median response along with 68 and 95 percent confidence intervals. The dashed line in the plot of the federal funds rate shows the real interest rate. The dashed line in the plot of stock prices shows the fundamental price response based on discounted dividends and constant risk premia (see Appendix A.8 for the derivation). The contemporaneous response of the consumer price index is restricted to be zero. Residual-based moving block bootstrap as in Lunsford and Jentsch (2016) is used to obtain confidence bands (block size: 20). Sample: 1988 M11-2017 M9. 

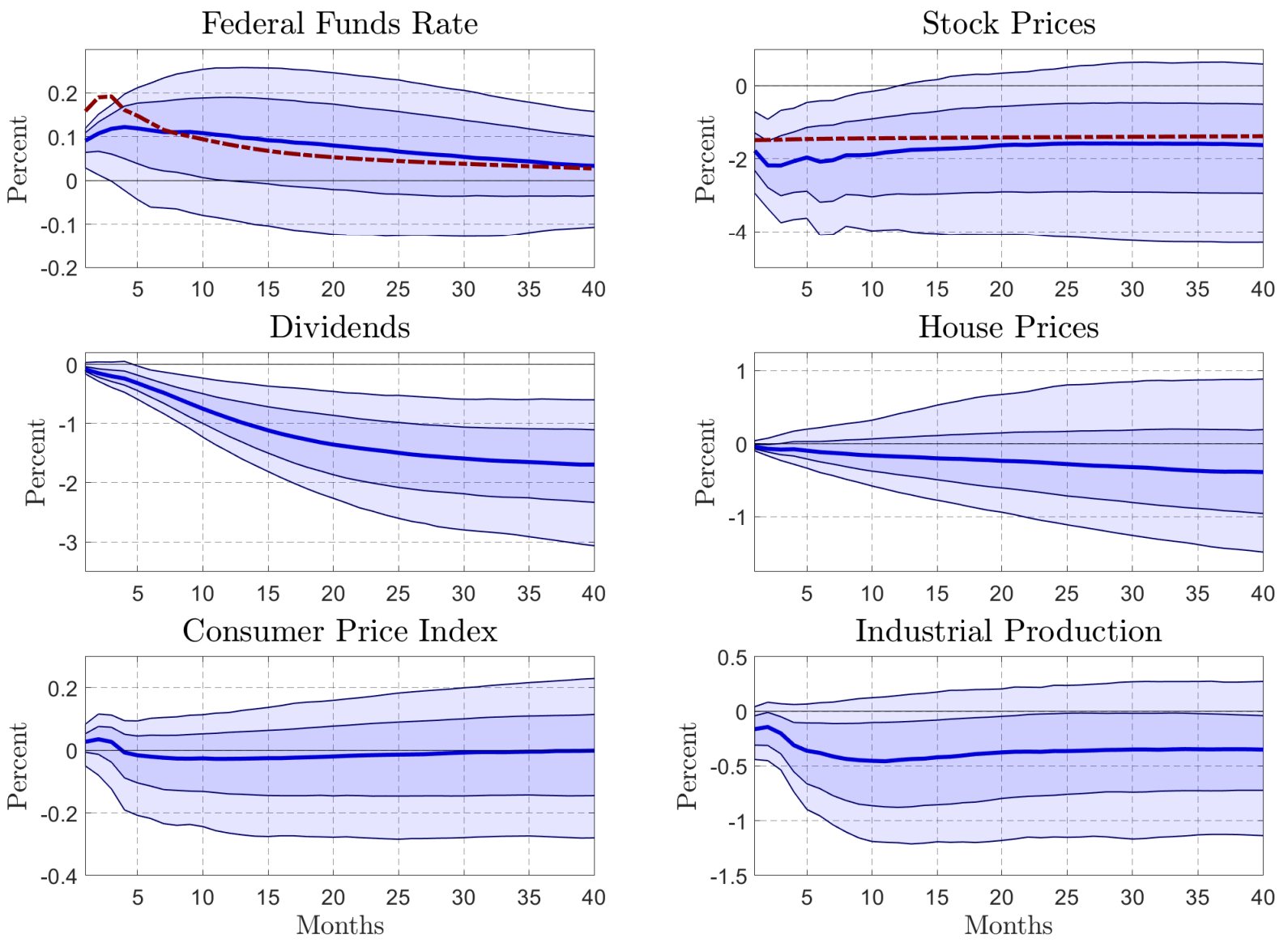

Figure 13: External Instrument Approach. Cumulative impulse responses to a one-standard-deviation contractionary monetary policy shock, median response along with 68 and 95 percent confidence intervals. The dashed line in the plot of the federal funds rate is the real interest rate. The dashed line in the plot of stock prices shows the fundamental price response (see Appendix A.8 for the derivation). Residual-based moving block bootstrap as in Lunsford and Jentsch (2016) is used to obtain confidence bands (block size: 20). Sample: 1988 M11-2017 M9. 


\section{A.15 Time-Varying Parameter VAR}
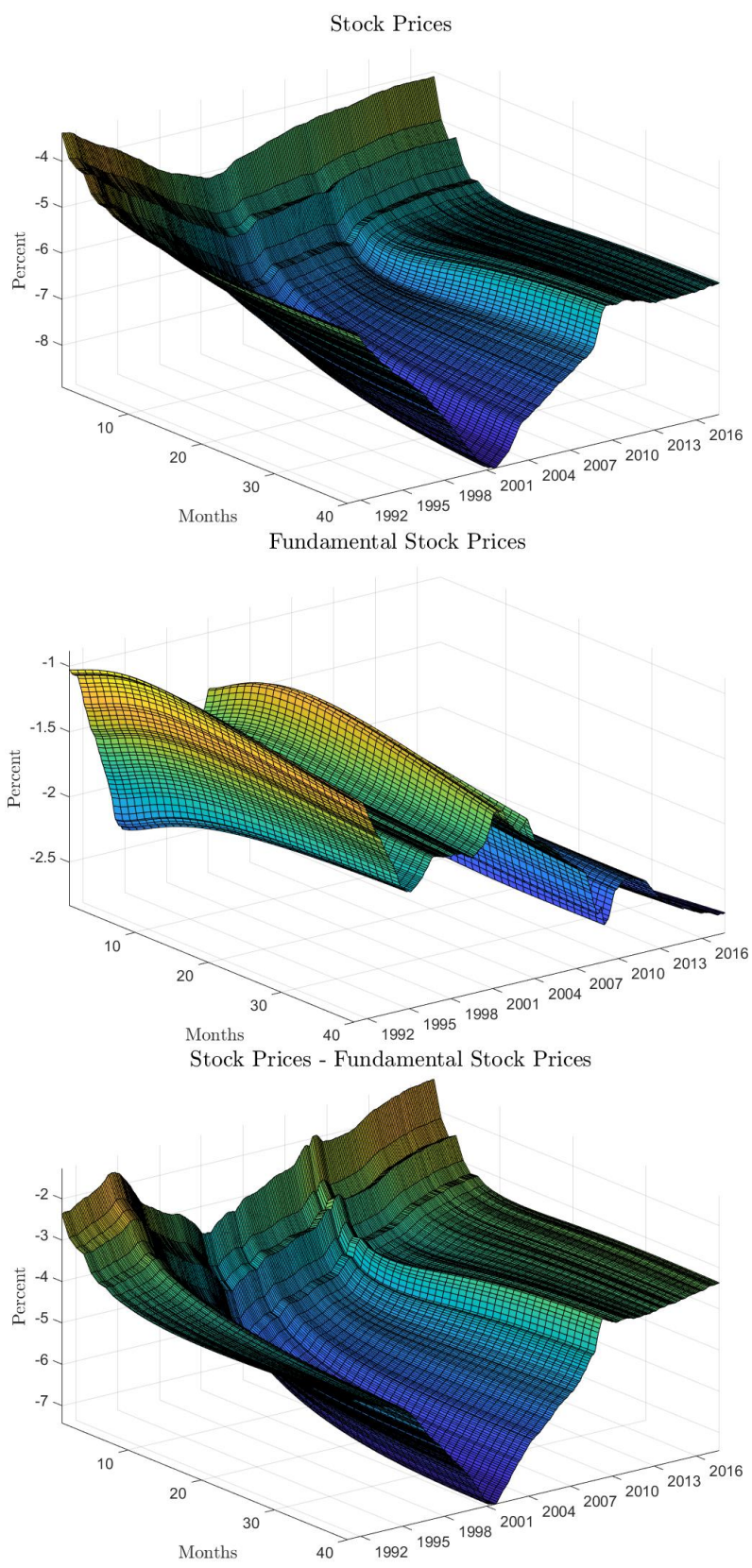

Figure 14: Time-Varying Impulse Responses. Cumulative impulse responses to a monetary tightening. Vertical axis: Percentage change. Front axis left: Months (Horizon IRF). Front axis right: Years. 

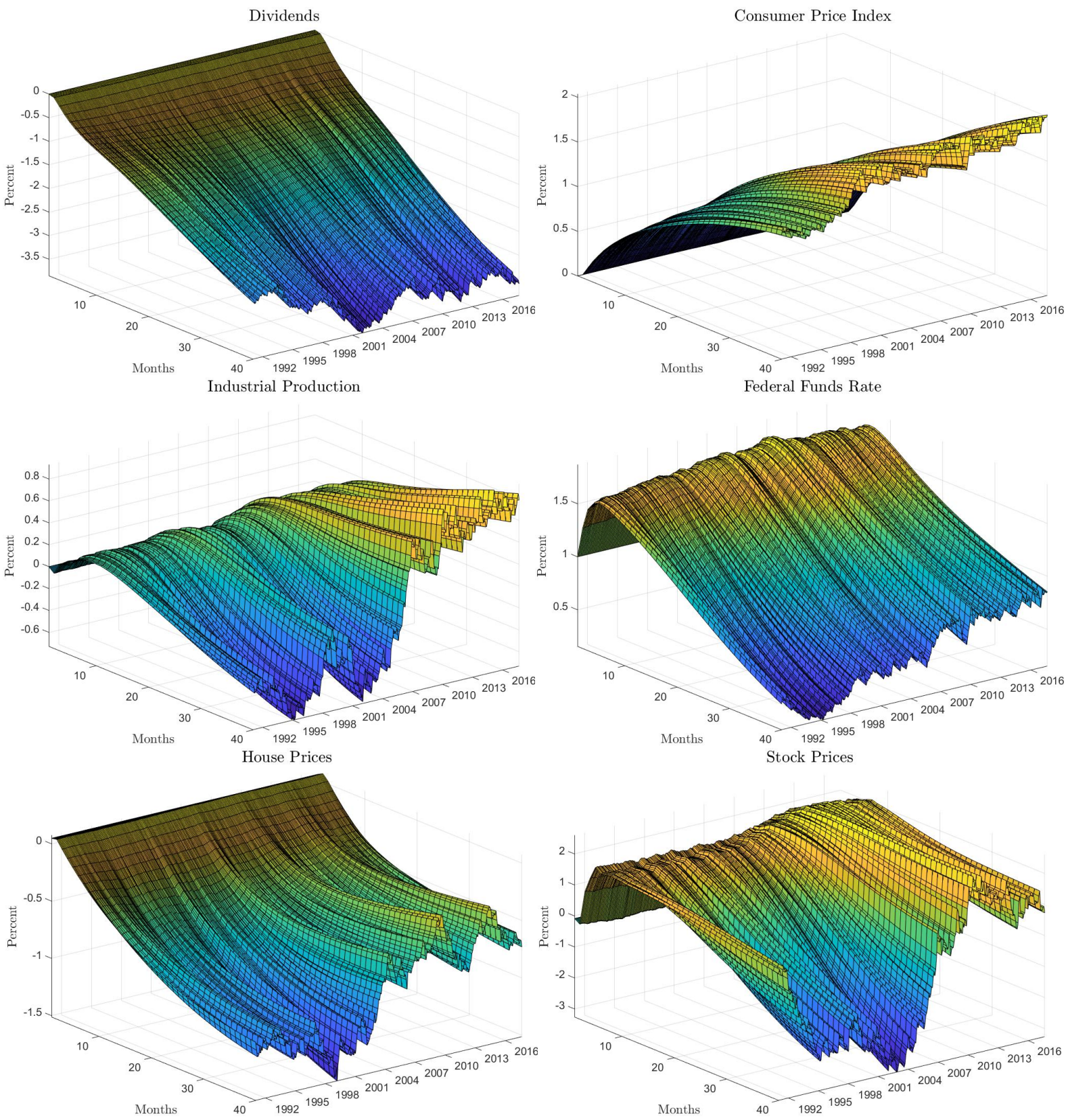

Figure 15: Time-Varying Parameter VAR - Cholesky Identification. Cumulative impulse responses to a contractionary monetary policy shock. The Cholesky identification imposes the following order: Industrial Production, Consumer Price Index, Dividends, Federal Funds Rate, House Prices, and Stock Prices. Results reported for $\kappa_{Q}=0.01$. Vertical axis: Percentage change. Front axis left: Months (Horizon IRF). Front axis right: Years. 


\section{A.15.1 Posterior Credibility Intervals}
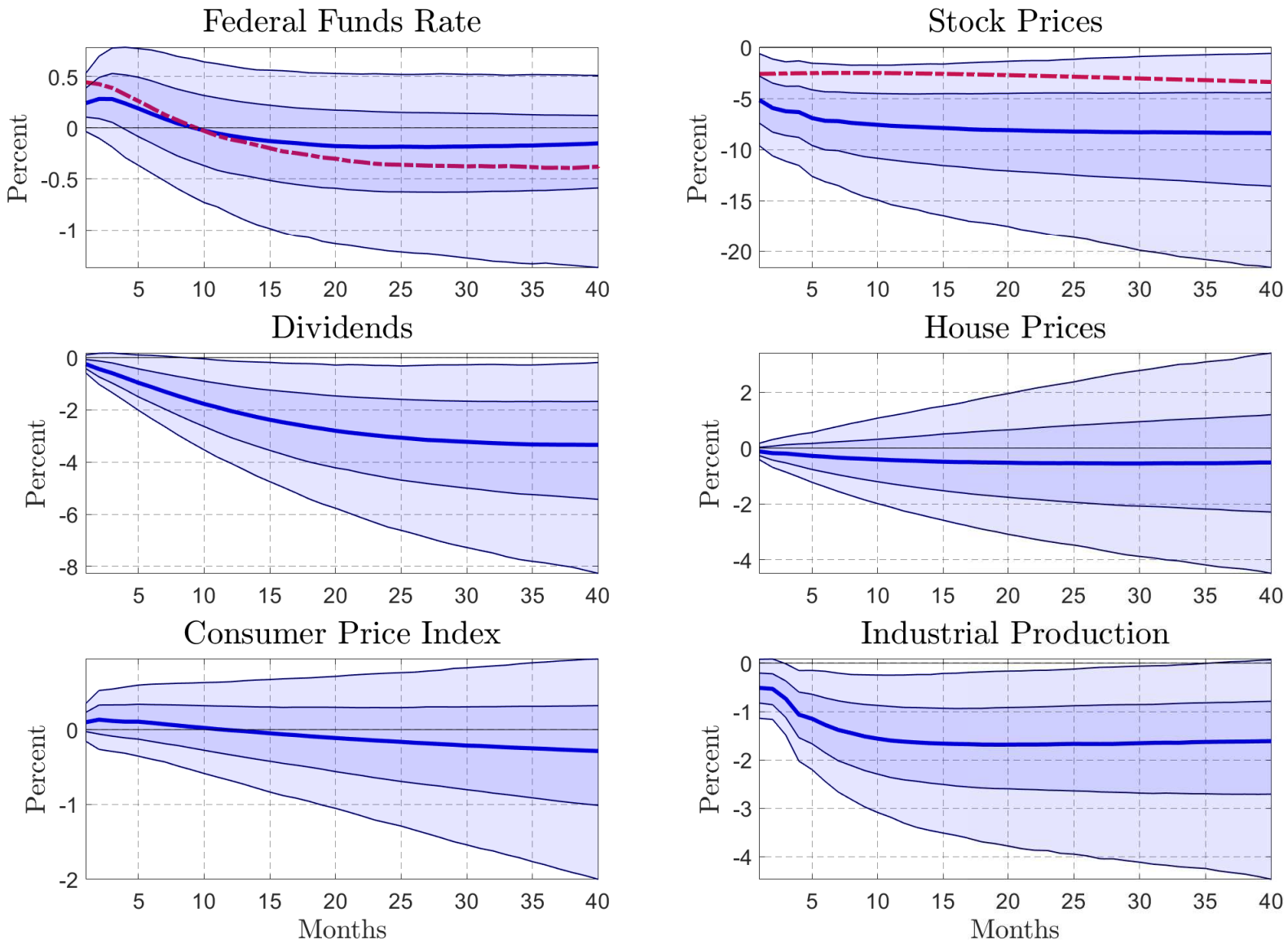

Figure 16: Impulse Responses based on time-varying parameter VARX for 2003 M1. Cumulative impulse responses to a contractionary monetary policy shock, along with 68 percent and 95 percent posterior credibility intervals based on iterations of the Gibbs sampler. The dashed line in the plot of the federal funds rate shows the real interest rate. The dashed line in the plot of stock prices shows the fundamental price response based on discounted dividends and constant risk premia (see Appendix A.8 for the derivation). 

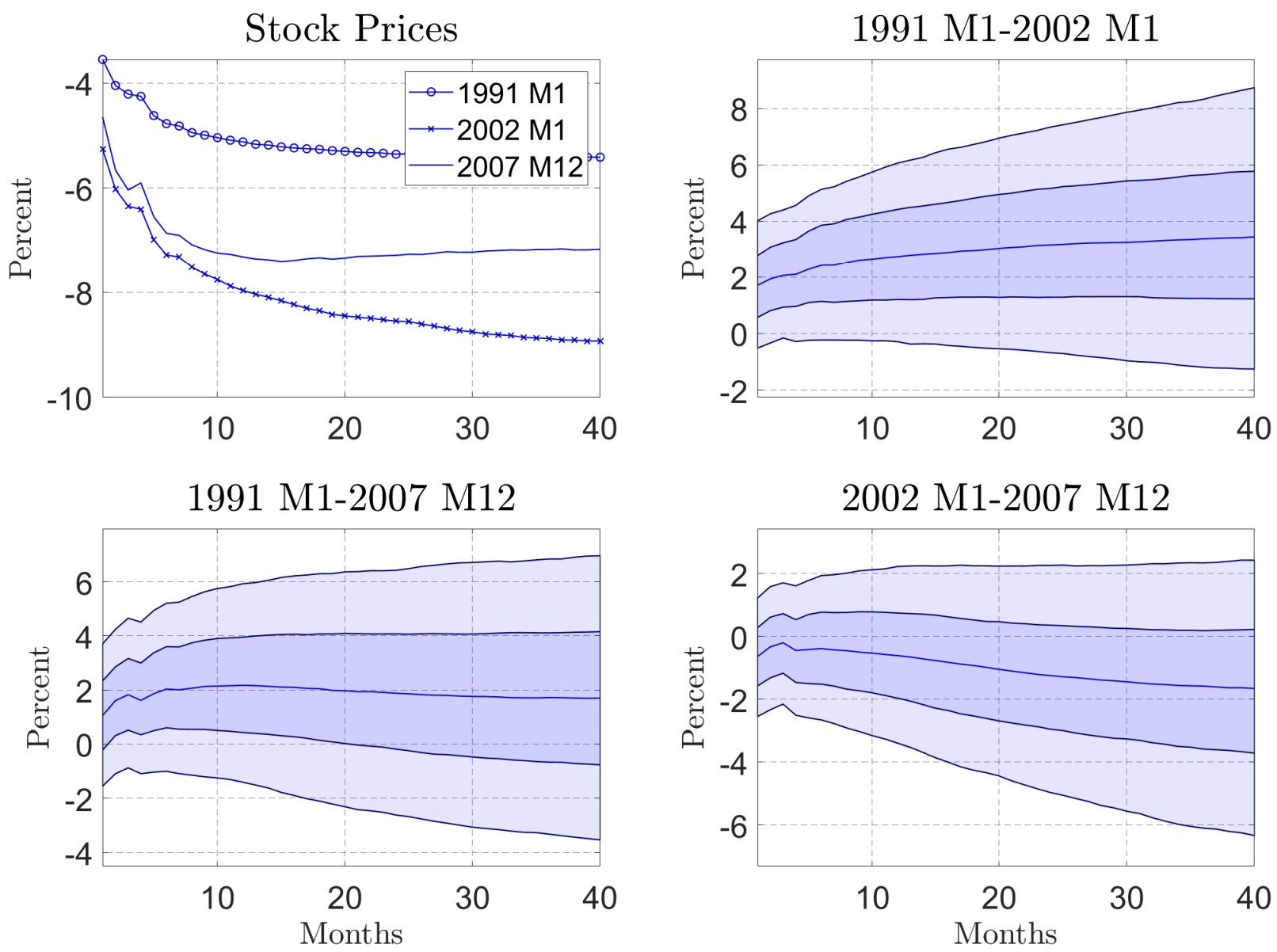

Figure 17: Differences impulse responses of stock prices for selected periods. Difference in cumulative impulse responses of stock prices, comparing episodes of strong and weak responses (1991 M1, 2002 M1, 2007 M12). Median, 38 percent, and 68 percent posterior credibility intervals are shown based on iterations of the Gibbs sampler. 

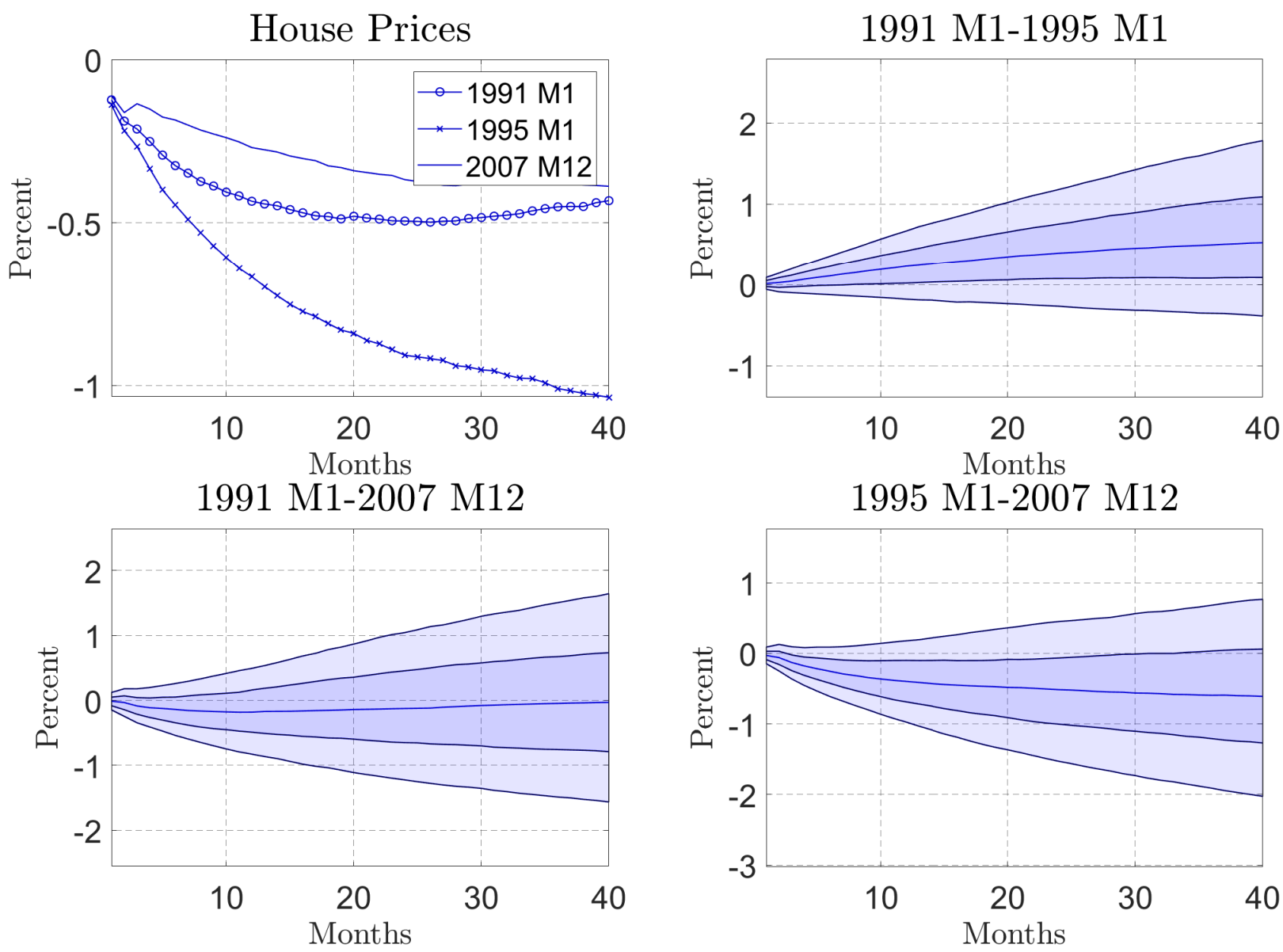

Figure 18: Differences impulse responses of house prices for selected periods. Difference in cumulative impulse responses of house prices, comparing episodes of strong and weak responses (1991 M1, 1995 M1, 2007 M12). Median, 38 percent, and 68 percent posterior credibility intervals are shown based on iterations of the Gibbs sampler. 

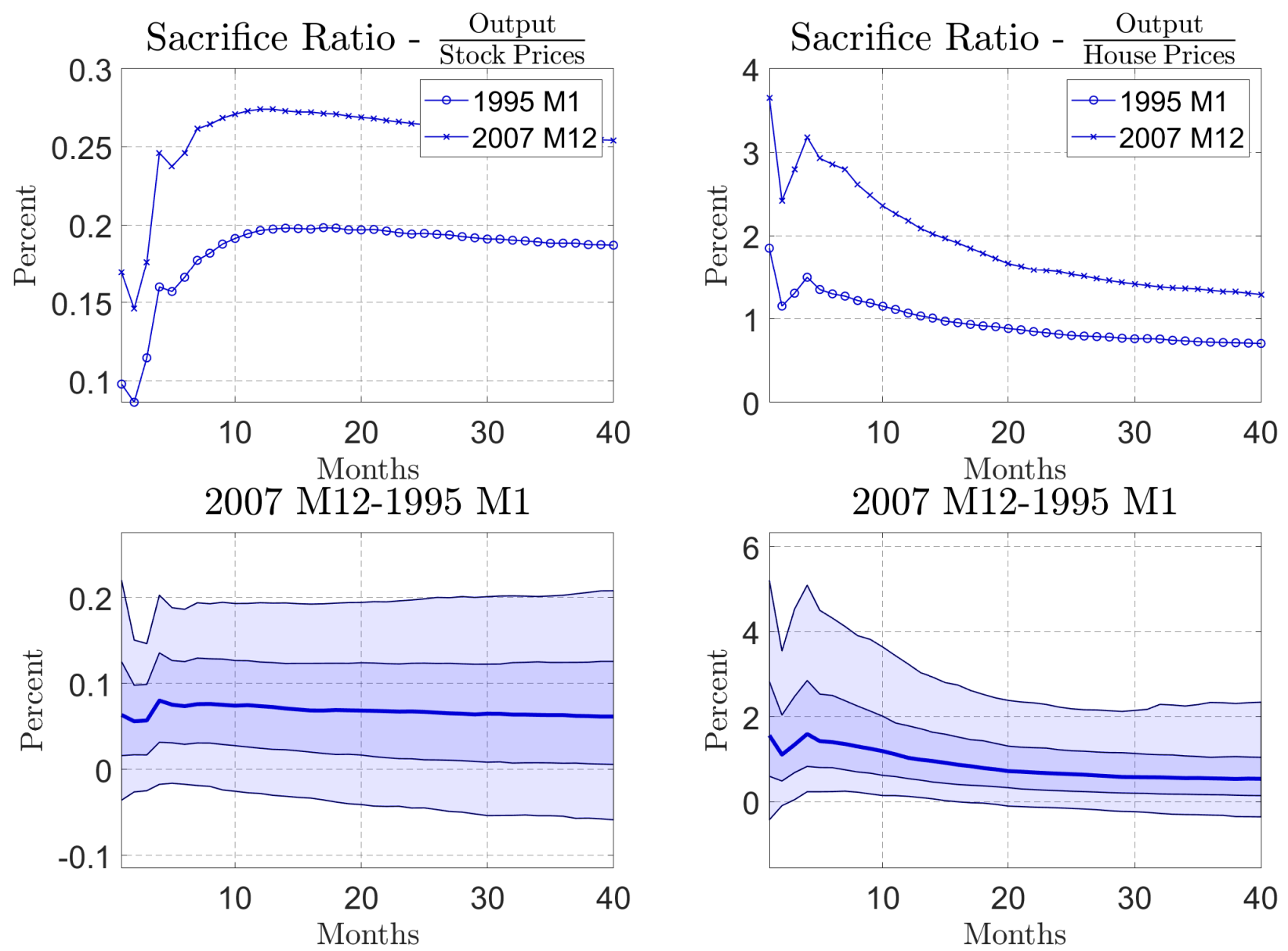

Figure 19: Differences in the responses of sacrifice ratios across periods. Difference in the response of the sacrifice ratio between 1995 M1 and 2007 M12, conditioned on a positive response for both periods. Median, 38 percent, and 68 percent posterior credibility intervals are shown based on iterations of the Gibbs sampler. 


\section{A.16 Sensitivity Analysis}

\section{A.16.1 Priors}
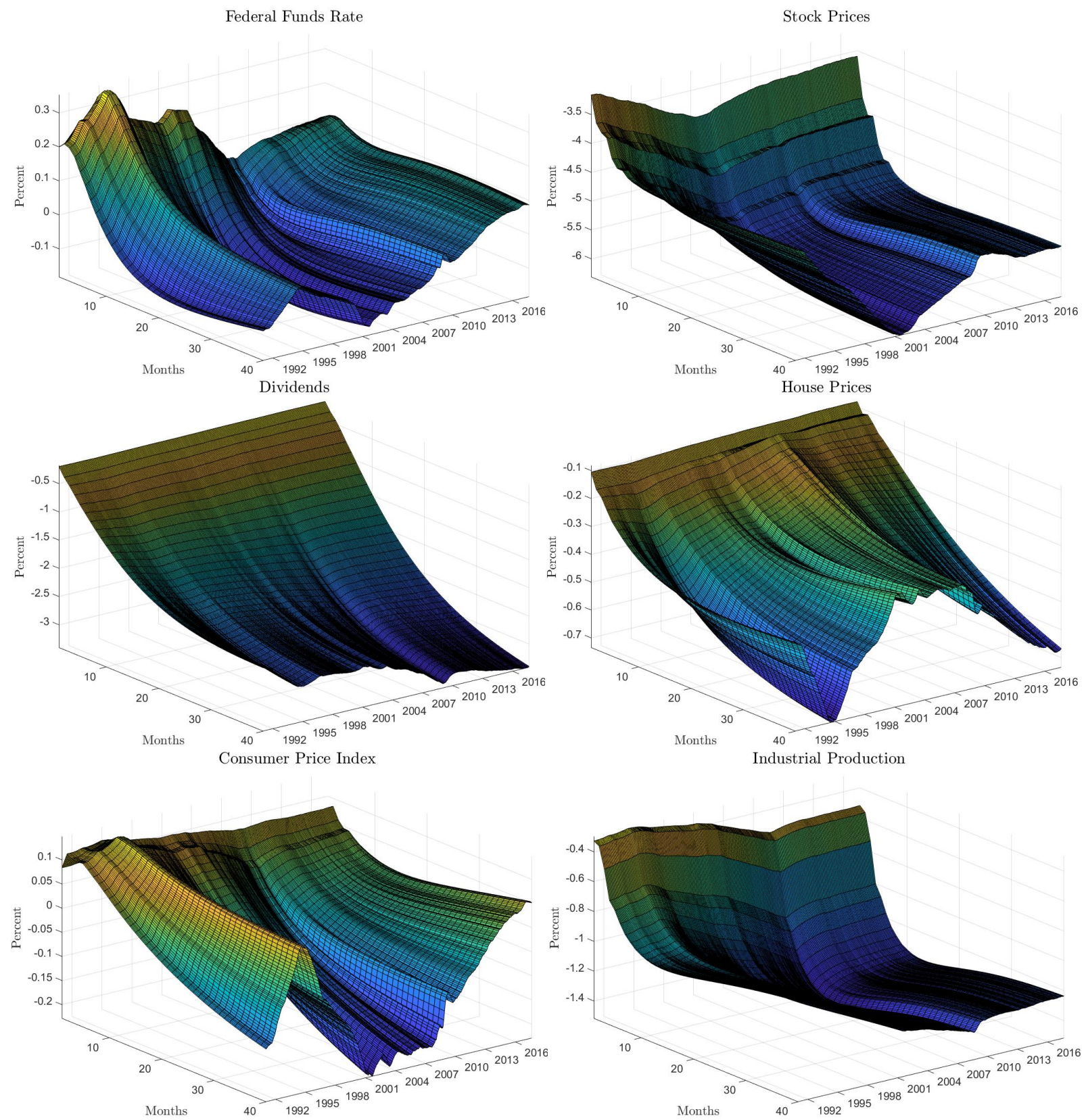

Figure 20: Time-Varying Impulse Responses. Cumulative impulse responses to a monetary tightening. Vertical axis: Percentage change. Front axis left: Months (Horizon IRF). Front axis right: Years. 

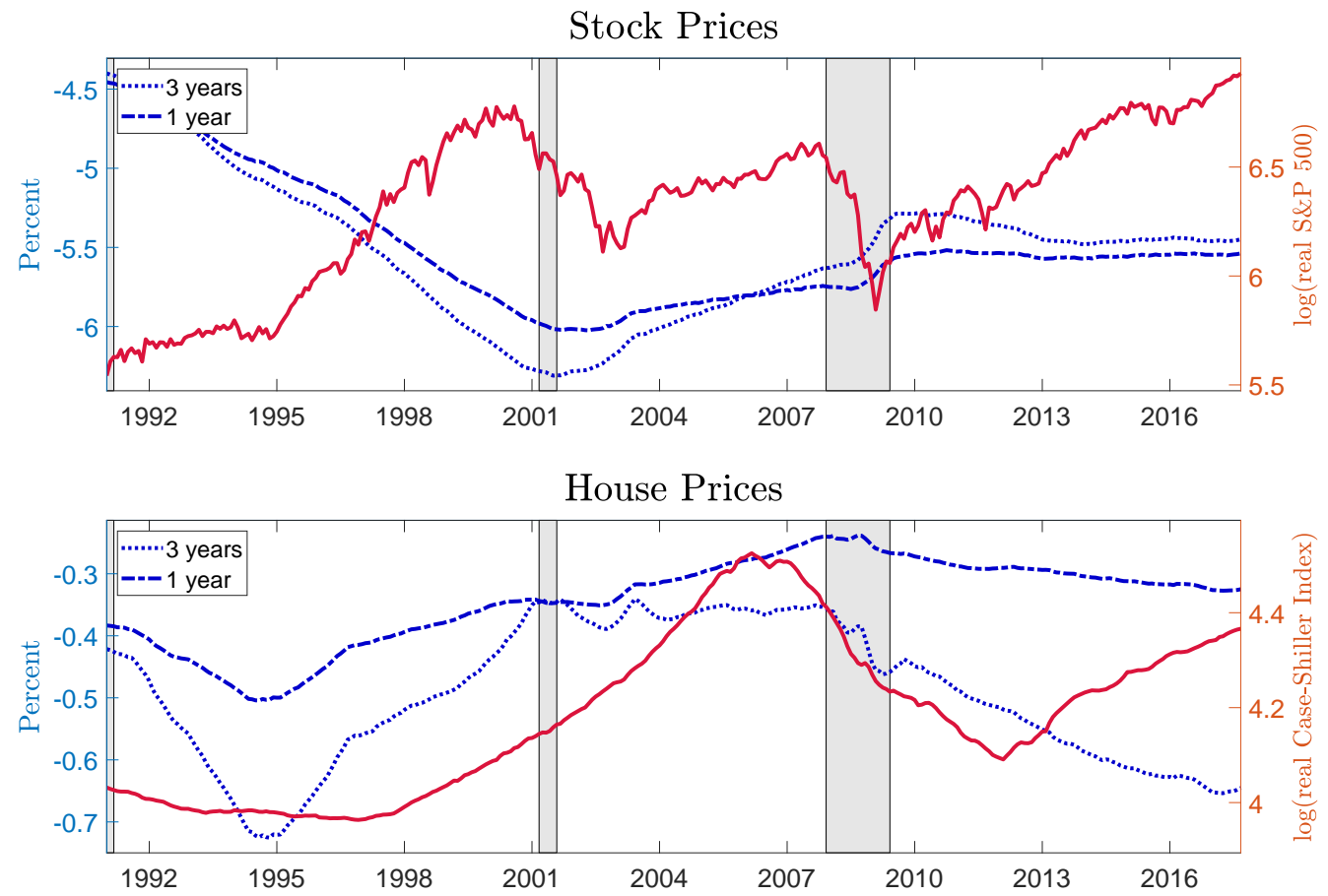

Figure 21: Time-Varying Impulse Responses for Different Horizons. Left axis: Percentage change in stock and house prices after one year (dashed-dotted) and three years (dotted). Right axis: Stock market or house price index in log-levels (solid). Gray bars denote NBER recessions.
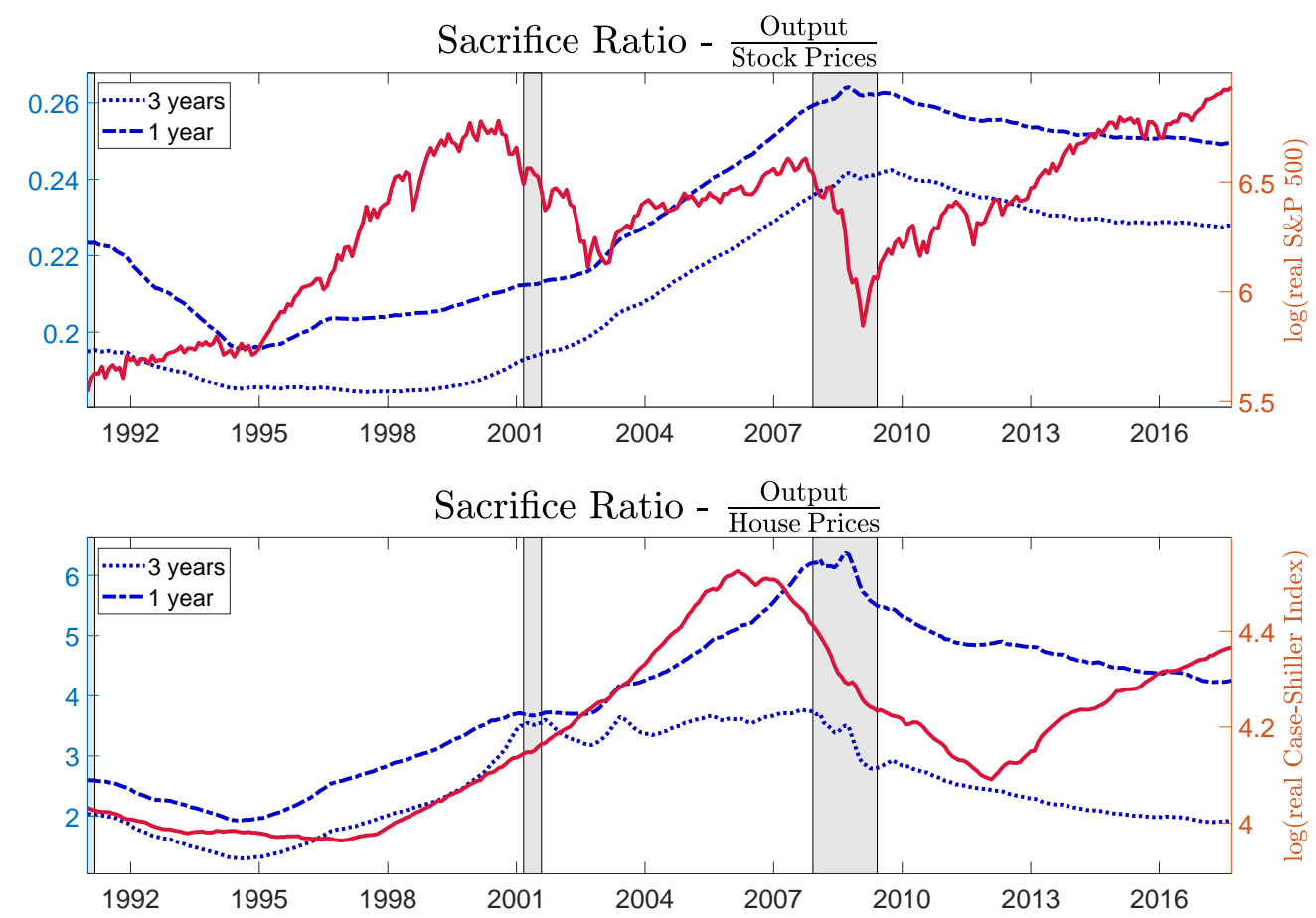

Figure 22: Sacrifice Ratios. Left axis: Percentage change output per one-percent change in stock and house prices after one year (dashed-dotted) and three years (dotted). Right axis: Stock market or house price index in log-levels (solid). Gray bars denote NBER recessions. 


\section{A.16.2 ELB Episode}
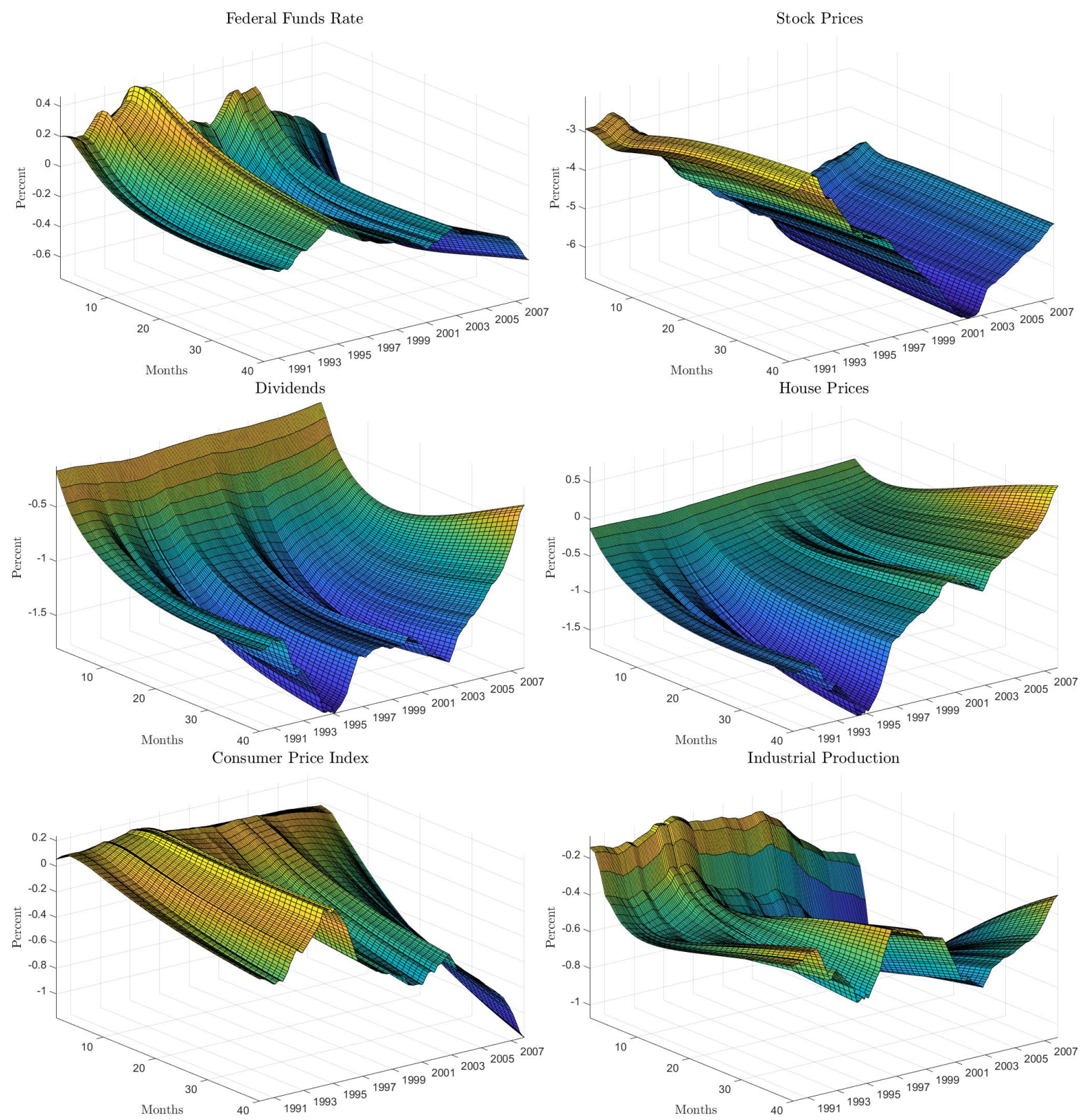

Figure 23: Time-Varying Impulse Responses. Cumulative impulse responses to a monetary tightening. Vertical axis: Percentage change. Front axis left: Months (Horizon IRF). Front axis right: Years. 

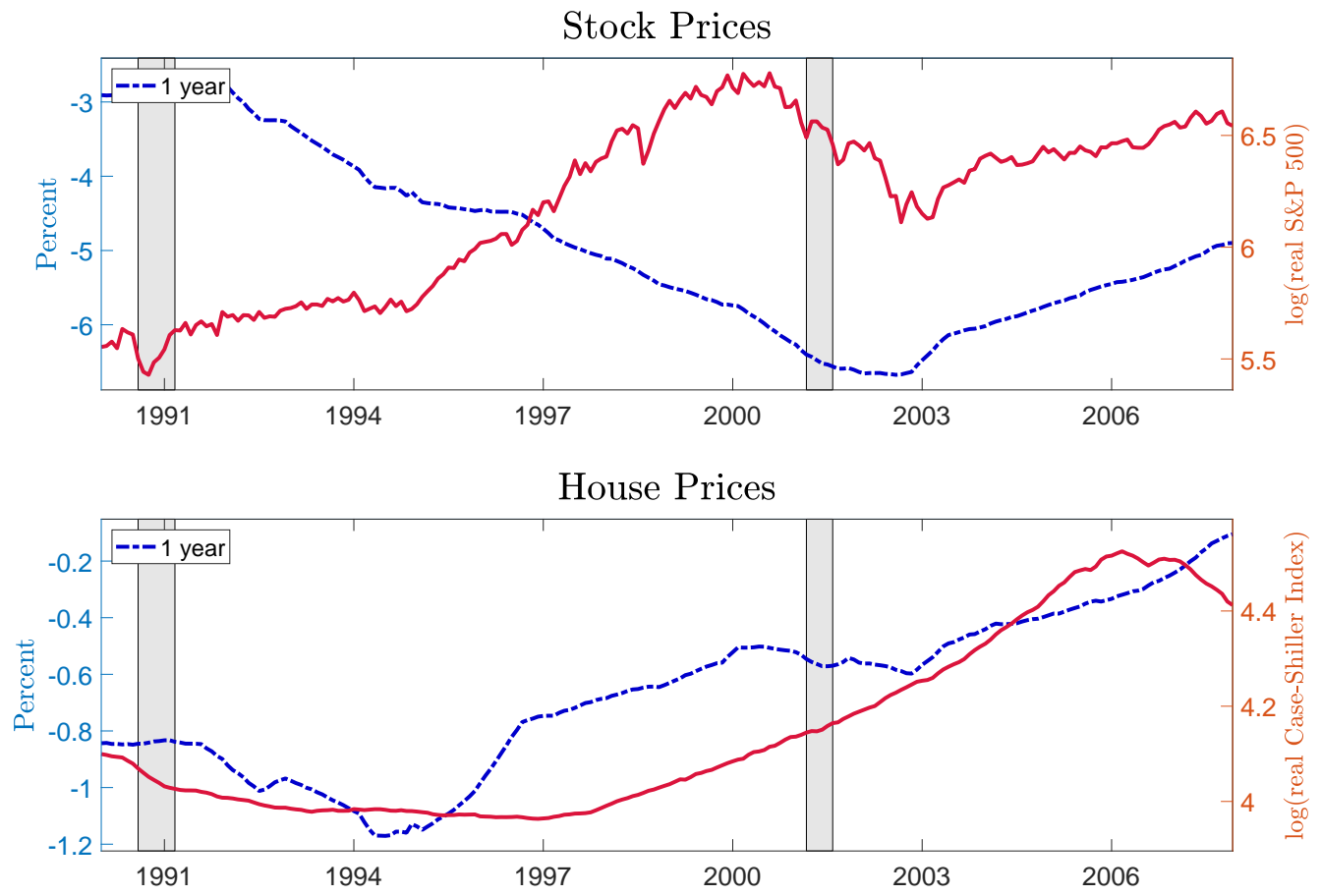

Figure 24: Time-Varying Impulse Responses for Different Horizons. Left axis: Percentage change in stock and house prices after one year (dashed-dotted). Right axis: Stock market or house price index in log-levels (solid). Gray bars denote NBER recessions.
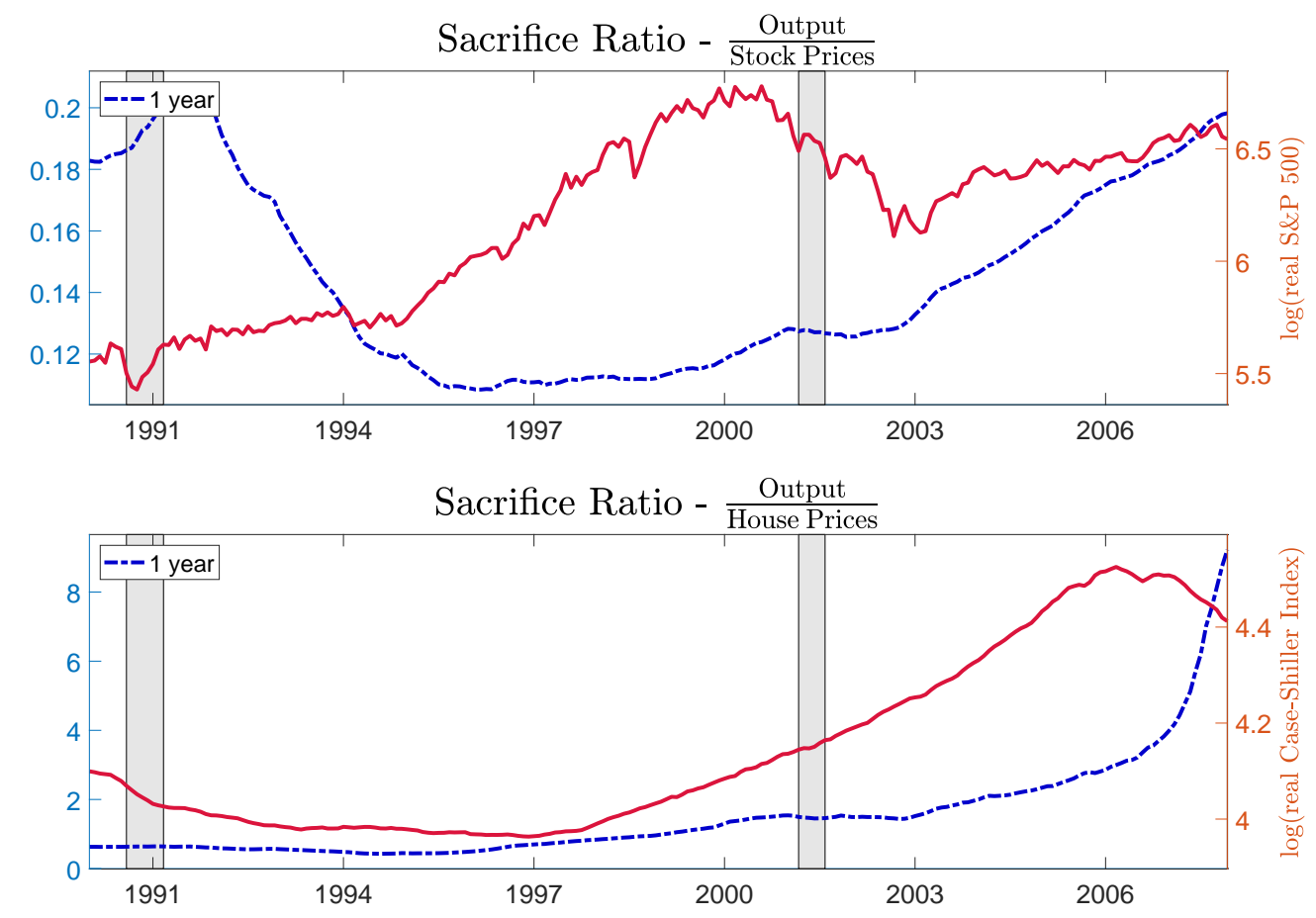

Figure 25: Sacrifice Ratios. Left axis: Percentage change output per one-percent change in stock and house prices after one year (dashed-dotted). Right axis: Stock market or house price index in log-levels (solid). Gray bars denote NBER recessions. 


\section{A.16.3 Timing of Actions}
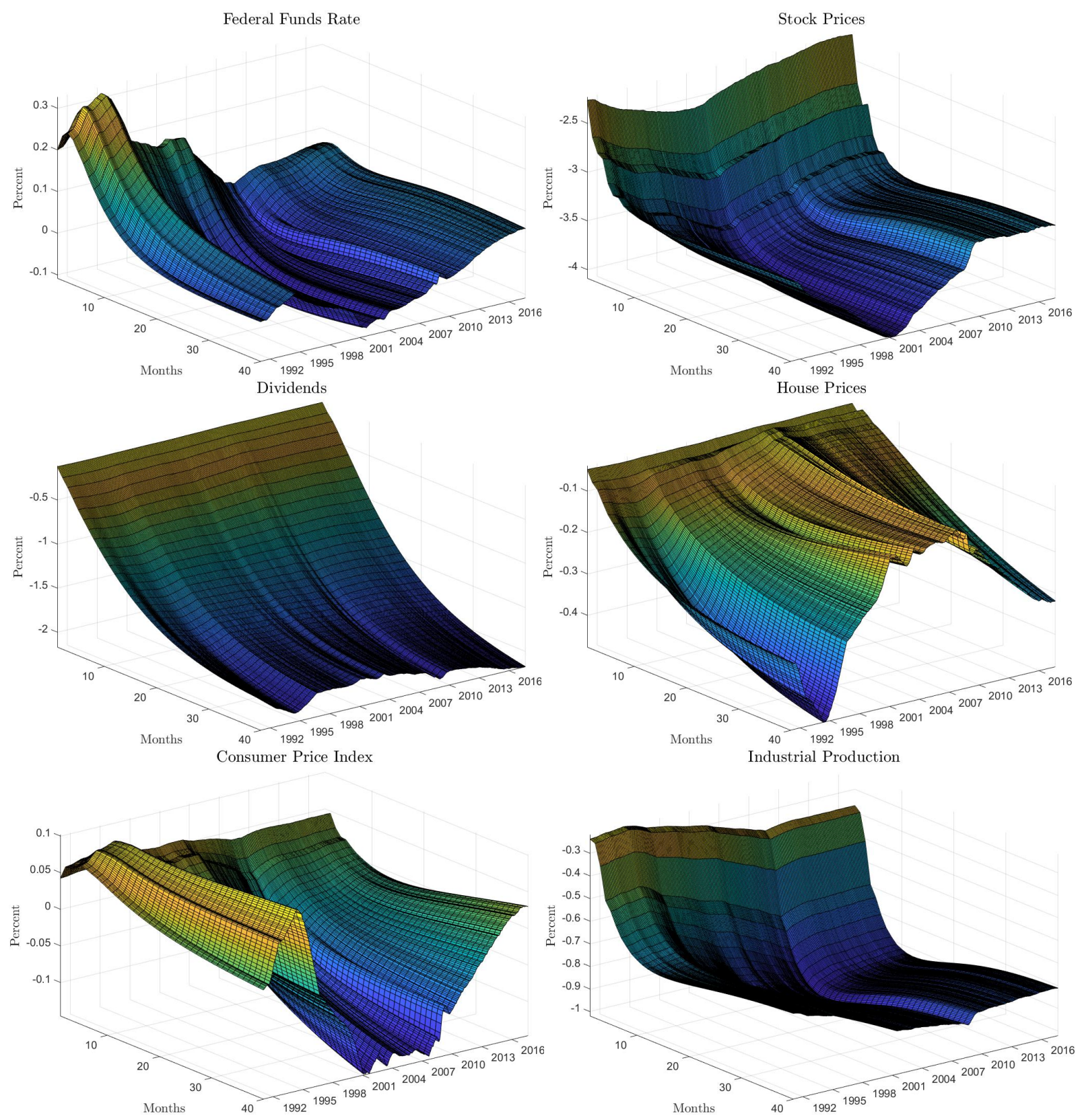

Figure 26: Time-Varying Impulse Responses. Cumulative impulse responses to a monetary tightening. Vertical axis: Percentage change. Front axis left: Months (Horizon IRF). Front axis right: Years. 


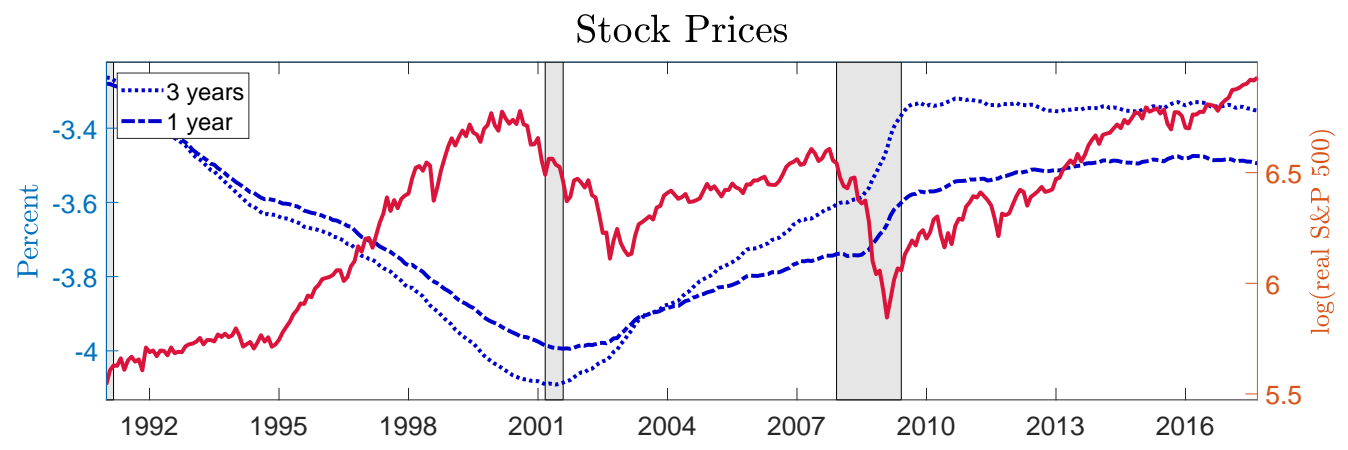

House Prices

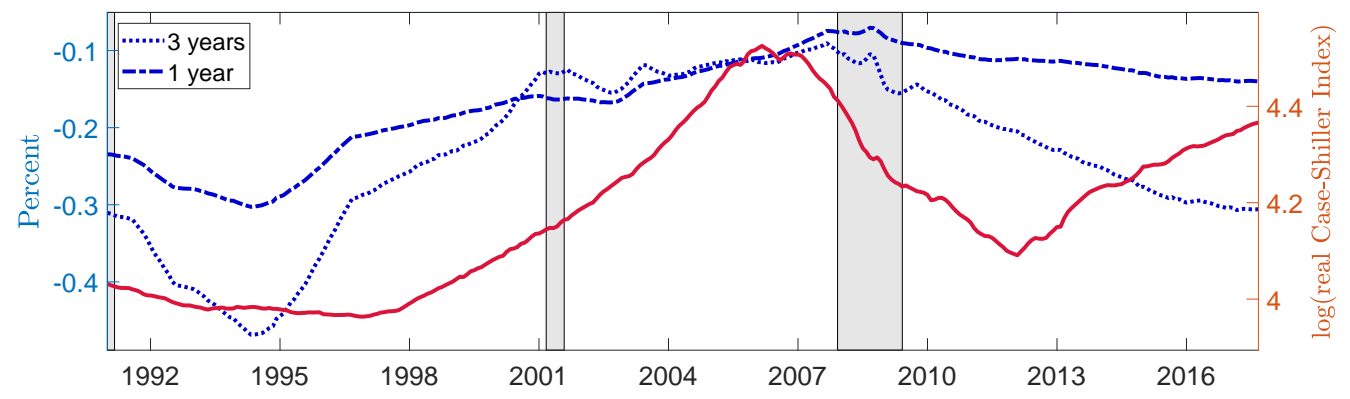

Figure 27: Time-Varying Impulse Responses for Different Horizons. Left axis: Percentage change in stock and house prices after one year (dashed-dotted) and three years (dotted). Right axis: Stock market or house price index in log-levels (solid). Gray bars denote NBER recessions.


Figure 28: Sacrifice Ratios. Left axis: Percentage change output per one-percent change in stock and house prices after one year (dashed-dotted) and three years (dotted). Right axis: Stock market or house price index in log-levels (solid). Gray bars denote NBER recessions. 